University of San Diego

Digital USD

2017

\title{
A Movement Against and Beyond Boundaries: Exploring the Impact of Transgressive Teaching on the Student Affairs Practices of White, Heterosexual Men
}

Conor McLaughlin

University of San Diego

Follow this and additional works at: https://digital.sandiego.edu/dissertations

Part of the Higher Education Administration Commons

\section{Digital USD Citation}

McLaughlin, Conor, "A Movement Against and Beyond Boundaries: Exploring the Impact of Transgressive Teaching on the Student Affairs Practices of White, Heterosexual Men" (2017). Dissertations. 79. https://digital.sandiego.edu/dissertations/79 Digital USD. It has been accepted for inclusion in Dissertations by an authorized administrator of Digital USD. For more information, please contact digital@sandiego.edu. 


\section{A MOVEMENT AGAINST AND BEYOND BOUNDARIES: EXPLORING THE IMPACT OF TRANSGRESSIVE TEACHING ON THE STUDENT AFFAIRS \\ PRACTICES OF WHITE, HETEROSEUXAL MEN}

\section{by}

Conor P. McLaughlin

A dissertation submitted in partial fulfillment

Of the requirements for the degree of

Doctor of Philosophy

April 2017

Dissertation Committee

Christopher B. Newman, PhD

Zachary G. Green, $\mathrm{PhD}$

Craig M. Elliott II, PhD

University of San Diego 



\title{
UNIVERSITY OF SAN DIEGO SCHOOL OF LEADERSHIP AND EDUCATION SCIENCES
}

\author{
CANDIDATE'S NAME: Conor P. McLaughlin
}

TITLE OF

DISSERTATION: A MOVEMENT AGAINST AND BEYOND BOUNDARIES:

EXPLORING THE IMPACT OF TRANSGRESSIVE

TEACHING ON THE STUDENT AFFAIRS PRACTICES OF

WHITE, HETEROSEUXAL MEN

APPROVAL:

\begin{tabular}{lll}
\hline Christophef B. Newman, PhD & & \\
\hline Zachary G. Green, PhD & 1 & Member \\
\hline Craig M. Elliott II, PhD & & \\
\hline
\end{tabular}

DATE: April 13,2017 


\begin{abstract}
Transgressive teaching can have a substantive and transformative impact on the experiences of students in primary, secondary, and higher education classrooms.

Transgressive teaching is exemplified by the engaged pedagogy outlined by bell hooks in the seminal work Teaching to Transgress, in which teachers seek to engage spaces of learning in deeper and more holistic ways. Scholars have theorized transgressive teaching, when implemented by student affairs professionals, can have similar effects on the experiences of students, especially those from identity groups which have historically been marginalized in higher education. However, there is a limited understanding of the experiences of student affairs professionals learning and applying these concepts to their practice.
\end{abstract}

This study used a qualitative phenomenological approach, augmented by modified grounded theory, to understand deeper connections between the experiences of nine student affairs professionals who identify as White, heterosexual, and male; work in a variety of functional areas and institution types; and have varying levels of experience in the field. Using a purposive sampling approach, data was collected in four stages via an initial interview with each participant, the collection of journal entries kept by participants while reading Teaching to Transgress, a second interview of participants immediately after their reading, and a final interview of participants three to six weeks after their reading. Data was analyzed using an In Vivo coding approach. The findings of this study address three major areas: (a) putting theory into practice, (b) identity salience, and (c) leadership. 
The findings of this study hold significance for higher education and student affairs. First, findings reflect ways transgressive teaching helps White, heterosexual, male student affairs professionals with multiple dominant group identities examine those identities' impact on practice. Second, the findings illuminate ways transgressive teaching can be incorporated into professional training in graduate school and professional development programs for White, heterosexual, male student affairs professionals. Finally, the findings explore how these experiences can contribute to White, heterosexual, male student affairs professionals understanding and practicing leadership. 


\section{DEDICATION}

This work is dedicated to bell hooks, who gave me the hope to teach and helped me find in myself the truth that learning is possible. 


\section{ACKNOWLEDGEMENTS}

Though I walk alone, I am never on my own. Cuz the places we've been become the times we have shared. They crash like waves and mark these days and I don't go anywhere without them.

- Bane, As the World Turns

There are not enough pages available to for me to name and thank everyone who has contributed to this work, nor will my memory be able to recall the hundreds and thousands of you that reach back generations. This is my best effort to acknowledge the village that it took to get me here, and this list, while representing those best efforts, will always be incomplete.

To my committee members, Christopher, Zachary, and Craig: I am forever grateful to you for your mentorship, love, support, and for constantly guiding me to make this dissertation better, to be a more full version of the values and the passion that inspired the project and drive me. Thank you all for seeing it in me, for believing it was possible, and for being a part of the ride. Many times when I felt as though I couldn't do it, like I wasn't strong or smart or capable enough, and you all helped me to do it anyway.

To my partner Windi: you have stood by me and had my back through the most challenging times, through unemployment and terminal degrees. You have been a constant support as I continually try to find my way in all of this. For reasons that quickly become far larger than I could possibly describe on this document, my work would be impossible without you. You are the first inspiration I take in every morning, and the thing that makes me excited to greet the work of each new day. I promise to spend the rest of my life supporting you and your work as much as you have done for me.

To my nine amazing participants: I am more grateful than I can describe for your willingness to share your stories, experiences, and lives with me as a part of trying to 
better understand our work. You all are helping to change this field, and I am better because of you.

To Esteban, Perse, Lan, Erica and Lanee: You helped me find my home, my calling, and my purpose at a point in my career when I felt like I had lost them. I could not have gotten this far without you; the care you have shown and the hope you have instilled in me has kept me going. You have also taught me so much about how to be better in the world. Every single day you all inspire me to keep doing the work.

To Nick: I know that at one point it was my job to help you learn about what it means to be a student affairs professional, but the truth is you taught me just as much if not more. I've could not imagine being more proud to call anyone a colleague and a friend. Your constant encouragement has been a driving force in this work, always wanting to bring into the world the joy and light that you offer.

To Mari, Grace, Megan, Erica, Maria, Jessica, and Peter: my critical friends. You have all given me so much of yourselves and taught me so much about teaching, learning, and what it means to hold one another up as we all get through this ridiculous marathon. The brilliance and joy of each of you is written all over this document, because it wouldn't have been possible without you all.

To Sr. Theresa Monroe: You helped me to find my voice, my roar, and my own warrior-ness. You showed me what it really meant to love people through the difficulty of learning and instilled in me a drive to bring that light into the world. You did all of that by giving me the space and the tools to look inside and to have hope.

To the members of the $2012 \mathrm{Ph}$.D. cohort in SOLES: It certainly has been a ride. Even when we were pushing off and bumping up against one another, each of you has 
provided me with valuable learning, without which I would not be able to be at this point. For as hard as it has been, it has also been fun.

To Shaun Van and Michelle, Scott, and Liz and Tutaleni: Each of you, at different points in my career, welcomed me in, gave me space to work on myself and to learn how to do my work better, and helped to guide me in the direction that lead me to this point. Your mentorship has made everything I have done possible.

To Kyle: Thank you for being a sounding board for this dissertation, for helping me to honor the voices of the participants and letting their beauty shine. It has been an honor to be on these journeys with you, and I'm excited for what the future holds for us.

To the staff and family of Heartwork Coffee Bar: Thank you for providing a comfortable space for people of all races, genders, nationalities, beliefs, and ways of being in the world to come together and be human together. You all given me an example of what it means to live and work "heart first." And an excellent cup of coffee.

Finally, to my parents Sheila and Charles McLaughlin: I know that you have always wanted what is best for me, and for me to find whatever it is I saw waiting out there in the world. I am because you continued to nourish me to be, because you were and are, and this work is a testament to what is possible with that kind of faith and hope. I have put all of the joy and passion and love that you taught me to find in the world and in myself into this work. My hope has always been to make this world a little bit better than it was when you brought me into it. Thank you both for the continued opportunity.

I won't carry you in my heart, you are my heart; my everywhere and everything, the walls I'll climb and the wars I'll fight. Loved you in the deepest way, made me the man I am today. You made me feel like a hammer in a world lined with nails.

- Bane, Final Backward Glance 


\section{TABLE OF CONTENTS}

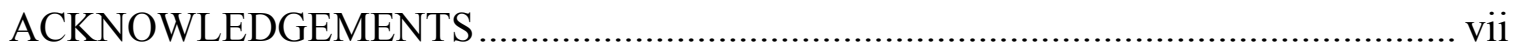

LIST OF TABLES ........................................................................................ xvii

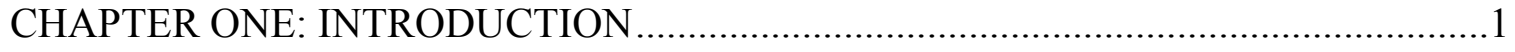

Problem Statement .............................................................................................

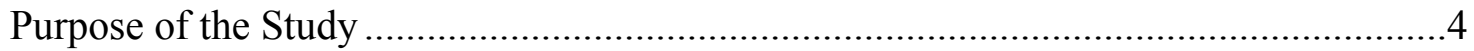

Research Questions/Hypothesis .................................................................

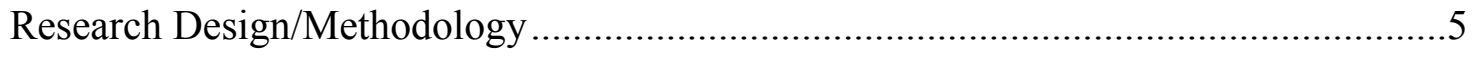

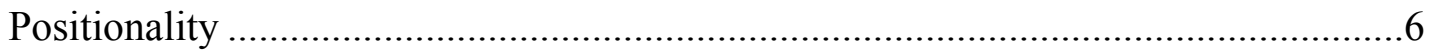

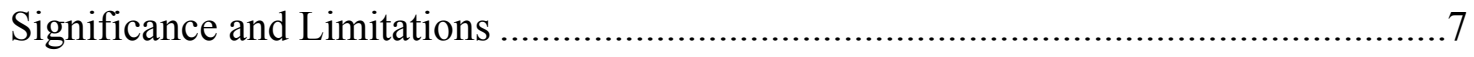

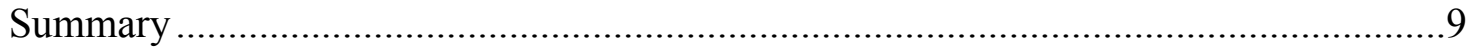

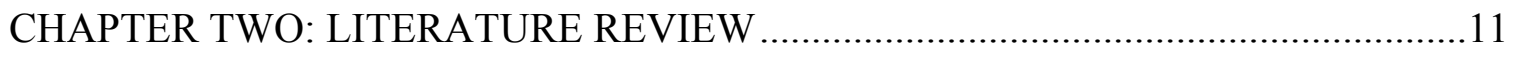

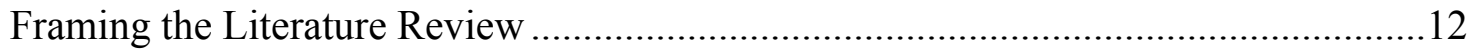

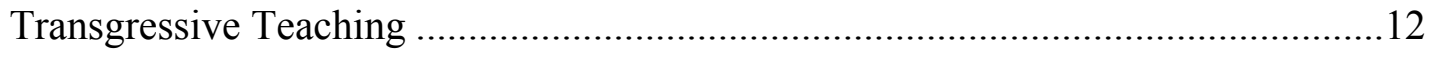

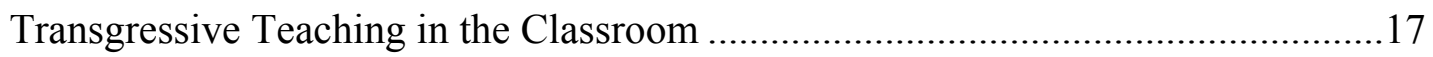

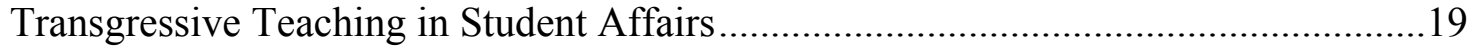

White, Heterosexual, Men ................................................................................22

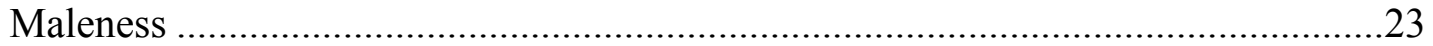

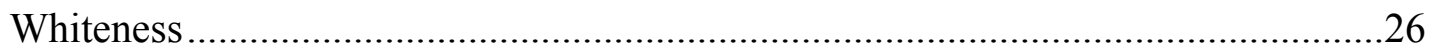

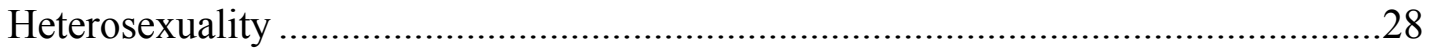

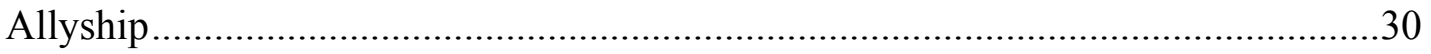

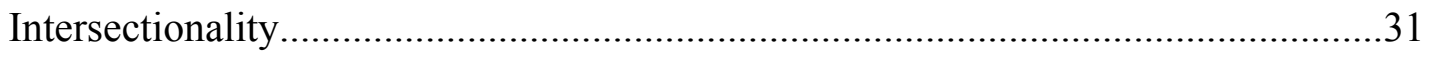

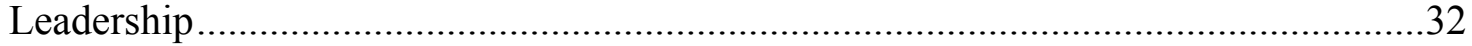




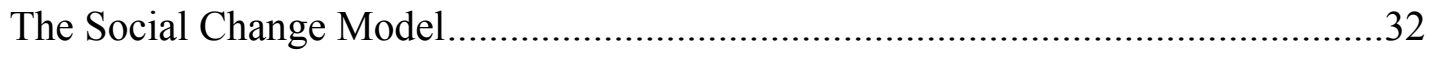

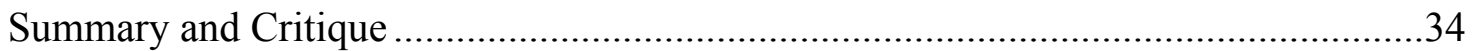

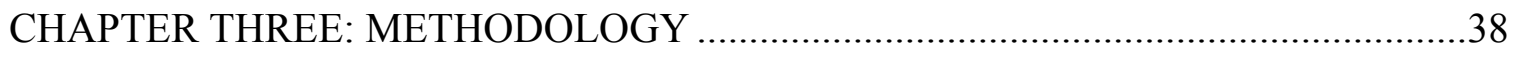

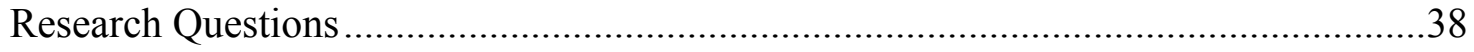

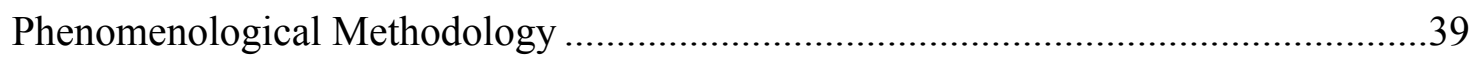

Grounded Theory Methodology ......................................................................... 41

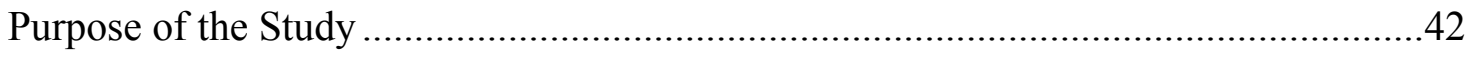

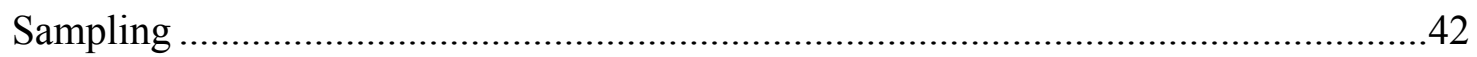

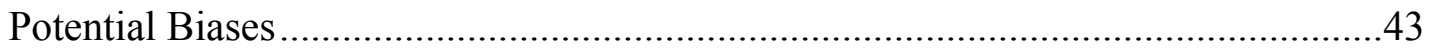

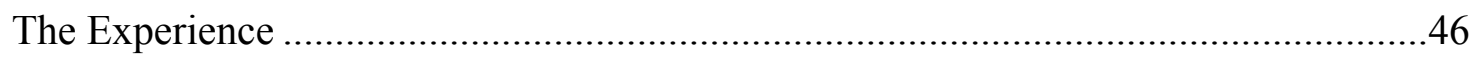

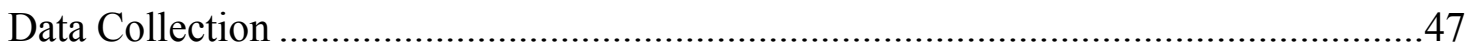

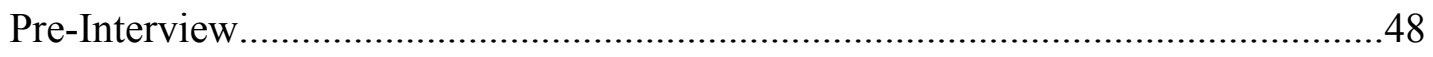

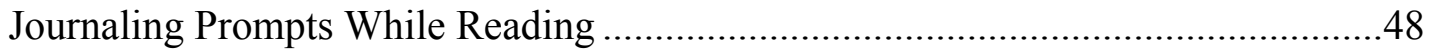

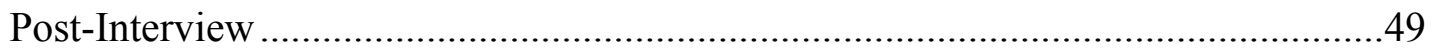

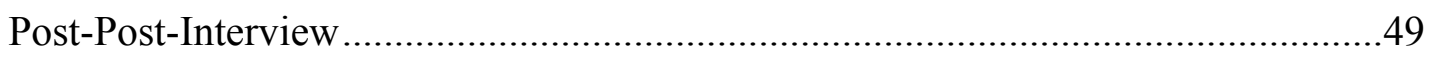

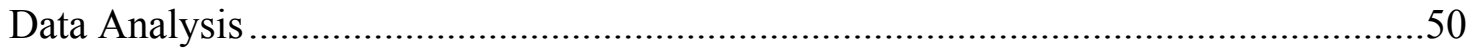

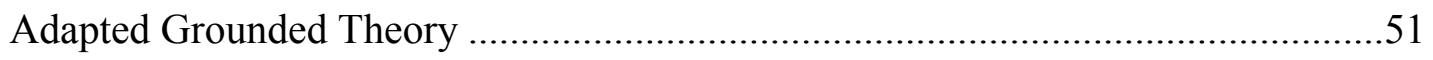

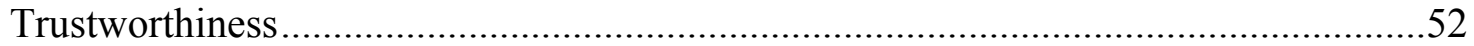

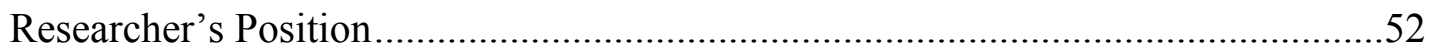

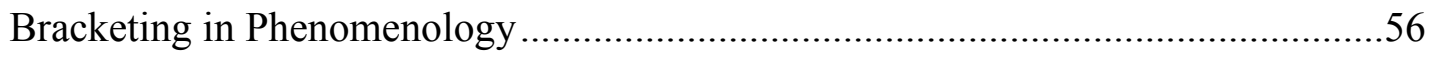

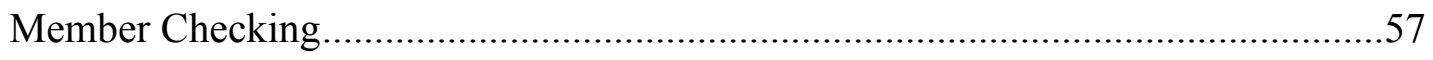

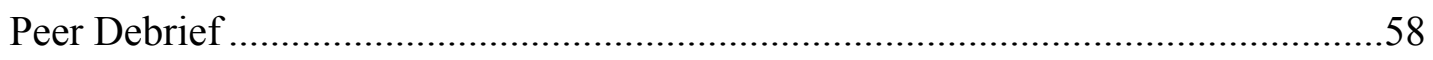

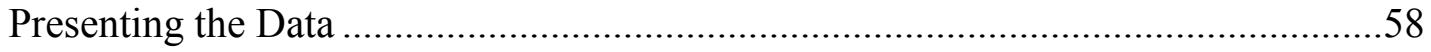


Summary

CHAPTER FOUR: FOUNDATION FOR FINDINGS ...............................................61

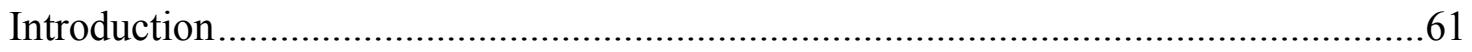

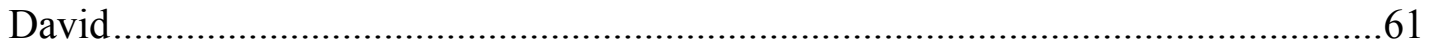

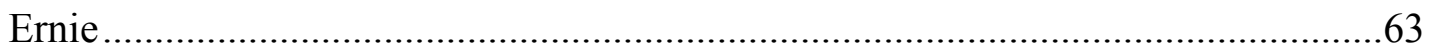

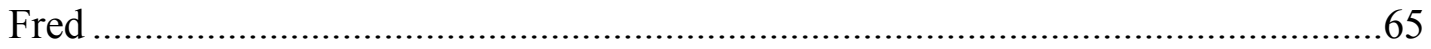

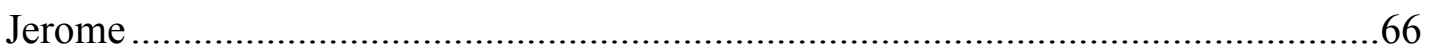

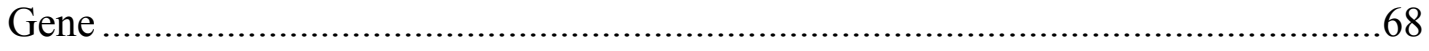

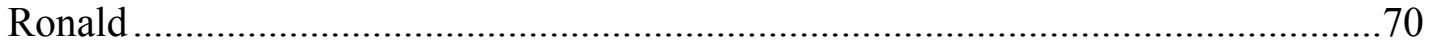

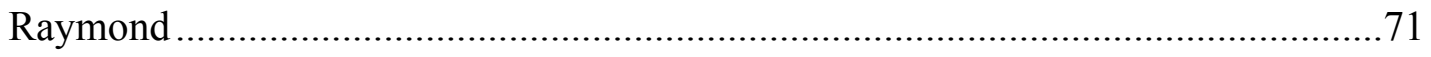

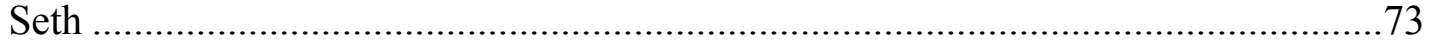

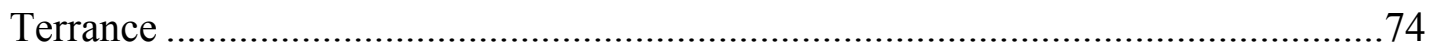

Summary

CHAPTER FIVE: FINDINGS OF CONNECTING THEORY TO PRACTICE................77

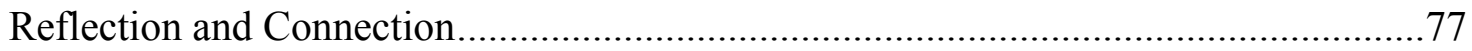

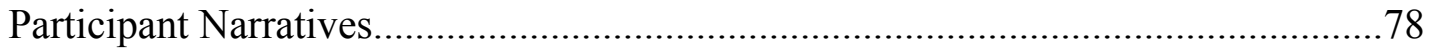

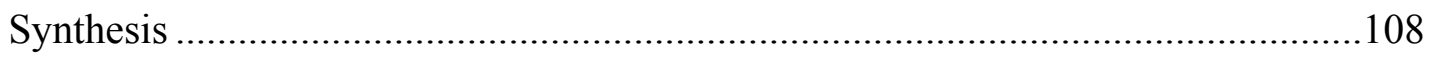

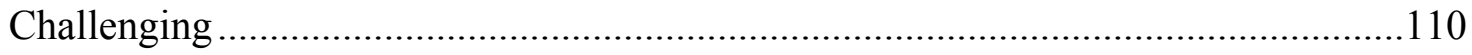

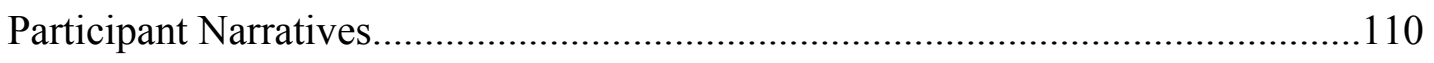

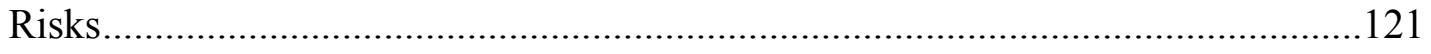

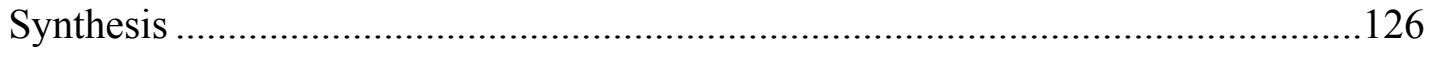

Offering a Structured Environment for Reflection and Development.........................127

Participant Narratives........................................................................................127 
Synthesis

Summary

CHAPTER SIX: FINDINGS ON IDENTITY.

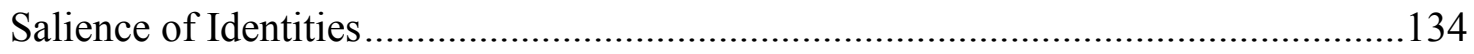

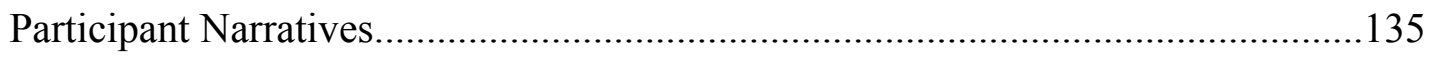

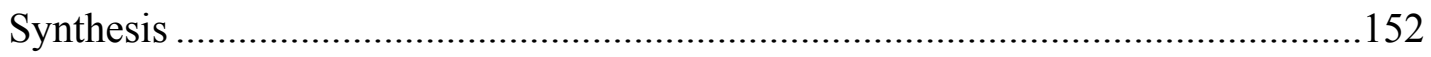

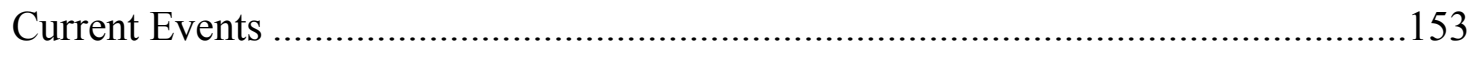

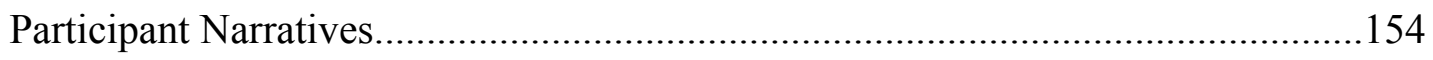

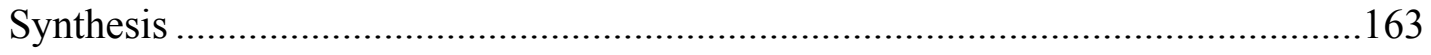

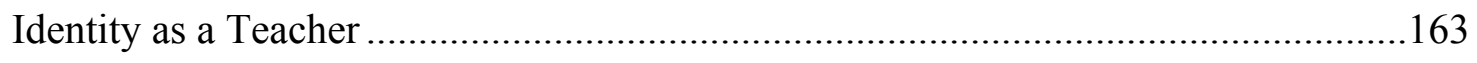

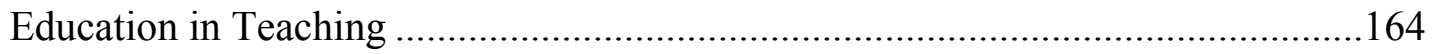

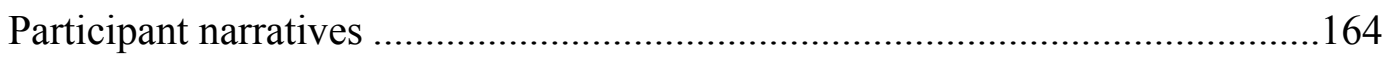

Experience Teaching College Students ............................................................170

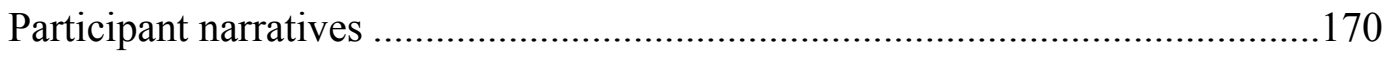

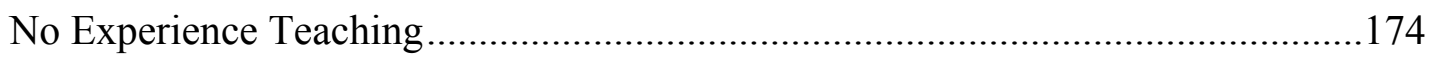

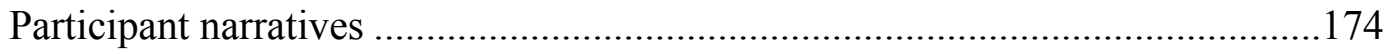

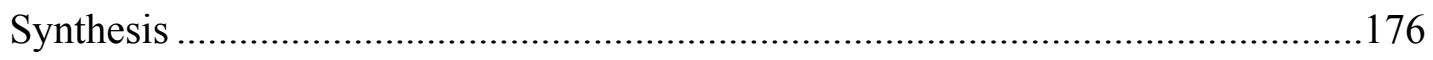

Summary

CHAPTER SEVEN: FINDINGS ON LEADERSHIP …………………....................179

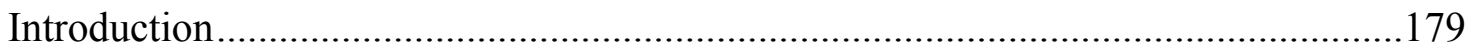

Leadership as Communal Participatory Change ...........................................................179

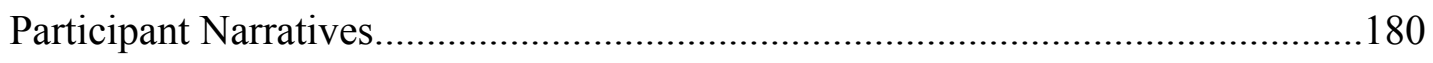

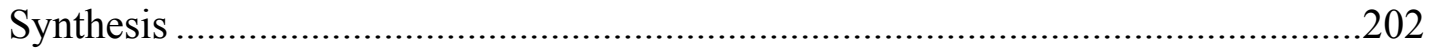




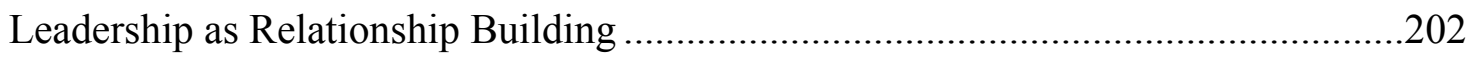

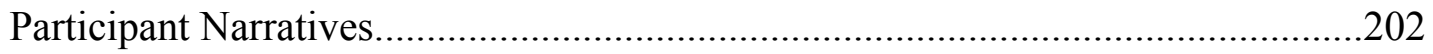

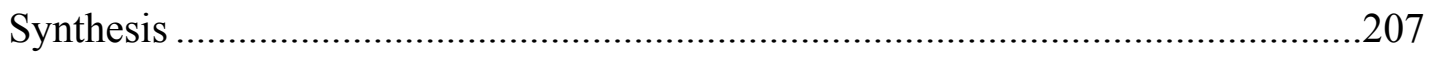

Leadership as Setting an Example ........................................................................207

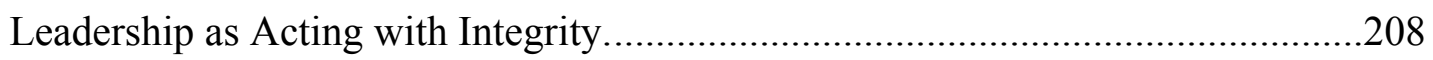

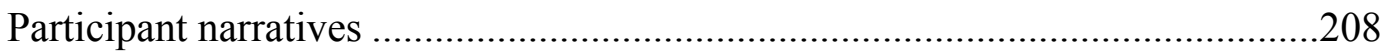

Leadership as Role Modeling. ........................................................................213

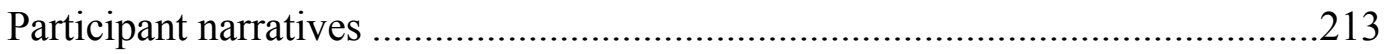

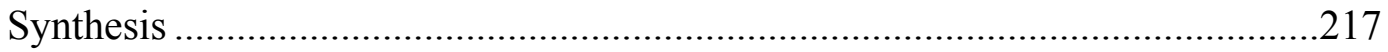

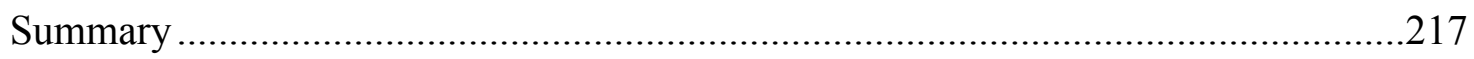

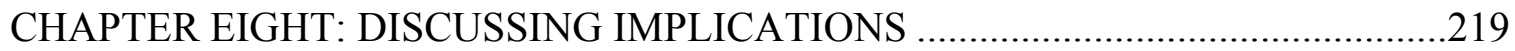

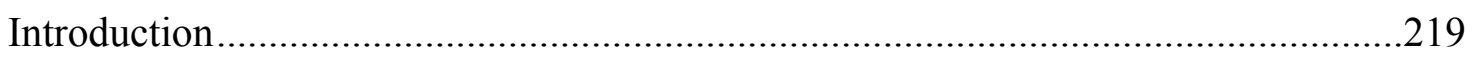

Implications for Transgressive Teaching in Student Affairs ....................................219

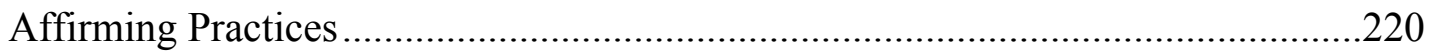

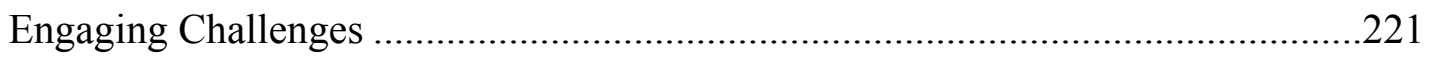

Supporting Future Development......................................................................222

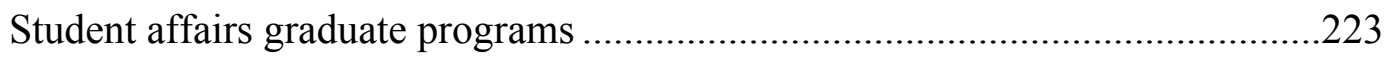

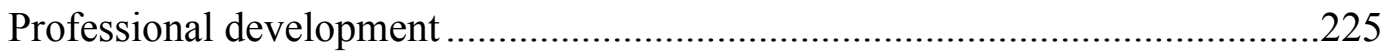

Implications for Transgressive Teaching and Identities ..........................................227

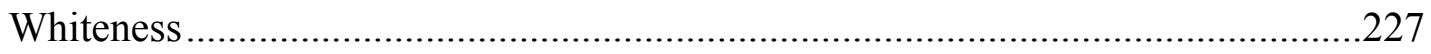

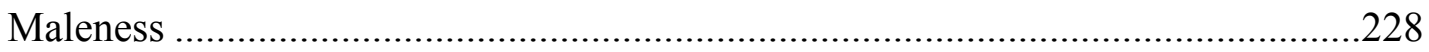

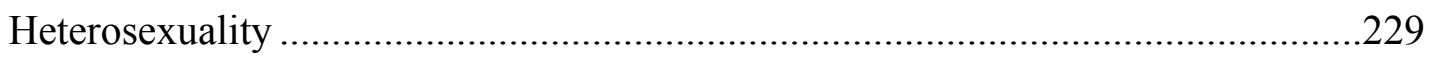

Allyship Informed by Intersectionality ..............................................................2. 
Identity as a Teacher

Student Affairs Graduate Programs

Professional Development

Implications for Leadership and Student Affairs

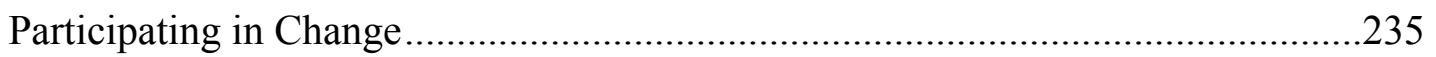

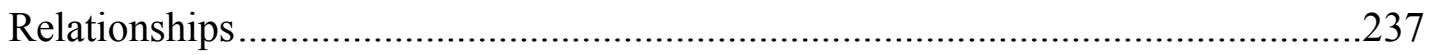

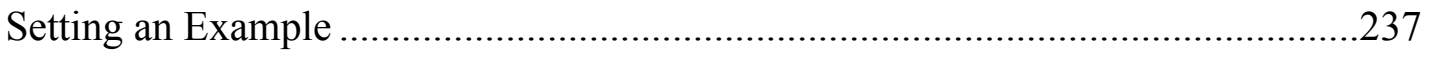

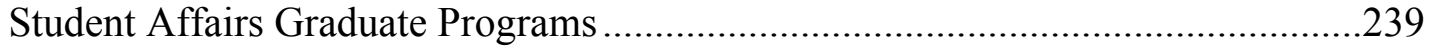

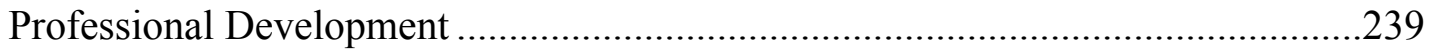

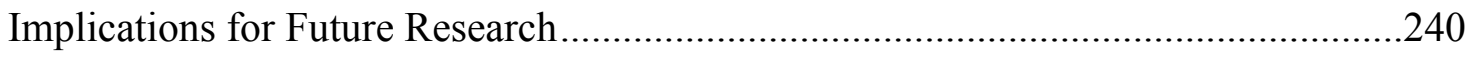

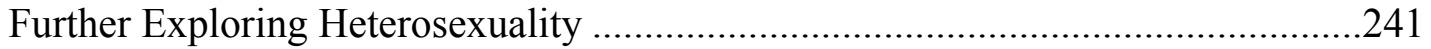

Incorporating Other Salient Identities.......................................................241

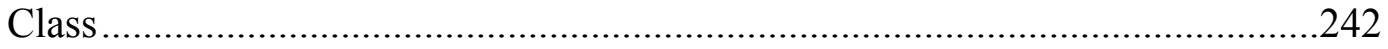

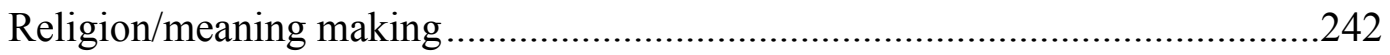

Beyond White, Heterosexual, Male Identities ..................................................242

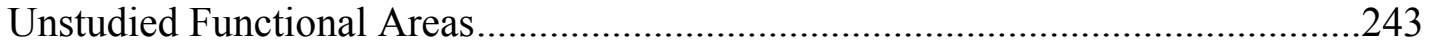

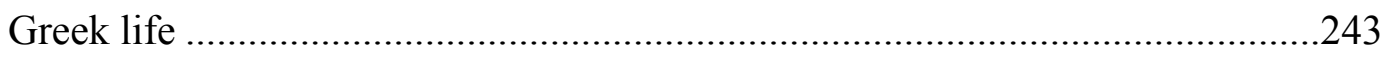

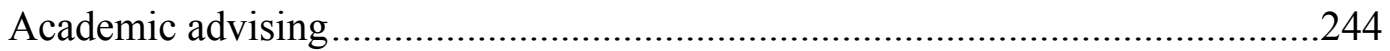

Student health and wellness ..................................................................24

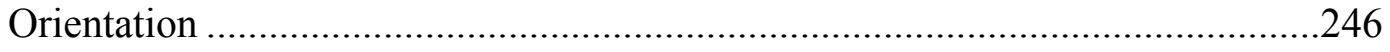

Outdoor education and recreation ...........................................................24

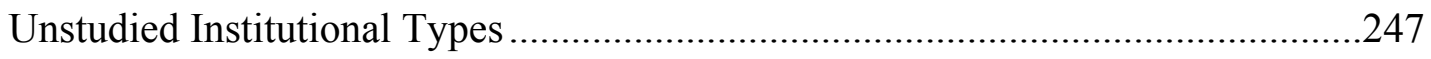

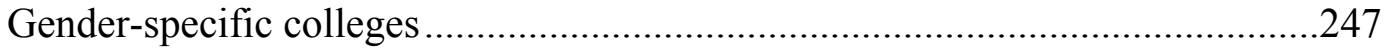


Historically Black colleges and universities

Additional Methodologies

Case study methodology

Significance .250

Summary .253

REFERENCES .254

APPENDIX A Recruitment Email .264

APPENDIX B Informed Consent Form .266

APPENDIX C Interview Protocols. .269

APPENDIX D Journal Prompts.... 


\section{LIST OF TABLES}

Table 1. Participant Pseudonym, Geographic Region(s), Institution Type, and

Functional Area(s)................................................. 44 


\section{CHAPTER ONE: INTRODUCTION}

Student affairs professionals serve as an important educational component in the university experience for undergraduate students. As a field, student affairs emphasizes each student's holistic learning (American College Personnel Association [ACPA] \& National Association of Student Personnel Administrators [NASPA], 2010; American Council on Education [ACE], 1937), espouses a commitment to "education and development of the total student, diversity, multicultural competence, human dignity" (ACPA, n.d.) and values "access, voice, acknowledgement, opportunity, and participation at all levels" (NASPA, n.d.). Because the field of student affairs espouses a focus on creating opportunities for full access, participation, and development of all students to their fullest potential, student affairs professionals, in turn, are positioned to empower all students whom they serve to access this potential and must be willing to continue to learn and develop along with students. Achieving these goals, in educational spaces, is also at the fore of arguments for the use of engaged pedagogy. For this reason, it is possible transgressive teaching can offer ways in which student affairs professionals can do their jobs in ways that align with the stated values and goals of their profession.

The book Teaching to Transgress: Education as the Practice of Freedom (hooks, 1994) is a seminal work in the field of education. Since its publication in 1994, the style of engaged pedagogy, an approach to teaching that seeks to engage students as cocreators of the learning in collaboration with other students and teachers, described in this work has been applied to a number of educational settings. While a host of literature exists on the use of engaged pedagogies in primary and secondary education classrooms and, to a lesser degree, in higher education and graduate level classrooms, there is little 
research on transgressive approaches' use in the practices of student affairs professionals. Scholars have called for its incorporation into these practices (Nicolazzo \& Harris, 2014; Stewart, 2008), and students, specifically those who hold multiple marginalized identities, indicate that they believe these practices would improve their university experience (McLaughlin, 2017).

This dearth of research means there has yet to be an understanding of how these practices can be incorporated into the work of student affairs professionals as they continue to work to engage students in the out-of-classroom educational experiences that serve as complementary learning to that of the classroom. The literature on transgressive teaching, when used in classroom settings, has indicated it is one approach to open up new avenues for engagement from students in ways that emphasize this potential (Danowitz \& Tuitt, 2012; Hackman, 2005; Quaye \& Harper, 2007). It could be possible, then, for transgressive teaching to present similar possibilities for the education within the work of student affairs professionals as well, since student affairs professionals play an equal but different role in the learning that takes place in the college experience.

There is an ever growing body of literature that emphasizes the benefits to students, particularly students holding one or more social identities that have been minoritized, in seeing their minoritized identities represented in the faculty and staff of the university at which the student attends (Bensimon, 2007; Guifridda, 2006; Museus, 2011; Museus \& Quaye, 2008). The word "minoritized" is used intentionally here, because it encapsulates the process of having minority status placed upon and continually enacted upon a group rather than using the term minority to refer to a constant state of being (Gunaratnam, 2003). There is substantial value to this literature, in that it offers a 
number of perspectives and potential interventions in which universities could engage to better meet the needs and support the persistence and retention of students with minoritized identities. More specifically, this literature often speaks to a need for validating the lived experiences and cultural perspectives of a variety of students, rather than asking those students to distance or dissociate from their cultural history to fit in on college campuses. This study seeks to better understand if introducing transgressive teaching to nine White, heterosexual, male student affairs professionals can have an impact on their capacities to create spaces for validation and valuing the lived experiences and cultural perspectives of the students with whom each of these student affairs professionals work.

\section{Problem Statement}

It has been well established any form of engaged pedagogy, and specifically transgressive teaching, can have a substantive impact on the experiences of students in primary and secondary education classrooms (Berry, 2010; Cochran-Smith, 2001; Grace \& Benson, 1999; Hackman, 2005; Vavrus, 2002). Literature has begun to emerge that also points to the practices of transgressive teaching as being important to incorporate into higher education and graduate level education experiences and that it has been similarly transformative (Barnett, 2012; Bradley, 2009; Danowitz \& Tuitt, 2011; Edwards, 2008; Labbe, 2010; Quaye \& Harper, 2007). However, there has yet to be an attempt to understand how student affairs professionals can incorporate these practices into their work, address the challenges faced in this incorporation, and what impact it has on the practices of the student affairs professionals attempting this incorporation. There have been scholars who have theorized these practices (Chavez, Guido-DiBrito, \& 
Mallory, 2003; Nicolazzo \& Harris, 2014), when implemented by student affairs professionals, can have similar, transformative effects on the experiences of students, especially those from identity groups that have historically been underrepresented and underserved in higher education settings.

\section{Purpose of the Study}

The purpose of this study was to address the current gap in literature on transgressive teaching. Specifically, there is a lack of previous research on what, if any, impact the introduction of these concepts can have on the practices of student affairs professionals. This study sought to better understand how White, heterosexual, male student affairs professionals, could work to expand their capacities to practice transgressive teaching. This is because transgressive teaching can be seen as one possible way to enhance White, heterosexual, male student affairs professionals' practices of leadership by better engaging students across individual identities and systems of oppression and ultimately engage in improving climates on college campuses. Expanding these capacities could begin by introducing the concepts of transgressive teaching to White, heterosexual, male student affairs professionals, and following their learning as they work to understand the concepts and the potential for incorporating the concepts of transgressive teaching into their practices.

\section{Research Questions/Hypothesis}

Three research questions guided this study:

- What, if any, impact does learning about transgressive teaching have on how White, heterosexual, male student affairs professionals think about their practice? 
- What, if any, impact does learning about transgressive teaching have on White, heterosexual, male student affairs professionals connecting their roles as student affairs professionals to an identity as an educator?

- What, if any, relationship do White, heterosexual, male student affairs professionals experience between transgressive teaching and their understanding of leadership?

The goal of this study was to examine how introducing transgressive teaching into the consciousness of White, heterosexual, male student affairs professionals may in some way impact their capacity to practice a form of leadership that better engages students and student affairs professions in continued learning. This study was intended to examine a new way for White, heterosexual, male student affairs professionals to practice leadership in their positions.

\section{Research Design/Methodology}

Discussed in greater detail in Chapter 3, I used a qualitative, phenomenological frame, which was then augmented by grounded theory, to explore the research questions. I interviewed nine student affairs professionals who identify as White, heterosexual, and male in a semi-structured format for roughly 45 minutes before they began reading Teaching to Transgress. These interviews focused on the participants' current perceptions of their work, their current level of familiarity with transgressive teaching, and their current conceptions of practicing leadership. Each participant then read Teaching to Transgress and kept a journal in which they addressed specific prompts related to the study's research questions and had space for free writing. After the participants read Teaching to Transgress, we engaged in another interview, again in 
semi-structured format, for approximately 90 minutes. The post-interview asked the participants about their current conception of their work and their conceptions of practicing leadership, and what, if any, impact reading Teaching to Transgress had on how the participants continued to think about their approach to their work, their interactions with students, and their practice of leadership. Approximately 4 to 6 weeks after the post-interview, I engaged the participants in a final semi-structured interview for about 45 minutes. In the post post-interview, participants were asked about their experiences in their work since reading Teaching to Transgress, what dimensions of transgressive teaching, if any, have they continued to reflect upon, and if they believed the experience would be beneficial to other student affairs professionals.

\section{Positionality}

Acknowledging the position of the researcher is also important as a way of acknowledging my own experiences and assumptions and their potential impact on this study (Creswell, 1998; Van Manen, 1990). I identify as a White, heterosexual, male student affairs professional. I have worked in the field for 10 years and have spent the majority of my career doing a variety of diversity-inclusion-and-identity-based work at large, public and medium, private universities. I also have worked in residential life at large, private and public universities. In addition to acknowledging my professional identities in connection to the participants of this study, I also believe it important to acknowledge my own use of transgressive teaching in my work.

I was introduced to the idea of transgressive teaching during my work at a lesbian, gay, bisexual, and transgender (LGBT) resource center, and since then I have actively worked to understand my own professional perspective through that lens. I acknowledge 
these parts of myself, which I carry and were very central to my own experience as the researcher because they created an ongoing potential for bias in this study. To address the potential impact of these positions, I employed trustworthiness measures of bracketing and analytical memos while I was collecting my data while also using member checking and peer debriefing to ensure the findings at which I arrived were not simply an excuse to confirm already-held personal beliefs about the topic. This positionality also informed some of the choices made in the design of this study, to center an accountability to those impacted by systems of oppression that benefit the identities I hold as a White, heterosexual, man. I will discuss my positionality and the measures I took to ensure that I was able to distill and mitigate the impact that positionality may have on the findings of this work, in Chapter 3.

\section{Significance and Limitations}

The issues faced by students on college campuses and by institutions often reflect the same issues faced by individuals and organizations in the larger society made up of those individuals and organizations. Just as White people, heterosexual people, and maleidentified people hold social power and privilege connected to these identities in the greater American landscape (Croteau, Talbot, Lance, \& Evans, 2002; Evans \& Reason, 2007; Macintosh, 1986; Simoni \& Walters, 2001), so it can be understood these identities carry power and privilege on college and university campuses. This study's findings can contribute to a better understanding of ways for all student affairs professionals who hold multiple dominant group identities - in this case White, heterosexual, and male identities - to create more positive campus-climate experiences for all students on college and university campuses. 
This study also yields implications for the study of leadership and its practice within the field of student affairs in higher education, as the framework hypothesized offers new insight into the potential for leadership within the population studied. More specifically, transgressive teaching is about making the boundaries between the roles of teacher and student more fluid than has been traditionally accepted, offering those in the traditional student role opportunities to also take up dimensions of the traditional teacher role when the students' lived experiences can contribute to the learning in ways outside of the knowledge of the teacher. From the data collected in this study, a specific approach to leadership emerged as the prominent way in which the participants view leadership: the social change model of leadership (Komives \& Wagner, 2016). The social change model of leadership, a model developed specifically for college students to understand and practice leadership (Komives \& Wagner, 2016; Pope, Reynolds, \& Mueller, 2014), also offers an opportunity for student affairs professionals to learn about leadership in ways beyond the assumption that leadership is only the focus of those who hold positions of authority within a system (Bryman, 2007; Dalton, 2002; Dalton \& Imanuel Gardner, 2002; Sandeen, 1991; Thomas, 2002).

The implications for future research include the need to study other identity groups beyond White, heterosexual, male student affairs professionals to understand ways to engage transgressive teaching across different identities and historical experiences. Similarly, this study contributes to the emerging field of critical White studies, masculinity studies, and critical race and gender studies. Additionally, this study's findings can offer a number of contributions to the field of student affairs in higher education. Specifically, this study can contribute to a better understanding of the 
ways that student affairs professionals with multiple dominant group social identities can engage with students and colleagues across identities and without engaging the amnesia of erasing the legacy of system of oppression (Bullen, 2012; hooks, 1994). This study also has the potential to offer framing for student affairs professionals holding multiple dominant group identities to engage in interventions at the individual and systemic levels to address systems of oppression with a mindfulness for the ways in which the intersections of their own identities also carry a legacy within those larger systems (Collins, 2002; Crenshaw, 1991; Davis \& Wagner, 2005; McCall, 2005; Reason, Roosa Millar, \& Scales, 2005; Washington \& Evans, 1991).

There were also limitations faced by the study I am proposing here. One such limitation, related to the qualitative nature of this study, is the difficulty of drawing a direct cause-and-effect relationship between the introduction of transgressive teaching to these student affairs professionals and any changes that occurred in their practices. This limitation was addressed by the study's reliance on the self-perception of the participants being the unit of analysis, rather than being subject to criteria determined by me, which would then be subject to my own biases. These limitations are discussed in greater detail in Chapter 3.

\section{Summary}

This chapter has served as an introduction to the study I conducted. I reviewed the problem this study has examined, which was that transgressive teaching has been theorized as helpful for student affairs professionals but not yet studied. I have also offered an introduction to the context within which this problem is situated, which was that transgressive teaching has been studied extensively within other aspects of education 
and has been shown to have a positive impact in those spaces. I reviewed the hypothesis I intend to test, which was that transgressive teaching will be connected to the work of student affairs professionals and have an impact on the practices of White, heterosexual, male student affairs professionals and that I studied these experiences using a phenomenological approach augmented by an adapted version of grounded theory. I reviewed the ways in which the findings of this study hold significance for the field of student affairs and higher education, practicing leadership within the field of student affairs, specifically for those who hold White, heterosexual, and male identities. Upon this primer, I will now offer a larger view of the context within which this study was situated by an in-depth review of the bodies of literature that informed this study and on which this study was founded. The next chapter will review literature on the use of transgressive teaching in the field of student affairs, the literature on the identities of White, heterosexual, males, and the literature on the social change model of leadership. 


\section{CHAPTER TWO: LITERATURE REVIEW}

There has yet to be substantive research conducted on the impact of incorporating concepts of transgressive teaching into the practices of student affairs professionals though the practices of have shown to be impactful when incorporated into primary, secondary, and higher education classrooms. This chapter will focus on reviewing the available literature for a number of areas that help to frame the historical context upon which this study will be structured. I will do that first by giving an overview of what literature will be reviewed for those contextual purposes (such as a review of Teaching to Transgress) and what areas will not be covered (such as literature on transgressive teaching in classrooms), including a rationale for those areas of literature, which may seem relevant but will not be reviewed in depth for the purposes of this study.

I will review the relevant literature in areas that are key to this study and its greater importance within the fields of student affairs and higher education. Those areas will include transgressive teaching in student affairs, White heterosexual men, and the connection of these identities to the concept of allyship. Finally, I will review literature on the theories of leadership that emerged as the perspectives on leadership held by the participants in this study, which could most easily be categorized as being related to the social change model of leadership.

Each section will offer a working definition for the terms used in each section, such as transgressive teaching, student affairs, White, heterosexual, and male identities and leadership that are constructed from the bodies of literature reviewed. This practice of constructing the definitions will be important because there are a number of perspectives and definitions available on these terms, some with only very minor or 
nuanced differences, and I believe it will help to ensure a level of internal consistency within the study if the terms are defined within the scope of the literature which will serve as the foundation of the study.

\section{Framing the Literature Review}

Before I begin to examine the current literature on transgressive teaching within the field of student affairs, it is important to understand how that literature is grounded in the broader literature on transgressive teaching. This section will offer a review of Teaching to Transgress, as the source from which transgressive teaching emerges, and also the literature on transgressive teaching's applications to classroom settings throughout elementary, secondary, and higher education.

\section{Transgressive Teaching}

It is important, in reviewing literature on transgressive teaching, to begin with the book from which the practice originates. Transgressive teaching is, at its core, the approach to education described by bell hooks (1994) in the book Teaching to Transgress: Education as the Practice of Freedom. While hooks described her approach as "engaged pedagogy," there are also a variety of ways of teaching can be described as engaged pedagogy, and many of those approaches can look very different from the ways of engaging with students as hooks described. Therefore, it becomes important to differentiate hooks' specific approach to engaged pedagogy from others. hooks' work is a collection of essays, dialogues, and reflections on her experience throughout education, from segregated primary schools to receiving tenure as a university professor.

Throughout the book, hooks described an approach to teaching that demands those in the role of teacher be willing to engage with compassion the fullness of being that each 
student brings into the space of learning.

Different chapters of the book described different aspects of hooks' (1994) approach to engaged pedagogy in different ways. The first chapter of the book, from which it gets its title, began the journey through hooks' educational career, and framed the approach taken throughout the book in which examples from bell hooks' life were used to illustrate a larger point about the nature of education and its interaction with the identity of all people participating in education. hooks began the book at the time leading up to her being granted tenure, then returned to her time in segregated primary school. While for many the only image of segregated schools is an illustration of the progress the United States had yet to make, hooks described that period of her education as joyful and exciting, being taught by Black teachers, surrounded by other Black students. She wrote that integration shifted the focus of her education to obedience. She wrote about losing her love of learning and a boredom that followed her through graduate school, realizing much of what was expected was to regurgitate information rather than to discover new ideas and new parts of one's self (hooks, 1994).

In a chapter written as a dialogue between Gloria Watkins and bell hooks (bell hooks is Gloria Watkins' writing voice), the two discuss the importance of Paulo Freire on Watkins' life and hooks' work. hooks said Freire's work gave her language to describe and express her experience in the world, but she experienced others engaging with his work in a detached, voyeuristic manner. hooks also offered a critique of Freire, that his work is still very much centered on men and uses a host of sexist language, while also insisting that there was a capacity for critique without dismissal, even though educational language often does not allow those two things to coexist. 
In that same light she spoke to the way in which her experiences with Freire's work was the point from which her own work emerged, rather than describing it as a breaking point. She spoke of Freire's object to subject framework, and that was not available in earlier feminist writings:

[It is easy] for everyone to forget that early on feminist movement was not a location that welcomed the radical struggle of black women, to theorize our subjectivity. Freire's work (and that of many other teachers) affirmed my right as a subject in resistance to define my reality (p. 53).

hooks (1994) wrote of her own approach to feminism as being “an intersection of Paulo's work and the lived pedagogy of the many black teachers of my girlhood (most of them women)" (p. 52), and described herself as taking "threads of Paulo's work and weaving it into that version of feminist pedagogy I believe my work as a writer and teacher embodies" (p. 52). In this chapter explicitly, and throughout the rest of the book, hooks described her work as being an approach to feminism and to education that learned from and built upon Freire, an approach to education that orients liberation at the center, while being informed by the lived experiences of an American, Black woman.

The approach offered in Teaching to Transgress was used in this study instead of Freire's work (such as Pedagogy of the Oppressed) because it offered a specific acknowledgement of the historical context of the United States. hooks described working and learning within the same context as those in which the participants of this study have learned and do work, as a Black woman. The U.S. context of Teaching to Transgress was also important because, while not exclusively a U.S. phenomenon, the field of student 
affairs, as framed within this study, originated in the U.S. higher education system (ACE, 1937; ACPA \& NASPA, 2010).

In continuing to reinforce that paradigm, hooks examined the ways in which there has been a false dichotomy constructed between theory and practice. She described the way many have asserted because theory has limitations, or that it does not always speak in an all-encompassing way to all experiences, it must be thrown out and cannot offer insight. She also spoke to the ways in which many movements, within and beyond education, work to recreate the hierarchies of domination that many of those creating them seek to escape. hooks (1994) concluded an ongoing construction of theory that holds more, was not held under this dichotomy, and is necessary for the liberation toward which she believed she was working.

hooks (1994) challenged the ways in which identities can be used as tools for essentialism and returned to the importance of embracing subjectivity of experiences and acknowledging the different histories that inform how an individual arrives in a space of learning. She offered an example of these histories in describing the ways in which Black women have been pushed out of many feminist movements for wanting to bring focus to the intersection of race and gender, as well as class.

hooks (1994) used this as a point of transition to write about the nature of learning environments and what the necessary conditions are to create a liberatory space of learning. She wrote on the nature of the current classroom, the nature of the world in which Black scholarship is important and yet still ignored, the importance of community in teaching and learning, the histories and limitations of language in working toward liberation, the ways in which class politics are mostly invisible in education, the place of 
Eros and sexuality in the work of teaching and the impact of its refusal, and the beauty of teaching and learning without limits (hooks, 1994). While the work did not offer a checklist of to-dos and does not serve as a collection of best practices to be applied identically to any and all educational spaces, she offered a framework upon which a more liberatory approach to education can be based.

Bullen (2012) wrote about the continued relevance of Teaching to Transgress and listed the key themes of the work, which can be understood as a distillation of the core concepts of transgressive teaching. While this could seem as though it was creating a checklist of best practices from a work designed to frustrate that attempt, it offered help in understanding a transgressive teaching approach by offering themes around which to base development and thinking. Bullen's (2012) key themes included: “Understand the reality you seek to transform" (p. 1); "Our lives, our work must be an example of critical reflections, changes in thought, and a willingness to face shortcomings" (p. 2); "Approach students with the will and desire to respond to their unique beings, even if the situation does not allow the full emergence of a relationship based on mutual recognition" (p. 2); and "Examine critically the way you, as a teacher, conceptualize what the space for learning should be like" (p. 2). These distillations offered a framing upon which to examine the ways in which transgressive teaching has been applied to a number of contexts.

Next, I will outline the literature on the ways in which transgressive teaching has been used in a number of in-classroom educational contexts. This is to create a foundation of understanding on both the theoretical perspective and the ways in which it has been applied in education in the past to frame both the ways in which an application 
has been suggested for higher education and what has yet to explored about this application, which will in turn ground this study in a more clearly articulated gap in the literature.

\section{Transgressive Teaching in the Classroom}

In the 23 years since its publication, Teaching to Transgress has come to be seen as a seminal work on feminist approaches to education. The book falls within a frame of constructivist education, which asserts that our thoughts and experiences are shaped by one's context (Kim, 2005; Richardson, 1997). Teaching to Transgress has informed a host of theoretical perspectives and approaches to an extremely diverse array of disciplines, including primary and secondary school teacher education (Berry, 2010; Cochran-Smith, 2001; Grace \& Benson; 1999, Hackman, 2005; Vavrus, 2002), to undergraduate and graduate level faculty development (Barnett, 2012; Bradley, 2009; Danowitz \& Tuitt, 2011; Edwards, 2008; Labbe, 2010; LaMantia, Wagner, \& Bohecker, 2015; Quaye \& Harper, 2007) and also graduate students of color peer support practices (Aguilar, Brito, Salazar, \& Alavarez, 2016; Ashlee, Zamora, \& Karikari, 2017). The diverse approaches to engaging in learning spaces have also begun to emerge in graduate programs that prepare student affairs professionals (Danowitz \& Tuitt, 2011; Hubain, Allen, Harris, \& Linder, 2016; Jones \& Stewart, 2016), library science programs (Ramos, Snow, Giovenale, Labadorf, \& Cadogan, 2016), leadership studies programs (Mahoney, 2016), counseling psychology (Vera \& Speight, 2003), and social work programs (Heule, Knutagård, \& Kristiansen, 2017) to name a few. However, there has yet to be a study that examines what, if any, impact a direct engagement with the text could have on the practices of student affairs professionals. 
The literature on the use of the concepts of hooks' (1994) work in Teaching to Transgress is extensive and well discussed in primary, secondary, and higher education classrooms. Because this study focuses on the work of student affairs professionals, who work outside of college classrooms, I will primarily focus on literature specifically on the use of transgressive teaching by student affairs professionals or connected to the work of student affairs professionals. The choice to approach the literature in this way is specifically to highlight two areas of importance: first, the dearth of literature on using transgressive teaching in one area of education (especially in comparison to its significant representation in other, very closely connected areas of education), and second, in pointing to the clear connections between the practices of transgressive teaching and the stated values of the field of student affairs. One reason for further study into the application of transgressive teaching in student affairs work is the substantial research being done on its application in other spaces of teaching and learning. This emphasizes its benefit to students, its transformative impact on the process of learning, and that, in turn, means that it could be equally beneficial in spaces of learning outside of the traditional classroom environment of teaching and learning.

In addition to the available literature on transgressive teaching in student affairs, I will cover a variety of literature on White, heterosexual, men with specific emphasis given to the development of those identities in people on college campuses. I will place specific emphasis on those identities as it relates to environments of higher education for two reasons: because student affairs professionals work with college students, which means it is important to understand the landscape within which these concepts are being explored, and because student affairs professionals will have had to themselves graduate 
from college, which can likely mean that they will have had similar experiences to those described in the literature on Whiteness, heterosexuality, and maleness in the college environment. In the section covering White, heterosexual men, I will review bodies of literature on each of those identities individually and then draw connections across each of those bodies of literature. It also is important to acknowledge that a number of bodies of literature that cover some of these areas in connection to other identities that I will not explore in depth. For example, there is a body of literature on men and masculinities focused on the experiences of Black and African American men (Harper, 2004, 2007; Harper \& Quaye, 2007; Harris, Palmer, \& Struve, 2011; Smith, Allen, \& Danley, 2007; Soloranzo, Ceja, \& Yosso, 2000; Wood \& Newman, 2015) and gay men (D’Augelli, 1991; Taub, Blinde, \& Greer, 1999; Tillapaugh, 2013, 2015); these studies examined, generally, the interaction between an identity that is given power and privilege socially (male identity) and an identity that is minoritized (Black/African American identity or gay identity, respectively). Again, here I use the descriptor minoritized to distinguish the process of having minority status placed upon and continually enacted on an identity and members of communities holding an identity (Gunaratnam, 2003). This study will seek to focus on how a collection of identities that are privileged interact with one another, while also acknowledging the three identities that are the focus of this research are not the entirety of the components of identity that may be held by the participants, nor will they consistently be the most salient identities for those participant's experiences.

\section{Transgressive Teaching in Student Affairs}

The concepts of transgressive teaching have been noted as one piece of a larger framework of approaches to engaging with students in transformational and liberatory 
ways. Stewart (2008) offered that transgressive teaching is a way of building a space of trust to continue to engage students. Stewart used the analogy of a guide, writing "to be an effective guide, those following me must trust me, that I know where I am going, and that I will make sure to reach the destination without undue harm or exposure to unnecessary danger” (p. 12). Chavez et al. (2003) framed transgressive teaching as part of a necessity in further developing capacities in student affairs professionals for addressing an ever-diversifying array of experiences of students on college campuses. Levtov (2015) added that these practices could be part of a process of sustaining not only the students, but also the student affairs professionals themselves, empowering processes of change in their work and in their lives. McLaughlin (2017) described transgressive teaching as a process involving an ongoing and iterative series of processes that take place internally for the individual, external in their engagement with students from their distinct, positional roles, and communal as a co-creative way of engaging across and among positional roles.

While the research conducted has been less voluminous on how transgressive teaching is or can be used in the field of student affairs than in other areas of education, there is still an obvious alignment between this as an approach to creating a space of learning with students and the values and mission of the field of student affairs. Student affairs can be defined as the aspects of a college experience that contribute to student learning and development in out-of-classroom settings while being in collaboration and connection with classroom learning. The goal of student affairs is to center the holistic learning of each student rather than focusing on a singular intellectual pursuit (ACE, 1937; ACPA \& NASPA, 2010). A commitment to "education and development of the 
total student, diversity, multicultural competence, human dignity" (ACPA, n.d.) and valuing "access, voice, acknowledgement, opportunity, and participation at all levels" (NASPA, n.d.) shows a field committed to ensuring all students are able to access spaces in which they can develop their full potential, actively participate in all educational spaces, and develop and expand their potential to achieve.

Transgressive teaching connects to all of these values and commitments and offers a frame through which to understand ways to take up practicing these values. As Bullen (2012) contended, educators will be able to empower students and be able to embrace all that the students have to offer only when the educators themselves are willing to embrace that which the students have to offer to the environment of learning. Nicolazzo and Harris (2014) connected this to the values of institutions and the to field of student affairs, pointing out that engaging these ideas as dimensions of their work on campuses can offer student affairs professionals, as well as students and faculty members, a greater capacity to live out their espoused values personally and institutionally. Watt and Gasman (2015) specifically framed these practices as ways of addressing the historical ways in which some identities have been centralized in policy and practice while others have not.

Given the descriptions and insights offered above, in moving forward I will use the following as a working definition of transgressive teaching, which comes from McLaughlin (2017):

an approach to engaging with students in spaces of learning that aim to make more permeable traditional boundaries of teacher and student roles, to engage the entirety of each persons' being, acknowledge the value of their experiences and 
perspectives, and connects with and to the potential for learning and teaching in a mutually constructed process of growth and empowerment. (p. 1)

McLaughlin's definition framed the specific nature of the style of engaged pedagogy hooks (1994) described in her work, and also acknowledges there is a power differential associated with the roles of student and teacher in learning environments. McLaughlin's definition articulated transgressive teaching as a series of ongoing processes that aim to address and shift that power differential, making the boundaries around the power more fluid and accessible. It is also important to acknowledge McLaughlin's definition implied, but did not state directly, that transgressive teaching is transgressing the boundaries of socially constructed difference by seeing those as valuable aspects of a person's experience rather than barriers to knowledge or growth.

\section{White, Heterosexual, Men}

Societal expectations concerning the roles associated with identities have been in various states of flux for some time. While systems of power and privilege are still deeply entrenched in our current society, which for the purposes of this study will refer mostly to the United States, it is very clear that the roles those who benefit from those systems are expected to play are not the same as they had been for a large portion of the $20^{\text {th }}$ century. It is for this reason I will review the available literature on people whose identities are categorized as White, heterosexual, and male. These are all identities that hold social power and are situated in current structures to be benefitted by unearned privilege. Yet, these identities can also offer insight into how these systems function, and what the process of addressing the problematic nature of the systems that benefit individuals 
holding these identities can mean for those individuals in their attempts to create change in their environments.

\section{Maleness}

Male identity is, of the three identities directly examined in this study, the most extensively researched. Within that body of literature, there is a large diversity of approaches to studying and understanding men and/or maleness. In fact, one key aspect to understanding the concepts of men/maleness is a willingness to accept that these concepts are socially constructed and thus will inherently continue to shift as the contexts in which they are created will do the same (Connell, Kearn, \& Kimmel, 2005; Harris, 2010). The societies that create these definitions and concepts are also responsible for creating structures that can give power and privilege to certain groups or conceptual ideas within those constructs, in this case usually men (Gardiner, 2005). Herek (1988) asserted these structures of power being codified into a society can mean, among other things, the structures and those working within them lose their ability to adapt to a changing environment. Further, he asserted maleness, as it has been constructed and reinforced by societal expectations, has outlived its usefulness to our society because it still meets some of society's needs, and those needs it no longer meets become the issues of others with which to contend rather than those whose identities represent this gap. With this understanding, I will use as a working definition of maleness, adapted from Tillapaugh (2013), as a set of actions continuously performed by people identifying themselves as male or as men, that maintain those individuals identities and societal expectations that are applied to people who claim that identity for themselves. 
Kiesling (2007) expanded upon this notion, offering that because of the social power granted to men through their identity's normalization as the standard against which other identities and experiences are measured, it is both invisible and dominant at the same time. Masculinity is a performance that is taught, he argued, giving each person in a society a set of thoughts, actions, and ways of expressing themselves that will be seen as valuable and important within a culture. While Kiesling (and many others) accepted that these aspects of performance can be taken up by anyone and are not exclusive to people who identify as men, these expectations are specifically enforced upon men in specific ways. We are able to understand these expectations and their consequences for identity formation, Connell et al. (2005) argued, because we are able to observe and even aggregate these expectations between and among people's interactions across and among genders.

Swain (2005) described a variety of ways in which boys and young men navigate and negotiate their performance and understand of their maleness. He further looked at the ways school is one environment in which these conceptions are negotiated and made clear these negotiations happen in both formal and informal cultures; they are in equal parts interconnected and individually dynamic. Anderson (2007) expanded upon this, indicating these spaces of negotiation can encourage practices of inclusion or exclusion of diverse performances of maleness, which, in turn, can impact the willingness of each individual to hold a more inclusive or exclusive view of appropriate masculinity. He also pointed out that each environment a person enters can be transformative, an acknowledgement of how individuals can impact larger groups and how groups can impact individuals. 
Harris (2010) found by the time men start college, they have already internalized a number of social messages about acceptable ways to perform maleness and how to be seen as a man socially. Harris asserted there is a need then for men to be exposed to a variety of expressions of maleness and for those expressions to be affirmed. Harris and Edwards (2010) found across different studies of men's experiences that men continually experience pressure to perform a singular, hegemonic version of maleness, while also noting performing this hegemonic version of maleness had material and felt consequences for those performing it and for the people with whom they interact. Harris and Edwards (2010) also presented models for supporting men through the process of challenging these expectations and conceptions of maleness, including mentoring from other male identified people, involvement in organizations, and taking classes that create space for reflection and deepened learning on topics of gender and identity. Harris (2010) and Harris and Edwards (2010) noted these interventions are related to how men are currently socialized and offered that earlier exposure and socialization of men to a variety of performances of maleness would deepen and bolster the impact of these practices. Davis (2002) offered similar suggestions and noted that even though male identity is given social power, those holding these identities are still in need of support and intentional development. Davis and Wagner (2005) expanded further still, discussing the ways in which modes of expression to which men are denied and deny themselves access limits men's capacities to create change for themselves personally and within communities of which they are members.

An important element of the perspectives on maleness reviewed here is that many of the theorists acknowledged there is a connection between identity as a man and other 
identities held by an individual (Connell et al., 2005; Herek, 1986; Kiesling, 2007; Swain, 2005). This point is important because it speaks not only to how maleness interacts with the world around the individual but with other aspects of identity within each individual, which also play a part in shaping how that individual interacts with the world around them. Gender does not function as separate from race, or sexual orientation, or class. Instead each of them informs one another, sometimes in tension and other times in alliance. This point allows for a more in depth discussion of a more narrowly and clearly defined group, in that we can discuss specifically the experiences and meaning making of men who also identify as White, another group whose expectations and norms have largely been built into societal norms of the United States.

\section{Whiteness}

Whiteness, similarly to maleness as described above, is usually unnamed or invisible, socially constructed, and has material outcomes, experiences, and consequences associated with the construction's integration into larger social systems (Evans \& Reason, 2007; Lipsitz, 1998; Reason, 2007). Reason (2007) further asserted, even after an experience or a number of experiences of emerging a consciousness of race and racial oppression/privilege, many White identified people still must engage in a continuous process of reexamining and redefining their relationship to Whiteness as part of their identity. This, he argued, develops group norms and expectations that, although unspoken, become engrained into the daily interactions and interpretations of daily life. Frankenberg, as cited by Evans and Reason (2007) asserted that, in fact, Whiteness is most visible to the people in a society or group against whom Whiteness is used to exert dominance. Bonilla-Silva's (2010) research affirmed most White-identified people living 
in segregated neighborhoods assumed this was just the (proverbial) way things are rather than a consequence of equalities connected to or stemming from race. Reason and Evans (2007) also found naming and understanding the role that Whiteness, as one dimension of identity, had an impact on their experiences in the world. They further asserted naming and understanding can impact the level to which White people see their experiences as normal and unconnected to race. Cobham (2011) offered a similar perspective: being White or embodying Whiteness carries with it a connection to systems of power that normalize values and experiences that are not universal.

Several authors have posited this social positioning can be an important part of development, even in understanding that for many it remains invisible or unaddressed. Crowfoot and Chesler (1996) asserted White people, more specifically White men, as social power holders can be important contributors to social change efforts while enacting their own personal growth and development through those processes. Cobham (2011) offered that being made aware of and being capable of noticing one's own Whiteness as a set of lived experiences and expectations that have been enacted individually and systemically can, in turn, offer those individuals new perspective on their positional situation within an environment (such as a college campus). Reason, Scales, and Roosa Miller (2005) noted that an environment that continues to support this development, and strategies for understanding and managing new emotions and experiences of cognitive dissonance from previous understandings of how the world works, is important in sustaining the development of this understanding and utilizing it in taking action.

Cabrera (2012) asserted Whiteness contains and advances a way of knowing and understanding the world that is based in ignorance. Mills (1997) further articulated the 
nature of Whiteness as a system that normalizes actions, approaches, and even spaces whose association with White people has made their existence and interactions with such spaces synonymous with Whiteness and interacting with Whiteness. This notion was affirmed and depend by Macintosh (1988), who described functional assumptions of Whiteness: other racial groups hold a desire to achieve to Whiteness, and those who are not able to gain access in the same ways as White people are either not existent or not trying hard enough. Given these perspectives, a working definition I will use for Whiteness in this study will be, adapted from Macintosh (1988), a set of physical characteristics that include skin tone and color that allows the individual access to systemic advantages and by acting in accordance with that level of access upholds the systemic expectations related to possessing those characteristics and accessing those advantages.

\section{Heterosexuality}

Similarly to the other socially constructed identity categories of maleness and Whiteness, heterosexuality can be understood as an unacknowledged social norm against which other identities are compared. Evans and Broido (2005) pointed out heterosexuality, because of its normative status, is rarely understood as an identity at all. They also found most research on the development of heterosexual identity and the positional power of that identity needed to include some level of self-exploration.

Worthington, Savoy, Dillon, and Vernaglia (2002) acknowledged an orientation to a variety of types of attraction is not a choice but rather a predisposition that a person can adopt and explore (or not). By “attraction," Worthington et al. (2002) meant any or all of the possibilities of affectional, such as romantic, sexual, and emotional. In the case 
of heterosexual identity, this would be an attraction to genders that are not the same as that held by the person in question. This framed all sexual orientation identities, even those that are normalized and given social privilege (in our current social structure this being heterosexuality) as being ones that can still be identities that can be developed and expressed in a variety of ways. This built upon Katz (1996) who examined the evolution of the term heterosexuality and its current common usage emerging in the late $19^{\text {th }}$ and early $20^{\text {th }}$ centuries as both an indicator of attraction to a partner of a distinctly different gender and as a socially normal function of desire and sexual expression.

Eliason (1995) found a number of men, in coming to an understanding of their identity as heterosexual, spent much of their development only viewing this identity as being an imposed identity from either an individual, a group of individuals, or by society. While some were able to move through that experience and understand this identity as something they adopted and expressed. An intriguing caveat to that adoption and expression was that it often manifested as a rejection of homosexuality or gayness rather than as a commitment to one of many possibilities considered. Worthington and Mohr (2002) noted there is a need to better understand how those who hold heterosexual identities relate to and understand their own level of connection to this part of their identity and the social privilege it carries as one way to better understand how to have an impact on the dynamics of difference in sexual orientation identity playing out among individual, inter-individual, and societal interactions. Simoni and Walters (2001) found increasing opportunities for development and engagement in a deeper understanding and development of heterosexual identity contributed to an increase in positive attitudes toward others who hold non-heterosexual identities. Ji (2007) noted that spaces of 
support to explore and develop a deeper understanding of these identities could also lead to a greater capacity for action and allyship. While not a central focus of this research, discussing allyship is an important aspect to acknowledge, given this work's implications for the concept.

\section{Allyship}

Broido (2000) defined "allies," in the context of social justice, as members of groups that receive social privilege or express social dominance who direct their actions toward ending the systems that oppress others while granting those individuals and their groups' social privilege. Broido's definition was adapted from a definition offered by Washington and Evans (1991), who added, in their discussion on heterosexual-identified people, members of dominant groups who advocate both for and with members of oppressed groups become allies to lesbian, gay, and bisexual identified people. They offered this aspect of advocacy for and with as an acknowledgement of the different power dominant voices can have, while cautioning that dominant group voices need to offer advocacy while lifting up and making space for voices targeted or oppressed. Bourassa (1991) also used the term ally in a similar fashion in discussing Whiteidentified people's involvement in protesting racism. While these concepts were not explicitly called “allyship," these ideas also emerged in Katz' (1996) and Herek's (1988) works on understanding heterosexual identity.

Davis and Wagner (2005) discussed allyship in terms of a series of both internal and external processes, just as the barriers to taking up allyship are both internal and external. They discussed the importance of understanding these barriers and using this understanding to create interventions that challenged and supported continued 
exploration. Reason et al. (2005, also citing Washington \& Evans, 1991 among others) offered a model of racial justice ally development, which work to develop a number of capacities from cognizance to action-taking, Reason, et al. examined the impact of college experiences on the development of these capacities in college students. Their model offered that a college experience, informed by a variety of interactions and exposures pre-college, with a variety of people holding different racial identities and opportunities to reflect and examine experiences of Whiteness in a supportive environment, can increase the depth (in their article they call it a "level") and the frequency of actions in service of racial justice.

Intersectionality. In relationship to the practice of allyship is the important notion of intersectionality. While the term has entered a more popular consciousness and is often used to describe the ways in which all of the social identities of each person intersect to create a unique experience, intersectionality's importance in relation to allyship comes from its original definition. Coined by Crenshaw (1991), intersectionality's purpose is to describe the specific ways in which the interactions of identity within systems of power and oppression are experienced (Collins, 2002;

Crenshaw, 1991). So while intersectionality can also be used as a methodological framework (McCall, 2005), for the purposes of this study it is helpful to frame allyship and its connection to the identity's of the participants. This framing also helps to retain an aspect of hooks' (1994) framework for transgressive teaching, that the acknowledgement and naming of identity is not to dictate an essential experience, but rather to acknowledge a history and legacy that also informs the experiences of people holding those identities. 


\section{Leadership}

In addition to being concerned with the ways in which transgressive teaching can impact the work of student affairs professionals who identify at White, heterosexual, and male, this study also is interested in the ways in which transgressive teaching may or may not connect to how White, heterosexual, male student affairs professionals conceive of practicing leadership. For this reason it is important to understand the context within which leadership, as an idea, is positioned and how that positioning will inform the findings and implications of this study. Many different definitions of leadership exist (Dugan, Komives, \& Segar, 2008), and within the field of student affairs, literature often posits that leadership is positional, whether describing students, faculty, or staff (Bryman, 2007; Dalton, 2002; Dalton \& Imanuel Gardner, 2002; Sandeen, 1991; Thomas, 2002;). For the purpose of this study, the review of literature on leadership will focus on a specific theory of leadership: the social change model of leadership, which emerged from the findings of this study as being most closely aligned with how the participants understand leadership and the practice of leadership within the field of student affairs and to which they connected many of their experiences reading Teaching to Transgress. It seems logical this model would emerge as relevant to this study, given that it both focuses on the environment of college, which is where all of the participants work, and that it prioritizes social justice and social change at its core (Pope et al., 2014).

\section{The Social Change Model}

The social change model of leadership offers those willing to engage with it an opportunity to challenge their own assumptions and can serve as a method for disrupting individualistic conceptions of leadership and forging a more collective orientation 
(Dugan, Turman, \& Torrez, 2015). It was developed between 1993 and 1996 by a group of educators whose work focuses on college students (Komives \& Wagner, 2016). For this reason, the model is very closely focused on the experiences of students in college (Dugan \& Komives, 2011; Komives \& Wagner, 2016). The model's primary goal is social change, which it defines as actions that intend to improve the condition of human beings and their environment. With change at the center of the model, it purports that three distinct and interactive bodies of values create the environment in which change can take place. The assertion of the model is the more elements of each body of values are aligned with one another, the greater the environment will support the change desired. Conversely, if some of the values or bodies of values are neglected or misaligned, change will become more difficult (Komives \& Wagner, 2016).

Dugan (2006) found this model can challenge students, especially in the areas of “controversy with civility, citizenship, and change" (p. 223), and mentoring relationships can be a critical factor in furthering the development of all of the capacities of leadership addressed by the social change model (Campbell, Smith, Dugan, \& Komives, 2012). This was reiterated by Priest and Clegorne (2015), who also spoke to the importance of understanding students' developmental readiness to be challenged by practices that seem counter to their expectations about leadership. Dugan et al. (2015) elaborated on this idea, asserting that the social change model, while oriented to social justice, "often fails to address the reality of systematic power and authority dynamics inherent to all social change processes explicitly" (p. 11). They continued, "Educators working with the model are encouraged to engage individuals and collectives in the process of self-exploration associated with raising power consciousness" (Dugan et al., 2015, p. 11). 
Dugan, Kusel, and Simounet (2012) found students who hold one or more identities that have historically been minoritized in higher education (in this particular article's case trans* students) spoke to a particular importance for mentoring and continued training for faculty and staff to be better capable of addressing the issues that either pushed trans* students out of leadership positions or kept them from applying or showing interest in the first place. The asterisk after the word trans is used to denote a wide variety of possibilities of experiences, more broad than only transgender (Jourian, 2014). Dugan, Kodamma, and Gebhardt (2012) offered a similar assessment of race and its impact on how students show up in student leadership positions on college campuses. Both of these findings are critical because, as Dugan (2011) found, both quality and a quantity of involvement experiences will be beneficial to students in their college experiences. Lane and Chapman (2011) suggested hope is another key dimension to enhancing student engagement in activities that will enhance capacities on which the social change model of leadership focuses.

\section{Summary and Critique}

In reviewing the previously published literature on these topics, a number of important pieces of information come to light. The literature on transgressive teaching in student affairs illuminates the depth of connection between the ideas and the practices of transgressive teaching and the orienting values and missions of the field of student affairs. It makes very clear that using a transgressive teaching approach to interacting with students would be one way of embodying the values of this profession and expressing them through the daily work done by student affairs professionals. However, the currently available literature does not offer an in depth analysis of the many elements 
of transgressive teaching put to use in the practices of student affairs professionals. The current literature recommends the use of transgressive teaching, highlights its value, and calls for a greater incorporation into the work done (Chavez et al., 2003; Levtov, 2015; Nicolazzo \& Harris, 2015; Stewart, 2008). In many ways, this study seeks to meet these recommendations and calls, to fill the gap to which I have pointed, and to more deeply understand what, if any, impact introducing transgressive teaching as an approach to being a student affairs professional can have for a specific subset of professionals.

Similarly, the literature on White, heterosexual, males provides a great deal of valuable insight. Authors have articulated clear articulations of the experiences of these identities, and situated them within the social constructions of identities and social systems of power and privilege and also offers a number of similarities among and between the systems of power constructed around these individual identities (Cabrera, 2012; Cobham, 2011; Eliason, 1995; Gardiner, 2005; Herek, 1988; Kiesling, 2007; Macintosh, 1986; Reason, 2007; Swain, 2005; Tillapaugh, 2013). However, the available literature has yet to examine the interaction between these dominant or privileged identities nor does it examine how those interactions impact the different ways in which, for example, maleness impacts one's ability to understand the role and impact of their Whiteness or heterosexuality on a personal, interpersonal, or societal level.

The literature on ally development offers a number of perspectives that have a common thread of beginning with awareness or cognizance, move through deepening education and skills to intervention, and finally acting upon the previously developed understanding and abilities (Broido, 2000; Washington \& Evans, 1991). Since the authors offer that being an ally is an ongoing practice of employing and expanding the 
development of these capacities, it may be more helpful and more accurate to discuss it as a practice of allyship rather than as a state of being an ally. Framing the ongoing nature of allyship more clearly connects the cyclical nature of the experiences of moving through Washington and Evan's (1991) model, in which taking action can lead to new dynamics of which the individual becomes more aware, beginning the process again and again. This approach has been used by Harro (1995), which is framed as a cycle of liberation, in which people do not arrive at an end but rather are continually motivated to take new action.

The literature on leadership, particularly that focusing on the social change model of leadership, in many ways mirrors the literature on the practice of transgressive teaching within the field of student affairs. Many of the studies have found aspects of transgressive teaching would be beneficial to students in enhancing their capacity for leadership, such as instilling hope (Lane \& Chapman, 2011) and empowering students whose identities have been minoritized historically in higher education (Campbell et al., 2012; Dugan, 2006; Dugan et al., 2012; Dugan et al., 2012). Those same studies recommended the staff working with these students offer opportunities for these experiences, yet none of the literature focused on either the development of student affairs professionals' own capacities or ways for student affairs professionals to cultivate the environments are able to sustain these practices. Further, the literature that does focus on the practices of leadership within the field of student affairs is dated, almost entirely focusing on management and executive level decision-making (Bryman, 2007; Dalton, 2002; Dalton \& Gardner, 2002; Sandeen, 1991; Thomas, 2002) rather than the types of leadership available to all members of a department or organization. 
This is especially important in interactions across differences of identities between students and student affairs professionals and even more critical when the student affairs professionals hold one or more dominant group identities, illustrated well by Priest and Clegorne (2015). They spoke to an important awareness of a student's developmental readiness to be challenged by these approaches to leadership, making the assumption that all student affairs professionals are themselves prepared to be challenged by these approaches to leadership. Dugan et al. (2015), similarly, encouraged educators to engage others (likely their students) in exploration of self without considering that this may still be unfinished work for those educators.

I believe the critiques offered here situate my study within the currently available fields of literature while highlighting the gap the findings from this study address, specifically seeking to understand what, if any, impact the introduction of transgressive teaching has on how White, heterosexual, male student affairs professionals think about their interactions across identities with while also examining the ways in which holding multiple privileged identities that interact with one another. The following chapter will outline the methodological design used to collect data to address these questions. 


\section{CHAPTER THREE: METHODOLOGY}

In this chapter, I offer an overview of the methods used in this study. I review the framework of phenomenology and explain its benefit in connecting to this study's purpose. I also describe my sampling strategies, the potential biases related to those strategies, and how I addressed those biases. I describe the procedures my study employed and the processes used to collect and analyze data. I examine my positional identities, highlight how my position can itself offer forms of bias, and describe the ways in which those biases were addressed through the research design. I then describe barriers to trustworthiness of my interpretation of the data collected in this study, specifically my positional experiences' impact on my interpretation and the impact of incentives I offered potential participants. Finally, I describe the measures I have employed to address these barriers and that I believe have enhanced the trust that can be placed in my interpretation of the data I collected.

\section{Research Questions}

This study has sought to answer three research questions:

- What, if any, impact does learning about transgressive teaching have on how White, heterosexual, male student affairs professions think about their professional practices?

- What, if any, impact does learning about transgressive teaching have on White, heterosexual, male student affairs professionals believing themselves to be educators?

- What, if any, relationship do White, heterosexual, male student affairs professionals experience between transgressive teaching and their 
understanding of leadership?

\section{Phenomenological Methodology}

This study was intended to understand the ways in which the introduction of concepts of transgressive teaching could impact the practices of White, heterosexual, student affairs professionals in interacting with the various groups of students on the campuses at which the participants work. As individuals make meaning of the experiences to which they were exposed in this study, have made a very diverse array of meaning from their experiences in graduate professional preparation programs, and have differently made meaning of their experiences in the field of student affairs to this point, it is important to begin by collecting and mining the multiple, subjective reality experiences as a first step to arriving at a deeper, connecting, experiential truth. Phenomenology is a beneficial methodology, as it seeks to understand the deeper essence of the participants' emerging understanding and meaning making of ideas. There is a need for a deeper sense of connection, of understanding even the core experiences beneath the individual, and unique meaning making of the experience (Van Manen, 1990).

Phenomenology, before being used as a methodological way of understanding data, was a philosophical perspective for understanding the world. Defined in a variety of ways, phenomenology was initially conceived as a science concerned with the essence of existence (Langan, 1959; Lawlor, 2002; Steinhoff, 2009), generally pursued by philosophers as examination to the understanding that all "knowing" contains a person's experiences and their own presuppositions. It then becomes more important to understand whether those presuppositions can be seen as accurate given an examination of the 
experience within the larger context of the world in which the experience takes place. More recently, phenomenology has emerged as a way of examining data by understanding the core essence of a particular occurrence, idea, or phenomenon (Jones, Torres, \& Arminio, 2013) as a way to interpret it for understanding.

Bryman (2012) asserted reality has meaning to those who experience it, and human actions are based upon the meaning those individuals make of their experiences in that reality. This means the researcher needs to gain access to many different people's processes of understanding their often-unique experiences and to interpret those individuals' actions and sense-making processes. This process also entails the distancing or conscious acknowledgement of the researcher's own preconceived notions about the meaning of experiences and actions so as to stand in the metaphorical shoes of each participant. At the core of doing phenomenological research is offering a wider range of people a chance to see themselves and their experiences reflected in the experiences of another individual. The research of phenomenology is, then, about making clearer the phenomena or experiences of an individual consciousness: an attempt to understand what makes a phenomenon a meaningful experience (Van Manen, 1990).

In this study, a phenomenological approach was employed to dig deeply into the experiences of each participant around a phenomenon, in this case reading Teaching to Transgress. By examining each of their individual experiences, I am attempting to find a deeper underlying connection around which a greater understanding of the experience can be understood beyond simply the sensory experiences that would be of concern in a purely positivist position. This also required an interpretive approach, in that each participant had experiences they described differently and which required that I analyze 
and interpret those experiences to ascribe a unifying theme to them (Bryman, 2012). This approach informed the ways in which questions were asked of participants in the interviews and in the journal prompts, which sought ongoing insight into the ways in which the participants were experiencing and making meaning of their reading and understanding of Teaching to Transgress.

\section{Grounded Theory Methodology}

Grounded theory emerged in the second half of the $20^{\text {th }}$ century as a way for qualitative researchers in sociology to allow theory to be generated from data through a series of processes and steps that work to ensure that the data has been sufficiently reviewed and the connections at which the researcher has arrived show a robust analysis and alignment with the theory (Bryman, 2012; Charmaz, 2014; Corbin \& Strauss, 2008; Glaser \& Strauss, 1999). This is achieved by comparative analysis, which Glaser and Strauss (1999) defined in its most broad sense as the comparison of social units such as people, organizations, or nations. The data gained from these comparisons is then coded, where similarities and disparities are first noted. These codes are then analyzed both to understand the broader categories that may emerge and also to interrogate the position and biases of the researcher or researchers creating these codes. The process then requires further sampling and analysis to achieve saturation, at which point theory has the potential to emerge in a way that is sufficiently grounded in the data collected (Charmaz, 2014; Glaser, 1978; Glaser \& Strauss, 1999).

While this study is not designed as a grounded theory study, an issue in addressing the third research question, concerning leadership, arose when attempting to use solely the phenomenological method. For this reason, an adapted grounded theory 
approach was used to assist in analyzing this area of the data collected. The

circumstances, decision to employ an adapted grounded theory approach, and the ways in which grounded theory was adapted in this study will be outlined more fully in the data analysis section of this chapter.

\section{Purpose of the Study}

The purpose of this study was to address the current gap in literature on transgressive teaching in the field of student affairs. Specifically, this gap is a lack of study on what, if any, impact the introduction of these concepts can have on the practices of student affairs professionals. This study sought to better understand how, if at all, White, heterosexual, male student affairs professionals' perceptions of their own work and engagement with students are impacted by the introduction of the concepts of transgressive teaching. By introducing the concepts of transgressive teaching to these professionals and following their learning as they work to understand the concepts and the potential for incorporating them into their practices, I examined the ways in which transgressive teaching may offer new insight into the ways professionals engage with students across, and among, social identities. Additionally, I examined the ways in which transgressive teaching may offer new insight into new ways leadership can be practiced.

\section{Sampling}

I recruited nine participants for this study, which gave me the opportunity to examine the experiences of White, heterosexual, male student affairs professionals from a variety of functional areas within the field of student affairs. This breadth of participants offered the chance to engage participants from a wider variety of institution types (4-year, 2-year, public, private, large, small, and mid-sized). Finally, this range of participants 
offered a chance to engage the experiences of people from a variety of geographic regions in the United States. The variety of these experiences offered the opportunity to examine the potential differences that institution types, ways of interacting with students, and the types of students with which the participants interact can have on their practices. Table 1 offers an overview of the participants' functional area, institution location, and institution type.

In this study, I used a purposive, or purposeful, sampling approach, meaning I recruited people who are directly connected to the identities and professions about which my research questions relate, in this case White, heterosexual, male student affairs professionals (Bryman, 2012). This approach was the most appropriate because there currently is not an exhaustive list of student affairs professionals in the United States, which also means that there is no way of knowing exactly how many people identify as White, heterosexual, and male within the field of student affairs. These criteria were determined before and worked with definitions that will likely not evolve over the course of the research (fixed and a priori), which Bryman (2012) calls generic purposive sampling. To recruit these participants, I sent emails out to a variety of student affairs professional listserves and posted requests for participants to a variety of social media pages dedicated to the interactions among student affairs professionals.

\section{Potential Biases}

Within the approach I used to recruit participants for this study there were a number of potential biases, and the impact of these biases is important to address. Selection bias occurred in two ways, the first way being the recruitment of participants through social media and email listservs. This created the potential for exclusion of those 
Table 1

Participant Pseudonym, Geographic Region(s), Institution type, and Functional Area(s)

\begin{tabular}{|c|c|c|c|c|}
\hline Pseudonym & Location & Institution Size & Institution Type & Functional Area \\
\hline Fred & $\overline{\mathrm{NW} / \mathrm{SW}}$ & $\overline{\text { Small/Medium }}$ & $\begin{array}{l}\text { Private Liberal Arts } \\
\text { /Community College }\end{array}$ & $\begin{array}{l}\text { Student Conduct } \\
\text { /Student Life }\end{array}$ \\
\hline Terrance & SW & Large & Public Research & Residence Life \\
\hline Ernie & NW & Large & Public & Residence Life \\
\hline Raymond & SW & Large & Public Research & Conduct \\
\hline Gene & SE & Large & Public Research & Scholarship Programs \\
\hline Jerome & $\mathrm{NE}$ & Small & Private Liberal Arts & Student Leadership \\
\hline Seth & SW & Medium & Private Liberal Arts & $\begin{array}{l}\text { Student Activities \& } \\
\text { Student Unions }\end{array}$ \\
\hline David & SW & Large & Public Research & Student Affairs \\
\hline Ron & MW & Large & Public Research & University Relations \\
\hline
\end{tabular}

Note. A / indicates a change in role or institution during the time of the study. Roles and institutions listed in chronological order.

who, while completely qualified and meeting the criteria for participation in the study, may not engage on social media or be a part of the list serves on which I had posted the calls for participants and so were not equally exposed to an opportunity to engage in the study. The second way in which a selection bias occurred was through the outreach over listservs was targeted toward student affairs professionals who engage in work connected to themes and values of social justice and inclusion. Again, this limits the ability of student affairs professionals, who are in every other way qualified to participate in this study, from participating because they may not have oriented their professional development plans or their work in the direction of these particular approaches and opportunities.

Third, there is a self-selection bias inherent in the various ways participants were recruited for this study. Because participants had to make a choice to participate in the study, it is likely these were people who interested in pursuing types of professional and personal development similar to those offered by participation in this study (Guo \& 
Fraser, 2014). This was a limitation of the sampling methods in that it does not offer a complete picture of how, if at all, this experience will impact the entire scope of student affairs professionals' perceptions of their work because it was not possible to study the outcomes of those who did not express interest in participating in the study. As such, it is possible the findings may not be immediately generalizable to larger populations of student affairs professionals or even the entirety of the identity communities to which those who choose to participate in this study belong (Galloway, 1994); however with the description of the experiences offered, it is also possible other student affairs professionals, whether or not they identify as White, heterosexual, and male, may also experience a connection or a similarity between their experience and those of the participants of this study, which could lead to the possibility of transferability (Guba \& Lincoln, 1994). Additionally, because of the phenomenological nature of this study and the interpretive nature of the coding of data, there is a degree to which there are internal generalizations being made about this group, which could potentially mean that there are possible generalizations that could arise for other members of a similar group (Maxwell, 2005).

Finally, there is the potential for a social desirability bias, especially given the other biases described above. Because this study likely attracted a group of participants who wanted to engage in this type of professional development and self-exploration, there is the potential that this led to a bias of social desirability, in which the participants may have been drawn to give answers they believe are the most desirable either to the environment or to me as the researcher (Bryman, 2012). While this, like the other biases addressed above, were impossible to eliminate entirely, it was important for me to 
incorporate measures into the procedures of the study that addressed these possibilities and mitigated, as much as possible, the impact on the findings. I will describe those procedures in the next section as part of a larger description of the experiences in which I engaged the participants, as well as how I collected and analyzed data in this study.

\section{The Experience}

The core of the research I have conducted is to understand what, if any, impact introducing concepts of transgressive teaching has on White, heterosexual, male identified student affairs professionals has on their approach to their work. Given this area of inquiry, I believe introducing these concepts was best achieved by having each participant read the book Teaching to Transgress: Education as the Practice of Freedom (hooks, 1994). As mentioned in the previous chapter, Teaching to Transgress is considered a seminal work in the field of education, and a wide variety of literature exists on the implementation of the concepts and philosophy approach to education outlined in the book in a variety of educational settings. Rather than design a process for imparting the information to the participants, which some studies have already attempted to do (Danowitz \& Tuitt, 2011), I believe asking them to read the book, along with some guided and open reflection during that experience, offered each participant a variety of opportunities to have their own experience with the concepts, to make their own meaning of it, and to examine what, if any, ways they can see their own practices and work reflected in the examples outlined by hooks. To achieve this experience, a copy of Teaching to Transgress was purchased for eight of the participants in the study. One participant already owned a copy of the book but had yet to read any part of the book before the beginning of this study. 
The decision was made to have the experience of transgressive teaching be communicated through the reading of Teaching to Transgress rather than through training or other methods as means of centering an accountability to hooks and an engagement with her work and perspectives. Because of my positionality, which I will discuss in greater detail later in this chapter, as a White heterosexual man it was important that I not be seen as the authority on or the owner of the framework of transgressive teaching. This choice was specifically intended to create an experience in which White, heterosexual, men's experiences were being informed by their own interactions with a Black woman who was very directly challenging the ways of knowing that may be directly informing the daily experiences in the world that seem very normal to these participants. As mentioned in Chapter 2, hooks' work specifically describes the dynamics in which the participants work, offering an intentional acknowledgement of the historical context of higher education, race, gender, and sexuality in the United States. Using Teaching to Transgress offered a direct opportunity for participants to understand how the experiences of hooks and their own experiences within education have shaped their approaches and asked them to center a different experience than those on which these systems have been built.

\section{Data Collection}

This study used two methods of data collection. One method, employed three different times throughout the study, was the semi-structured interview. This type of interview involves having prepared questions around general themes and topics but with the flexibility to ask the questions in varying order depending on the experiences shared by the participant being interviewed, and to provide leeway to ask follow up or probing 
questions based on what experiences are shared by the participant (Bryman, 2012). The interview was employed as a method of data collection because it served the purpose to explore deeply with the participant the nature of their experiences in the world as well as to develop a relationship of ongoing reflection between the participants and me (Van Manen, 1990). Data was also collected in the form of journals kept by participants while reading Teaching to Transgress.

\section{Pre-Interview}

The first part of data collection for this study involved a pre-intervention interview with the participants. The interview focused on their current perceptions of their work, their current level of familiarity with transgressive teaching, and their current conceptions of practicing leadership. The pre-interviews lasted between 24 and 44 minutes, averaging 35 minutes. The questions started with a group questions about personal information of the participants. Additionally, participants were asked questions about the current conceptions of their work, their exposure to transgressive teaching to this point, and their current conceptions of practicing leadership. These questions were used to establish a foundation of understanding the participants' starting conceptions of themselves, their work, and transgressive teaching for the purposes of comparison between the pre-interview, post-interview, and post-post-interview. The interview questions for all three interviews can be reviewed in Appendix D.

\section{Journaling Prompts While Reading}

While the participants were reading Teaching to Transgress, they were asked to use journal prompts to describe and reflect on their experiences around reading the book in four collections of chapters. They were also asked to journal freely, an opportunity to 
express their feelings and ideas as they go through the experience. The process of keeping a journal was chosen as an additional form of data collection because it offered opportunities for study participants to reflect on their lived experiences and track the development of their own perspectives over time (Van Manen, 1990). The journal prompts are available in Appendix E.

\section{Post-Interview}

The next part of data collection was a second semi-structured interview, conducted after the participants finished their engagement with the Teaching to Transgress. These interviews lasted between 48 and 88 minutes, averaging 66 minutes. The post-interview asked the participants similar questions to the pre-interview about their current conception of their work and their conceptions of practicing leadership. The post-interview also asked questions to draw out information related to what, if any, impact reading Teaching to Transgress had on how the participants thought about their approach to their work, their interactions with students, and their practice of leadership. The questions for the post-interview can be reviewed in Appendix D.

\section{Post-Post-Interview}

The final part of data collection for this study consisted of another interview, conducted between three and five weeks after the post-interview. This interview, called the post-post-interview, examined with the participant their experiences in the world after having experienced reading Teaching to Transgress. These interviews lasted between 18 and 42 minutes, averaging 30 minutes. In the post-post-interview, participants were asked questions around the themes of incorporating transgressive teaching into their work over 
the time period following the post-interview. The questions for the post post-interview can be reviewed in Appendix D.

\section{Data Analysis}

I have used several approaches to analyze and make meaning of the data collected in this study. The interviews conducted were transcribed verbatim to ensure the entirety of what was communicated by each of the participants was available for analysis. Filler language, words including "um" and "like" and phrases such as "you know what I mean", were edited out for clarity. Next, an In Vivo coding approach was used as a way to use the language of each of the participants to represent their experiences (Saldaña, 2013). Van Manen (1990) suggested the words and phrases each participant used would each be a thread, and it was around each thread that a larger tapestry of meaning could be constructed. The coding of these transcripts was done by hand and without the use of software. I viewed each transcript in its electronic format and used MS Word's highlight and comment features to note any underlying ideas or themes within the responses to the interview questions and in the participants' journal entries. The first way in which these ideas were grouped was around which of the research questions the participant's answer could address. I then examined each participant's responses, and looked for larger themes that connect the experiences being described by examining the different ways in which a similar feeling or idea could be described. This emphasizes the importance of using an In Vivo coding approach in alignment with the phenomenological methodology, which was the primary guiding methodology for this study. 


\section{Adapted Grounded Theory}

This study did not begin with an a priori construct of leadership with which participants were expected to have their experience of reading Teaching to Transgress align or diverge. Therefore, the theories of leadership to which the participant's conceptions were connected needed to emerge from the data collected. Therefore, aspects of grounded theory were used, while other aspects of grounded theory were not used. It is for this reason that I refer to this section of the data analysis as "adapted grounded theory."

To begin the explanation of "adapted grounded theory" in this study, a theoretical sampling approach was not employed in this study. Participants were not recruited in any way that related to their understanding of leadership or how it might connect to their experience being introduced to transgressive teaching, and so the sampling did not seek to "maximize opportunities to develop concepts in terms of their properties and dimensions" (Corbin \& Strauss, 2008). Additionally, theoretical saturation was not sought in this study, in that additional samples were not collected nor additional participants sought to expand or extend the comparative analysis beyond those who had already been recruited for the study (Charmaz, 2014; Glaser \& Strauss, 1999). However, a comparative analysis was used to code data, explore categories and themes that emerged from those codes, the process of which lead to the theories of leadership for which the findings of this study have implications. After I had determined the particular response in question was speaking to the research question on leadership, I examined the phrasing used by each participant to describe an idea or a feeling, distilling the operative or most important words. I then interpreted these ideas into themes, which were then 
examined for relevance to a body of literature around an existing theory of leadership. In describing this process of data analysis, I used the term adapted grounded theory to describe the process by which the findings related to leadership were analyzed and by which I arrived at the theories of leadership to which those findings are connected.

\section{Trustworthiness}

I used a number of strategies to ensure my interpretations of the data collected could be trusted. In this section, I outline the steps I took to address the potential barriers to trustworthiness in my study. I address my own positional experiences and the incentives I offered my participants, and I review the ways in which I built processes into my data analysis that addressed these barriers. Researchers name this process differently, "validity" (Bryman, 2012) and "verification" (Creswell, 1998) being two other descriptors used. However, I have found that "trustworthiness" is a descriptor that more accurately captures the nature of what I aimed to do with these measures. While there was some verification that took place, and that verification led to some validation of my findings as accurate, qualitative research, particularly in the realm of phenomenology, requires a variety of measures to ensure the interpretations made by the researcher can be trusted by the reader as these methods do not offer the more traditional measures of validity found in qualitative research (Golafshani, 2003). For this reason, I use the word "trustworthiness" to describe the outcome measures described below aim to achieve.

\section{Researcher's Position}

Acknowledging my own identities and the positional perspective they bring to this study is an important aspect of understanding the barriers to trustworthiness present in my study (Creswell, 1998; Van Manen, 1990). I, like the participants, identify as 
White, heterosexual, and male. Since 2007, I have had a career as a student affairs professional. The reason for choosing to pursue participants who hold White, heterosexual, and male identities, the identities I myself hold, has to do with my own experiences encountering transgressive teaching, and in my continuing understanding of it as a practice and incorporating it into my own work engaging students on college campuses. My connection to transgressive teaching has been, in large part, because I believe I use it as part of my approach to interacting with students, making decisions about programs, policies, and practices on a daily basis. My own engagement with this approach to the field of student affairs has been a major contributing factor in my own professional development and career trajectory.

I grew up living in a suburban area of Pennsylvania and then in a rural area of New Jersey. To my memory, all of the people with whom I interacted personally were White until at least the fifth grade, in which I was 11 years old. Before that time all of my interaction with or understanding of non-White people was through media. I attended public school for kindergarten and first grade, and in second grade I began attending a private, Catholic school.

I attended a private, single gender, Catholic preparatory school for high school, where there were a number of students of color, mostly Black and Puerto Rican, though the cliques of the time meant that very few of us interacted across racial identities. There was a strong narrative among the student body that all of the Black students were there on scholarships to play football and basketball, while all the Puerto Rican students were on scholarship to play baseball. Since I did not play sports, I felt little connection or encouragement to spend time with those of my peers who were not White. 
I attended college at Cabrini College. I was somewhat involved on campus, in particular in my last few years where I became an orientation leader and a resident advisor. While there were a few non-White students I knew and with whom I would say I had a friendly relationship, I also would not say we were close friends. All of the people with whom I built strong relationships were White, and there was a relatively even split between male- and female-identified people. At the time, none of my close friends were out as members of the LGBT* community. Through college, these continued to seem normal to me; I would simply develop friendships with people who shared my interests, such as movies and video games, and those people happened to be White.

From there, I pursued a master's degree in organizational leadership with an emphasis on higher and post secondary education at Teachers College, Columbia University. There I would certainly say I was exposed to a much more diverse student body, and I can say that as a result of the people with whom I was sharing spaces (living, working, classrooms), my friend groups diversified. This, however, did not entirely address some of the deeper systems of oppression I had internalized. I remember a situation in a class, in which we were discussing our readings of Women's Ways of Knowing, when I asked the professor if there would ever be a need for a book called men's ways of knowing. I remember at the time believing, and having only ever seen examples of, system of power in which one group had power and the opposing group (in this case men and women) did not. I was curious to know if the power structures, which at the time I was aware of at least on some level, were to be reversed would that be a good thing. It is possible, however, this question was not phrased in that way or that my peers were differently impacted by my curiosity than its intent. I remember my 
classmates having some very loud non-verbal responses to my question and it being quickly brushed over the by the professor. It was also during that time that I began my training in being a student affairs practitioner through an internship. I had a strong mentor relationship with a person who spent a great deal of time deepening my already established ethical perspective to interacting with students and working in a college or university setting. These were the first times I remember having deep conversations with another person, particularly another White, heterosexual man, about what being White and heterosexual and male meant to me personally.

Since entering the field of student affairs, I have held professional positions at Cornell University in the area of residence life, San Diego State University in the area of residence life, and the University of California, San Diego in the area of multicultural affairs. While working at San Diego State University, I attended the Social Justice Training Institute, after three years of continuing to reflect on and attempting to put into practice the reflections I began with my mentor at Teachers College. It represented, for me, a shift in my goals and my sense of purpose in my career. I knew from that point on it was no longer enough to simply do the work that was outlined in my job description, but that I needed to be looking at how systems of oppression were at play in my interactions with students, faculty, and staff. These systems of oppression, in my mind, were keeping me from fully meeting my purpose and goals because they were detracting from the experiences of students I had committed myself to serving.

Some time later, while working at University of California, San Diego, I first encountered the ideas of transgressive teaching and was introduced the bell hooks' approach to teaching and education. One reason that this experience sticks with me is that 
I remember upon discussing the ideas with a colleague, in many ways this was, to the best of my understanding, a theoretical distillation of the espoused values of the field of student affairs and of the values and ethical perspectives instilled in me by my mentor a number of years prior and those I had continued to build upon in my continued work to understand my place in the fight for social justice.

I offer these experiences as a way to address the variety of positions I bring into this study and the potential impact they may have had on my interpretation of the findings of this study and the experiences of the participants. I believe my positions and experiences supported the choice to use a phenomenological approach for this study, in that the approach offered me an opportunity to understand the deeper thematic connections between my experiences and the experiences of others. By bracketing my experiences through journaling, an essential part of doing a phenomenological study according to Van Manen (1990), I was able to acknowledge these positions and examined what possible impact they might be having on my initial interpretations of the data I collected. Similarly, the intentional choices of the processes of member checking and peer debriefing offered me, in my role as the researcher, an opportunity to compare my understandings and interpretations of the participants to the understandings and interpretations made by the participants themselves and another, more objectivelyminded student affairs professional.

\section{Bracketing in Phenomenology}

Part of digging deeply into understanding a phenomenon as an experience that is meaningful also means setting aside pre-existing understandings, ideas, and meanings made on the part of the researcher about the topic or phenomenon at hand (Van Manen, 
1990). This concept, in phenomenological research, is known as bracketing and describes placing the phenomenon being studied outside of the researcher's previously attained knowledge or experience (Van Manen, 1990). To address this, I continued to keep my own journal throughout this study, in which I specifically and continually called to the fore my pre-existing knowledge about the topics of transgressive teaching, student affairs work, and incorporating my understanding of the former into the practice of the latter. I did this by both free writing about my experiences with the participants and answering specific questions of my own such as,

- What are my initial leanings or reactions to what was said?

- What metaphor would I offer to make sense of what was being said?

- In what ways are those connected to my own assumptions?

- What other ways of interpreting these events and ideas which are different?

- Is there a different metaphor I would use?

\section{Member Checking}

Another way in which I worked to ensure the trustworthiness of my findings was by engaging in a process of member checking. A selected section of my own narrative descriptions of the findings were sent to the participants (Saldaña, 2013). Participants were asked to review the findings and to offer their opinions as to whether the themes and categories at which I arrived accurately represented the perceptions and feelings they expressed during the interviews. Two participants did offer feedback on the description of their experiences, and the feedback they offered was related to the ways in which the interviews were transcribed and the clarity of their speaking in the interview. Of those two, one participant asked that I clarify what I meant when speaking about the challenges 
reading Teaching to Transgress presented to the participants, and when that was clarified that participant said they agreed with the findings as I interpreted them. These processes added to the trustworthiness of the findings in ensuring that the interpretation of the data was an accurate reflection of the responses provided by the participants in the interviews and also ensured the meanings I made from coding and analysis were consistent with the meaning made of the experience by the participants.

\section{Peer Debrief}

A third way of ensuring the trustworthiness of the findings of this study was through a process of peer debriefing (Creswell, 1998). I engaged a fellow White, heterosexual, male student affairs professional, who is also a doctoral student studying student affairs professionals and their meaning making connected to privileged identities (a person I consider a peer), to review and discuss my analysis as a way to help ensure my interpretations were objectively reasonable to be derived from the data collected. My process of peer reviewing involved collecting all of the quotes from the interviews and journals into a single document and asking my peer to describe any categories or themes they observed, while I did the same process. We then reconvened and discussed our outcomes, which we then used to conduct more analysis to dig deeper into the underlying connections among the experiences of the participants. The purpose of this was to have outside confirmation of the patterns noticed in my own analysis and to affirm that my analysis was logically and rationally arrived at upon (Creswell, 1998).

\section{Presenting the Data}

Different approaches to collecting and analyzing data also offer a variety of options for presenting the data collected. Phenomenology, as an approach to qualitative 
research, can offer an approach to presenting data collected that flows from its inherent nature of examining the meaning made by individuals of their experiences and examining deeper, underlying connections that join individual experiences in a larger meaning made. Given this, I believe I have presented the data I collected in a way that is consistent with the approach I have used to collect this data. I included verbatim excerpts from transcribed interviews, an analysis of the thematic elements of each transcript, followed by a process of structuring the meaningful connections between/among the experiences shared by the various participants (Creswell, 1998; Moustakas, 1994). Additionally, because of the longitudinal nature of the data collection and because the experience of this study in many ways in centered on the story of each participant's journey through Teaching to Transgress, I have chosen to present the data in a narrative format. I believe this best captured the experiences and provides an effective flow in relaying the experiential nature of the study (Rhoads, 1994; Richardson, 1990). Additionally, using a narrative approach compels the attention in a way that humanizes the experiences of the participants, which has been a key imperative throughout this study (Van Manen, 1990).

\section{Summary}

In this chapter, I have outlined the methodological approach I used to answer the research questions and the gaps in literature that have catalyzed this study. By using a phenomenological approach to document and analyze the experiences of nine White, heterosexual, male student affairs professionals reading Teaching to Transgress and reflecting on its potential to impact their work, I have been able to gain greater insight into the meaning made by a group of people, of their experiences, and look for deeper, underlying connections between those individual experiences. I have outlined how I have 
collected this data: a pre-interview, four prompted journals while reading, a postinterview, and a post-post-interview. I analyzed the data in a way that addressed the questions for which I have sought answers through an In Vivo coding approach, and I outlined the measures I took to ensure my interpretation of the findings can be trusted to accurately represent the phenomenon and the meaning made by the participants rather than being a projection of my own assumptions, perspectives, or identities onto the thoughts and experiences of the participants. I did this through the processes of bracketing with analytical memos, member checking with the participants, and peer debriefing with an external person. The following chapter presents the findings of the data analysis. 


\section{CHAPTER FOUR: FOUNDATION FOR FINDINGS}

\section{Introduction}

It is important for the findings of this study to be grounded in the stories of the people who participated. Stories are all around us. Given the longitudinal nature of this study, much of the data collected was in the form of stories and connections to other life experiences. Additionally, these introductions offer a great deal of context with which the findings interacted and by which many of the findings were informed. For this reason, I introduce each of the participants as a way to ground their experiences in the context of their lives (Rhoads, 1994; Richardson, 1990).

\section{David}

David started his story by saying he is in his $28^{\text {th }}$ year as a student affairs professional. He currently works at the institution he attended as an undergraduate student and holds a point of pride that he was the last student to receive a degree in rhetoric at the institution. After graduating, David worked in sales before returning to the institution to work in the career center. David often chuckled and told jokes during our conversations, which is evidence of his approach to connecting with students.

During this time David found out about a graduate program at his institution and decided to attend full time while also working full time. From there, he continued to be promoted up through the university, eventually being promoted to a position in the Dean of Students' Office, first as an Associate, then later transitioning into the position of Assistant Dean, which holds as part of the position an appointment as a faculty member in the campus's graduate school of education. David had been teaching courses for a number of years since receiving his Ph.D. These courses were often in adult education 
programs for senior citizens at a local community college. David's role focused a great deal on the university's new student populations. He worked with first year students, newly arriving international students, transfer students, and also with all of the graduate students on his campus, which was a relatively small population on a campus of around 22,000 . He described a particular relationship with the graduate student population as that of an uncle.

David, somewhat jokingly, described much of his current work as "signing a lot of forms," but he also sees his role as being a champion for the efforts of the units he oversaw, which are veterans resources and the career center (the same center at which he started his career). David also managed large teaching teams in his role as a faculty member, working closely with 20 teaching assistants on courses taken by all first year students. David also spoke excitedly about his university’s role as a Hispanic Serving Institution, and also that even though the campus is large and research oriented, all undergraduates lived very close to the campus and provided the campus with a much more residential, small college feel.

He described his race as either White or European, depending on the context of the question he was being asked. He also described himself as male and heterosexual, taking pause to say that he is often making efforts to stay current on the most appropriate terms with which to talk about identity. David talked about his identity as an ally and a feminist as being very important to him, and he took a moment to reflect on what it means to identify that way, not wanting to be the sort of person who uses a feminist identity to make himself seem more enlightened. 
David talked about a practice he tries to use in his allyship was not having pictures of his partner and family around his office, saying he would not want to give the impression to students that he would be judging them or that they should feel unsafe in his office because of how he projects his identities. This caused David to pause and to remember that he left out his very strong identity as a humanist/atheist. He spoke about being concerned that expressing those identities would make students feel targeted, that he wanted spaces in which he interacts with students to feel more welcoming and open, hoping to avoid a student believing that he uses this identity to judge or invalidate them, especially with his identities as a White, heterosexual, male, high level administrator. Ernie

Ernie lived and worked in the Pacific Northwest and had worked as a student affairs professional since 2007 . He started by talking about being a middle child of three boys, being born on the West Coast before moving to the Pacific Northwest as a young child. He spoke about growing up in a low to lower-middle income household, and being a first generation college student. He went to community college after graduating from high school, receiving a full scholarship because of his GPA. He spoke about working full time while completing community college and then choosing an in-state school that was the right balance of close to and far from his parents.

While attending college, Ernie gravitated to psychology courses, which lead to that being his major. While a student and working in the intramural program, he was offered a graduate assistant position, which lead to his enrollment in a graduate program in psychology. Ernie continued to work in intramurals for 10 years, two as a graduate student and eight as a staff member. During that time he was able to do a number of 
things, including teach courses in recreation department, an opportunity that Ernie had expressed some frustration about no longer having.

At the time of the study, Ernie's role was working on his university's Sophomore Year Experience program, working within the department of residence life. He spoke about the initiative, which was new for the campus, to continue support for students in their sophomore years; he emphasized the program focused on supporting students to make their own choices. Ernie mentioned that a large number of the sophomores on his campus are low-income and first-generation college students, and the college population is about one-third racial and ethnic minority students. He spoke about this change in role as being connected to the realization of the value he places on higher education and student development, which also moved him to begin working on his Ph.D. in an online program studying organizational psychology.

Ernie had four children, one of which was born as this study was being conducted. He spoke with admiration of his partner and the support he feels in their relationship to be able to work and go to school. Ernie said that his marriage, in part, kept his identity as heterosexual relatively salient for him because it is a frequent topic of conversation among his relationship with co-workers. Ernie described his race as White, although when beginning the study he spoke about feeling more American than White. Some of the other identities important to Ernie were his Christianity, his identity as growing up low-income, being a first generation college student, and being an alumni of the institution at which he works, believing that informs a great deal of the work he does on the campus. Ernie spoke a bit about his experience as a sober person as well, having just completed one year of Alcoholics Anonymous when his participation in the study began. 
When I asked Ernie, in the same way I asked all participants, if there were parts of his identity that were less salient in his work environment, he offered "there is nothing that I think I am hiding or not sharing in the work place. If there is something I need to share, I share. That is part of my White privilege. I can recognize that I feel comfortable in most settings."

\section{Fred}

Fred began this study as a Director of Student Conduct at a small, private liberal arts college in the Pacific Northwest. Fred had been working in the field of student affairs since 2007. Fred talked about his role as being closely connected to Title IX, the Violence Against Women Act (VOWA) in higher education, and beginning to work with the recent Dear Colleague federal guidance on trans* students in higher education, feeling challenged and fascinated by the legal aspect of the job. Fred had a movementfilled career, working at three prestigious private schools, a public research university, and a private for-profit college. During the time of this study he also transitioned from his role in student conduct into a role in student life at an open access community college in the Southwest.

When talking about his identities and his work, Fred shared that while accepting his first director-level position was exciting, it also gave him some pause, realizing that he was now another straight, White, man who runs an office. This was something of which Fred said he was always hyper-aware. Fred also spoke about his experience working at a women's college having an impact on the salience of his male identity. He also reflected on the ways in which his identity of a first generation student had been important to him, especially when working at prestigious institutions. He said the 
identities that were the most salient are his maleness, Whiteness, and straightness, while also feeling a connection to his atheist identity, the distinction between having a high ranking title and living paycheck-to-paycheck, being an Italian American, and being a child of immigrants.

\section{Jerome}

Jerome grew up in the Midwest, in conservative, White, Christian area that also had a high level of affluence. He was particularly aware of the notion that wealth moved in his family: they moved to an undeveloped area, which then began to be built up around them. Jerome also described in growing up that his family didn't need for money and also became aware of the differences in family incomes in the neighborhood. He spoke about being exposed to a much greater degree of diversity, specifically racial diversity, diversity of sexual orientation, and class diversity, than many of the other children in his neighborhood were, thanks in part to his parents professional roles as a teacher and a theater director in the nearest city.

Jerome's interest in social justice began in high school when he got involved with his school's Gay Straight Alliance. The first time he participated in activism was through this organization. He also recalled experiencing pushback from peers during a Day of Silence protest; he saw students wear shirts decrying homosexual people and even implying violence. Jerome said that much of his involvement in the organization had to do with wanting to be around friends who were also involved in that organization. Jerome's involvement in LGBT rights opened up additional opportunities during college, which lead to his working at the campus' LGBT Center. This then led to Jerome being a part of the multicultural council in his residence hall, which was pivotal for him. From 
this point on, he said he was the White guy who was always at these sorts of events. He believed much of this was related to his desire to distance himself from Whiteness and privilege.

In college, Jerome wanted to be a teacher, and after graduating became involved in Teach for America because he saw it as an opportunity to get into the classroom and teach right away. He held a great degree of frustration at the experience, both because of the nature of the program and the experiences he had with the staff at the school to which he was assigned. This experience led Jerome to begin to do some reflecting on his experiences, and he ultimately returned to his undergraduate institution for a master's degree in higher education.

After graduating from his master's program, Jerome started a college access program at a large public school in the South and also worked with different departments around the campus to incorporate more concepts of social justice into their training and practices. After a few years, Jerome relocated to the Northeast, where he worked (during the time of this study) at a small, private college in the functional area of student leadership. Jerome's specific focus was on multicultural and inclusion programming. The school at which Jerome worked had not had a tradition of infusing the campus culture with social justice, in Jerome's view, which in many ways fuels his work.

Jerome spoke about struggling with some of the characteristics of the environment and also appreciating others. While the campus had a large Black population, Jerome described changes designed to admit more students who were better prepared for college and was worried that a shift in admissions may impact the diversity of the campus. In his current work, Jerome mentioned his identities as White, 
heterosexual, cisgender, US citizen, atheist, and male were usually most salient for him. He also mentioned that some of his recent work experiences brought his identity as an able-bodied person into a greater degree of salience.

\section{Gene}

Gene grew up in the Southeast, in a small city. The first identity about which Gene spoke was as a geek. Gene received a full scholarship to attend his state's land grant institution when he was in eighth grade, a program for which he now works. He spoke about the importance of being from communities like the ones from which most of the scholarship recipients come. The scholarship program Gene served was housed in a department called undergraduate education, which also housed the university's honors program and managed the core curriculum. This particular program had one staff member who oversaw the high school processes and mentoring for students going through the scholarship applications, and Gene, who worked with the students as they prepared to go to college and also throughout their time at college. He described his role as a one stop for all of the needs of the students receiving these scholarships. He provided academic advising, financial aid advice, registration information, and a variety of other kinds of counseling and advising. He was aware some people in the university believed his job was to coddle these scholarship recipients, and he worked to balance that by supporting students in making their own choices.

When Gene graduated from college, he worked for his undergraduate institution's admission office doing enrollment management. After a year, he moved over to the business school doing enrollment management and graduation audits with students. It was during this time that colleagues encouraged Gene to pursue a master's degree in 
higher education. Two weeks before graduation, Gene received a call from someone with whom he used to work in the business school, asking him take on his current position, which he had held for five years when we began this study.

When asked about other identities that were salient outside of being White, heterosexual, and male Gene shared a story about why he is particularly conscious of class in his work. He shared a story about his experience being a full scholarship student, especially after growing up poor, and then having to learn how to manage money for the first time after graduating. He said this experience was now a key part of the advising he gave to the students with whom he works, hoping they can avoid accumulating debt and struggling in the way that he did and also not having them fall into the trappings of class privilege.

Gene spoke about his identity as an atheist being particularly important to him, saying of religion "it does more harm than good." He connected this aspect of himself to his work with the students receiving his scholarship as well, saying that it provided him an example to show them the ways they have learned to understand the world are important but also limiting and that college can be a place where students open their minds to new ideas. He extended this idea beyond religion to the ideas of gender, sexual orientation and politics as well.

Another dimension of Gene's experience that was very present when we began had to do with the state of his local political climate. The state was undergoing a massive cut to higher education spending, which was likely going to lead to at least 75 people within student affairs losing their jobs. While Gene had some relief that his endowed program would not be touched, the university at which he worked was also restructuring 
many departments and this did include his own. When we finished our first interview, there was still much on the horizon for Gene, and after he had begun reading Teaching to Transgress, Gene notified me he lost his job.

\section{Ronald}

Ronald grew up a few hours from the university where he currently works and described his experience growing up as an "average, White childhood.” Originally attending school with the intention to become an astrophysicist and then discovering that was not the course of study for him, Ronald spoke about his experience as a resident adviser being very impactful, that the training on social justice and privilege sparked a passion for working with students. This led him to change his academic course to African American studies with minors in women's and LGBT studies.

Ronald decided to attend graduate school in a different part of the country, originally attending an institution in a major metropolitan area in the Southwestern US and then realizing that was not the place for him. He moved to a different program, still in the Southwest.

After graduation from his master's program, Ronald worked in a few different functional areas, in housing doing social justice programs, Greek life as a house manager, and a brief stint in Asian American student affairs. From there, Ronald moved to the East Coast, working in housing, before returning to his undergraduate institution. He worked in housing for three years, before transitioning into a new position in university relations, overseeing the student information desks, the student tour guides, and working with staff in the student unions. Ronald had been a student affairs professional since 2010, and in his current position for only a few weeks at the time he began participating in this study. 
Ronald reflected on his experiences being a White male in his role, describing it as being important that he recognizes the role this creates for him on campus. The example he gave was that many people often assume he is in charge or a higher ranking position than he actually holds. He spoke about these experiences being part of how he kept these identities close to the fore of his thinking and awareness in his work. He also spoke about his class background as being particularly salient for him, in part because of how it connected to his ability identity. Ronald had a brain tumor when he was a child, which was removed, but required him to be on medication for the rest of his life. Because he had always had access to money and insurance, the ability experience had little impact on his life. He also acknowledged religion or spirituality was less present for him, in part because he did not identify strongly with a religion, while also saying that he learned how to operate in and move through a Christian society and so likely was able to work within people's assumptions of his religious identity. While thinking about the perceptions others have of him and his identities, Ronald offered he often was assumed to identify as gay because of the amount of rainbow decorations he kept in his office.

\section{Raymond}

Raymond had worked in student affairs for 18 years, but the first thing he used to describe himself was his age and being married for 20 years. He worked as a mid-level professional, and 15 of his 18 years of work was in residential life. He worked in the student conduct functional area, though his responsibilities and role had changed very little. It appeared the change in functional area had more to do with a restructuring of departmental responsibilities rather than Raymond deciding the change jobs. He saw the two main areas of his work as being data reporting for Cleary Report statistics and 
managing a conduct case load, which in the past was comprised entirely of cases from housing but later encompassed other cases from around the university. Raymond worked at a large, public research university in the Southwestern United States. The campus served a large population of Asian American and Latinx students, as well as a moderate sized White population and small African American/Black and Native American populations that were mostly from within the state.

When talking about his different identities, beyond identifying as White, heterosexual, and male, Raymond described the ways in which the identities that were salient for him were often in flux. He was working toward a Ph.D., and his partner held an advanced degree, but their family of six often qualified for low-income programs because he was the sole wage earner. He also felt connected to his Christian identity and believed this had to do with the ways in which people with whom he worked often use Christian symbols as punch lines for jokes, which frustrates Raymond.

Raymond spoke about his awareness of his position and how that could be an identity that could be used to navigate social situations in a variety of ways and required some awareness. Being a mid-level professional could be used against others and others could use it against Raymond, depending on the dynamics of the situation.

Raymond spoke about another of his identities, one that is also connected to a role of his, as being less salient in his work: his identity as a father. While there were people with whom he worked that offered him space to connect with that identity, and there were times when he interacted with students he could use his experiences to make connections, he said those experiences are pretty rare. He spoke similarly about his experiences 
growing up in the Pacific Northwest, saying that while it was very important to him personally, it almost never came to his mind while doing his work.

Seth

Seth lived in the Southwestern United States and worked at a medium, private, religious liberal arts university. When he began participating in this research, he served as a director in student affairs, working with facilities operations and student activities. Seth went to college in the Midwest, but when talking about where he grew up, said that his dad's work took him around the East Coast and the South.

Seth's undergraduate degree was in education, and for a time he really saw himself working as a teacher in primary or secondary education. He was also involved in student affairs through a variety of student roles as an RA, being in student government, and other kinds of leadership that made him think less about being a teacher and more about working in higher education.

Seth moved to the Southwest to attend a graduate program in higher education at the institution at which he now works. He spoke about staying at one institution for his entire 12-year career as being a defining aspect of his experience, as well as being connected to both his personal and professional fulfillment. Seth began his career in residence life, and from there became the Director of Student Conduct and Graduate Student Life. After holding that position for eight years and after completing a doctoral degree at the institution, Seth spoke about wanting to explore more professional opportunities, which almost led him to leave the institution but was offered the job he held at the beginning of this study after he had submitted his resignation. Seth spoke 
about his current role being a lot of thinking about how to invite people to see themselves in a space on the campus.

Seth spoke about working to be mindful of the ways his privileged identities impact the work he does. While this was, in part, a reflection on his experiences as a White, heterosexual, male, he also spoke about the privilege of his position as a director. One dynamic of his office that reminded him of this was only director-level staff members had private offices, while staff that had more direct student contact had to have their meetings in open spaces. He also reflected on the ways in which his position comes with a full salary and benefits, enough for him to make a living for his family, as well as the privilege of his education. Seth felt a salience to his identities as a father and spouse, having three young children who were all boys. He also reflected on interactions with students and how his role as an administrator, his age, and his race become very salient for him in those moments, especially when they were different from the identities of the students with whom he was interacting. This also led him to reflect on how these feelings grew after he received his doctorate and had "Ph.D." added to his campus nametag.

\section{Terrance}

Terrance grew up in the Northeast. He described growing up in a middle class, sheltered environment. When Terrance was 15 his father died and his mother sent him to a Quaker boarding school, which was where he was exposed to residential life. Terrance moved to the West Coast for college and became involved in residence life very quickly. During his first year he was president of his building, became president of the Residential Housing Association his second year, and from there became a residence advisor and held an assistant resident director position in his last year. 
After graduating, Terrance spent the majority of his 23 years in student affairs working at different campuses in one of the public university systems on the West Coast before returning to his undergraduate institution, where he served as an Assistant Director of the Residence Life program. The campus was a large, public, research institution, and was designated as a Hispanic Serving Institution. Terrance believed the campus was very adept at doing social justice work.

Terrance was a father of five daughters and also an avid "geek." He was particularly excited to talk about the presentations he had done at comic conventions on geek culture and college campuses and also saw this as part of his identity that was very salient in his work, reflected in the way he chose to decorate his office.

Terrance described himself as White, heterosexual, and male, and in some contexts would talk about being Russian and Polish. When talking about his identities, Terrance said he spent a lot of time focusing on privilege and how that impacted many of the choices he made on a daily basis. He offered that this was not always the case, but that he had come to understand these concepts because of the mistakes he had made throughout his career, and having others tell him about the impact of those mistakes on them. He said he worked very hard to learn from mistakes rather than repeat them. Terrance also spoke about feeling very connected to his experience being raised on the East Coast, saying that he communicated like someone from the East Coast and that it could be off-putting to people in his current region, that he can be perceived as abrasive. Terrance described himself as both fully Jewish and fully Christian, in that he understood how both systems of meaning making and cultural values were present in his decision making and understanding of himself in the world. 
Terrance spoke about how his identity as a father and a spouse was not as salient for him in his work, though it did come up from time to time. He described those times as moments when he saw dynamics or behaviors in his work that reminded him of moments from his experiences at home, a role that Terrance did not mention until later, but that was very important to him is his recent election to the position of president in a regional professional association. He was reminded of this when we began to discuss his understanding of leadership within the field of student affairs, and this role became a very important part of our conversations throughout this study.

\section{Summary}

This chapter was intended to serve as an introduction to each of the participants in this study. It offers a beginning to their stories about how they came to the field of student affairs and their current positions, as well as the levels of salience each participant had around aspects of their identities as ways to understand the contexts and at which each of them entered this study and began their engagement with the ideas of transgressive teaching and examining its potential impact on the practices of student affairs professionals. In the next chapter, I will present the findings that address the ways in which the process of reading Teaching to Transgress impacted the ways in which the participants of this study think about their work as student affairs professionals. 


\section{CHAPTER FIVE: FINDINGS OF CONNECTING THEORY TO PRACTICE}

The previous chapter having set a foundation for the experiences of each of the participants and their experiences leading up to the beginning of their reading Teaching to Transgress. This chapter will focus on the findings from this study that speak to the ways in which the participants believed there was a connection between the concepts of transgressive teaching which hooks (1994) outlines in Teaching to Transgress and their work as student affairs professionals.

In this chapter, those findings will be separated into several themes that arose from the data collection and analysis processes that speak to the ways the participants believed the theory was connected to their practice, as well as some areas in which they did not see a connection or struggled to find a connection. This chapter will offer findings that examine the reflections and self-work of the participants, as well as the times when they were challenged by the ideas they were reading in Teaching to Transgress. The section on challenging will also include a subsection on risk taking, as that was a substantive theme discussed by a number of the participants. Finally, this chapter will present the findings from the participants that focus on the theme of future possibilities, or the times when participants spoke to how applicable the experience of reading Teaching to Transgress might be to other student affairs professionals.

\section{Reflection and Connection}

The participants spoke to a variety of ways in which the experience of reading Teaching to Transgress inspired them to reflect on the experiences they were having might be connected to their work as a student affairs professional. While the participants worked in a variety of functional areas and institutional types, thus making the specifics 
of their work very different from person to person, there were still a number of ways in which each of them connected what they were reading to both their individual experiences in the field and to their understanding of what the work of being a student affairs professional is on a larger scale. This section will present those findings.

\section{Fred}

"I always think of kind of the paradigm maybe of how we do our work." Fred began his engagement with reading Teaching to Transgress in our pre-interview by thinking about what the idea of engaged pedagogy might mean to him and if it connected to how he understands his role as a student affairs professional. He said, thinking about what pedagogy as a whole meant, "Maybe the bigger answer, the how we put our theories into practice." He continued, "How do we help the administrators, or educators, actually do that, and not learn great academic theories and practices and actually engaging in them, making them practical." Fred reflected some more on what it might mean to connect an approach to teaching to his work, asking a question about the more broad work of the field of student affairs, "Do we, do we challenge ourselves to say is this action going to cause this result and is this grounded in something that we have learned?" Fred stayed with that thought in his journals. He wrote:

hooks reminds us that we must "commit ourselves to the work of transforming the academy so that it will be a place where cultural diversity informs every aspect of our learning, we must embrace struggle and sacrifice. We cannot be easily discouraged. We cannot despair when there is conflict" (hooks, 1994 p. 33). This final quote resonated with me the most because advocating and fighting for 
cultural diversity, equity, and inclusion is tiring work and, most of the time, it is work being done by a select few.

He continued, reflecting on the nature of his work in student conduct as being a role that immersed him in conflict on a day-to-day basis and how that conflict was both difficult and important,

We need confrontation and the "forceful expression of ideas" (hooks, 1994 p. 39) to challenge ourselves to look introspectively at our identities, including how we are privileged and how we are oppressed. Important learning happens when we disagree with someone and have to examine the source of their position, as well as reassess our own.

Fred also wrote he had to accept that no matter how many trainings he attended he will always be in the process of unlearning the messages he has internalized around race and privilege. He wrote, “These assumptions and behaviors play out in all aspects of my life, so I imagine how they are perceived and received in my work in Student Affairs."

Fred wrote more about the connections between his work and the way of teaching hooks described. He asked himself a series of questions to assess not just if he incorporated it, but how. He wrote,

I have reflected on whether or not I utilize an engaged pedagogy, as hooks describes. So far, my answer is, "Yes, I do." I feel that I have practiced and role modeled an engaged pedagogy in the way I approach student conduct. I always evaluate the "whole student." Who are they before they enter my office? What do I know about their hometown, academic major, campus involvement, and previous conduct? How can I address the whole person when addressing the 
alleged violations of university policy? Reading hooks' introduction was refreshing in its honesty and reaffirming in its vision of teaching as a practice of freedom.

He also wrote about how the dynamics described by hooks could easily describe the world of student affairs as well as she described the faculty. He wrote "This feeling [people being unwilling to engage race, class, sex, gender, sexuality in class] has been most salient for me in recent years, especially as I have transitioned to a more prominent role in student affairs, such as Director of Student Conduct."

During our second interview, Fred reiterated his excitement about the connections he had felt between the teaching hooks described and his work. He said of the excitement, "We can point back and say look, we teach this way, or we in student life we do programs this way, or we connect with students this way or we hold trainings this way because there is evidence." Fred also spoke about feeling inspired and validated by the experience, saying,

[the] most defining part of whole project or the whole read is where can I, the Director of Student Conduct, soon to be the Director of Student Life, how can I continue to bring my identities appropriately to the front of our work, or at least making them an aspect of our work so that they aren't seen as being like not important enough or just not relevant.

Fred spoke to feeling as though this was important because, in his experience, this work was becoming more and more the responsibility of student affairs professionals. He said, "It feels like student are spending less and less time in the classroom. In my experience here, especially this year and half faculty are less and less willing to get their hands 
dirty." He continued, "From the student conduct point of view, they don't want to be disciplinarians in their own classrooms. They, it feels like they consistently refer things out."

Fred connected his two reflections, on needing to understand how to bring his identities and experiences into his work and the experience of faculty referring out many aspects of the learning experience:

We are not just responsible for providing services, we're trying to shape experiences, we're creating opportunities for leadership or engagement, or social interaction. But we are also in some respects being handed the keys, like from the faculty, "you need to be the ones who are teaching them about race, social justice, inclusion."

Fred spoke to what that looks like for him in his role, which at the time was still in Student Conduct. He said,

If we are going to be fearless and do our work in that manner where I can acknowledge for example in a conduct case, that race or gender or social economic class is not the root, but an aspect of the conflict or the alleged violation and I can admit and call it and ask it, "how has this impacted you as a student here, you know you talk a lot about your identity as blank, or X, where does that come for you? Where does that change your outlook or how does that influence or motivate your decisions?"

At this point Fred again connected back to the excitement of the possibilities this could offer: "What a richer conversation I could have in just in the little part of the universe I control or that I work in, in student conduct." He continued to connect to the 
excitement, and thinking more about what might be activating that in him: "There is a lot of excitement and there was a lot of ah ha moment as we described it." He continued to describe those experiences as "a lot of confirmation and affirmation of things I have either have adopted into my practice or that I just heard from other leaders and teachers about how we can or should approach our work." He reiterated again, “There was an excitement and hearing her language reinforce what I've been doing or at least reinforce what I've heard from others we should be doing that there was a reality to the lived experiences of our students."

When we spoke again, after Fred had transitioned to his new role at a new institution, he stayed connected to this idea of bringing his authentic self to his role: "The number one that I've really taken away was this idea that you must bring your true authentic self to your work." He also offered a new connection back to Teaching to Transgress: "If we expect students to be vulnerable in our classrooms or in our office, we need to be willing to meet them there." Fred also shared a story about challenging the decision making process. His institution usually holds their graduation while classes are still in session, meaning many students miss their own graduation. He said of the moment when he spoke up,

I felt compelled to just say can I ask a question, "Who's commencement for? Who should be there?" And people were like "the students and their families," and you know and I'm like okay, if we are open access institution you know are we giving access to really big lifetime milestone and achievement, who can come on a Thursday at two? 
He described it as a moment of inspiration; "it was directly bell speaking through my spirit." He connected,

We need to connect more than just the logistics of time, place, and facilities. We have to actually remember the intrinsic part of what the ceremony means, who it represents, what is intended to do, where it fits in our student's lives.

He shared this story as a way to connect back to his earlier reflections, on how the value of students' experiences need to be affirmed by and at the center of the work of student affairs professionals.

\section{Terrance}

"I love the book. It speaks my language." Terrance began his experience reading Teaching to Transgress feeling like the experience offered him a lot with which to connect. He wrote, "So many highlights and underlines that spoke to me. It energizes me in the work I do, and encourages me that my paradigms of education are on track." He continued to describe the ideas to which he was connecting, "A lot of my passion is for student autonomy and engagement. A lot of the concepts speak to that. Learning is NOT hierarchical—but a process." Terrance wrote later in his journals that he often saw this type of engagement pushed out of higher education. He reflected,

I love that engaged pedagogy necessarily values student expression. Often we are afraid of students expressing themselves because it takes us outside our comfort zone. I love it. I am surprised by higher-level admins who get scared when I try and open spaces for students (and staff) to express themselves. This to me is the heart of our work - and we often shut down the expressions of others - either by minimalizing, ignoring, or even squashing the voice of the student. 
Terrance also expressed his appreciation for the theory and how it represented a point of growth for him across his professional career, "I really loved the fifth chapter on theory, as my journey with theory has been one of discovery." He continued, recalling his graduate school experience and early career, "I hated theory in my early professional career because I again thought experience was tantamount." He concluded, What is most fascinating is I now find myself back at the institution I began my professional journey in, and I have discovered how much I have grown in my practice — mainly because I have understood the practice leads to theory leads back to practice.

He also wrote about the ways in which the challenges to grow, both those offered by students and by theory, could be ignored and led to being stuck in a way of being and doing: "In many ways, as a student affairs professional, we get locked into the norms of how we have done things over the past 30-40 years." He continued to reflect, in many ways giving voice to the philosophy of the field with which the observations he described seemed to be in conflict "We have been unwilling to wrestle with the changes needed to improve our practice. We are afraid to engage in confrontation and conflict for the sake of appearing positive."

Terrance, as he continued through his journal, wrote more about seeing the practices described by hooks in her classrooms as also being available to him in his work "I may not be able to impact the entire department, but I can impact my individual classroom. For me in housing, this is my residence hall, my Resident Directors and Assistant Resident Directors, my resident advisors and residents." He concluded, "I am able to empower and create environments that allow the knowledge in the room equal 
access to decisions being made." Terrance also noted there was a specific importance to people holding dominant group identities to engage with these ideas, writing "It reaffirms my need to make my choices to engage on these topics less of a choice." He went on, "I need to forgo the power I have to disengage, and choose to lean into these concepts, especially with my fellow White, heterosexual colleagues." As he finished Teaching to Transgress, Terrance reflected on a bigger concept he took away from the experience, "Most of all this book has offered me courage to speak up. To speak to power systems and challenge the inherent oppression that exists."

During our second interview, Terrance described his overall experience with the book, saying "the book provided new ways of looking at things that I think was very helpful.” He continued, “Overall, it was really enjoyable and it really motivated me to prioritize more than I actually had done so in the past." Terrance spoke to the ways in which this experience brought forward his own experience and the experiences he observed others having, with the difficulty of engaging in conversations about power and identity. He said "There is a perception of not recognizing or deemphasizing the real power they have; out of guilt or out of concern."

Terrance spoke to the ways in which this experience also has given him a new lens with which the look at his profession saying, "I think it's impacted me. I think it made this topic more real, and now I look at student affairs in a more realistic perspective." He went into more detail to unpack this thought, "This book has helped codify for me what those issues were," which is something on which Terrance continued to reflect throughout this process. Terrance also returned to the idea about which he wrote in his journals, about the patterns and habits into which student affairs professionals can 
get stuck. He spoke to continuing to see those patters play out and how reading Teaching to Transgress offered him a some motivation to use his position to address these patterns: At my campus a lot of the power issues and the power dynamics I run up against here (in terms of who has power and who doesn't have power, who has perceived power or who may not have perceived power). I realized I actually have power.

He continued, noting the ways in which the experience of reading Teaching to Transgress had been a motivating experience,

Now, after reading this book, I begin to speak out: "Hey, we need to think about how this impacts our staff of color." I recognize I need to be the one to push the envelope because most of the other people have been here for 30 years.

Terrance also spoke to the ways in which he used this new lens to assess his own engagement with other colleagues and his own patterns of behavior saying, especially as it related to his male identity in a department where woman hold higher positions of authority. "I could see it play out [the power of White women] and she [hooks] gave me more context within my job, my role, and how I approach it. The book helped me keep my masculinity in check."

In our final interview, Terrance again returned to the lenses metaphor for his experience reading Teaching to Transgress. He began by describing the experience as "It's like having a different pair of glasses. So in terms of how I live my day to day life and how I go through things." He expanded on that thought, describing what those new lenses have offered him. He said, "Feeling comfortable having that conversation (around race and ethnicity), embracing the concept that being White means you are part of the oppressed system that created this country and you know we have a problem," while also 
acknowledging some of the internal resistance he feels "and there is a strong desire to want to put the solution to the problem of our marginalized friends, neighbors, colleagues, and say it's their work to do instead." He expressed some frustration with that internal feeling and yet saw this experience as a reminder of his role in addressing these dynamics: "I hate that's the internal push inside of me; that I can't do this work because I don't know the information. This is where the book has challenged me to understand the responsibility is on me to do the work because we are the ones that set the system up."

Ernie

"We are always talking about, 'How are we reaching students? How do we help them connect and how are we helping them learn?"' Ernie began his experience reading Teaching to Transgress with some hope for the process. In our first interview he spoke a desire to better connect with his students: "Sophomore Year Experience is one of the things that I want to create academic experiences that uh are outside the classroom. So if any of those things can help me connect to that group, absolutely." While reading the book, Ernie reflected on the ways in which safe spaces are established by administrators on his campus, and wondered if that actually has the impact it is intended to have. He wrote,

I have been in too many situations that we deem "safe" spaces on my campus. Rather than foster discussion of difference and understanding, the safe space moniker represents the silent acceptance of others and the understanding that we will have a mutual respect of each other.

He continued, connecting this thought to what he was reading in Teaching to Transgress "I believe [hooks] advocates of mutual respect earned through trust and conversation and 
our campus creates mutual respect through separating groups into support systems and does not require much involvement from the students." He also reflected on his own role in that "I also am guilty of minimizing our differences and treating groups the same rather than acknowledging the differences inherent in each group and take the effort to allow for differences in support based on need."

As he continued through the experience, Ernie further reflected on his own ways of engaging with students and how reading Teaching to Transgress had offered him a chance to try new approaches. He wrote,

I've become so much more aware of it that I've started to discuss some of my own personal struggles and opinions throughout my meetings, to share with the students that we are all individuals with different backgrounds and we come into each of these experiences with our own backgrounds.

He concluded that journal by saying that this experience, and the practices he has started to attempt to employ in his work, helped to make him a better professional. Ernie continued to journal about what he saw as new ways to approach his work. He wrote about experiencing a different awareness of his behaviors and their impact on students, "I know that my actions will have an effect and need to ensure that I do not condone behaviors of microaggressions." He continued, describing a pattern of his own behavior, "Typically I look towards those that I respect and gauge their reaction to events to determine mine own." He also connected these two ideas, writing about what it might mean for him to try to make a different kind of impact with his actions: "I am not easily offended and am able to say things that others cannot because of my White privilege and acknowledge the fact that I have not had to yell to make my voice heard." He then wrote 
about the ways in which the experience of reading Teaching to Transgress offered him a new way of orienting those actions, "Since last June I have worked to make sure that my voice is contributing to the good of others."

During our second interview, after Ernie had finished reading the book, he spoke about the experience offering him a number of opportunities to reflect on how he works with students. One example he gave was about how he used language and how he expected students to use language, saying,

[the book was] definitely a great example or great ideas and value in walking to room with how I need to be more aware of the language that I am asking students to use versus languages I am asking myself to use, and in what ways would it could be viewed as microaggressions. Some of those different aspects of leading a groups were very valuable to me.

Ernie connected this broader idea to a specific project on which he has been working and related the experience of reading this book to offering him ways to build new partnerships on campus and possibly have a different impact with his work. He spoke about, while reading Teaching to Transgress, "I immediately grabbed the book I ran over the [office of] diversity and social justice." He continued, "I chose to speak with them because I felt like this would help me rise my political clout to work with them on programs I wanted to run." He went into more detail about this program and what he believed could come out of talking with these particular professionals about his experience

I have been working on a students of color peer mentoring program and I've been working on students of color reception and this was one of those win wins. I was 
able to read this book and learn a little bit better perspectives about a black feminist perspective and I was also able to use this to start conversations. He offered that while that action wasn't connected to any particular content from the book, "the act of reading it definitely was helpful as I work to speak with them" and make new professional connections. Ernie spoke more during this interview about a concept about which he wrote in his journals, how he used his own voice. He spoke about how reading Teaching to Transgress offered him a new, or more in depth, sense of purpose "to just be content in the world that I am in and content and the education that, would be a disservice to privilege that I received and I share work towards achieve more to do more with this privilege."

During our final interview, Ernie began by saying he felt most connected to what he saw as the greater theme of the book and this study, rather than one particular section or action within the experience. He said, I don't think I can pick one thing out of the book I can say and point to that, but you know some of the idea of taking it outside the classroom and applying it practically and how we are supposed to be educating students living in society and navigate society translating those educations into acts and I've really where my thoughts have been.

He continued, connecting this back to the sense of purpose that he had mentioned in his journals and post-interview "it's been good to talk the talk but what are the actions I actually do to demonstrate that I'm part of the community that is also hurting and need healing right now." He spoke to one way that this new perspective has been coming up in his work, particularly within the current political climate and how students are taking that 
climate up, "you know if I tell you this is where you can protest and this is what you can say, that marginalizes those are already feeling under represented and under heard and you know their voice is minimized." As we continued to discuss his experience, he offered a summary of what he believed this experience offered him, saying "I am more sensitive since reading [the book], to my own privilege in ways that I don't even acknowledge."

\section{Raymond}

"Rather than just being prescriptive, with alright, so here is what you did, here is what the result going to be, really trying to engage, connect with the student, figure out what's really going on." Raymond began his experience reading Teaching to Transgress by feeling as though the ideas expressed connected closely with how he approached his work in Student Conduct and also offered him space to grow. In his first journal, he

wrote, "I feel like what I am reading matches with how I believe education should be; but I think my actions often fall far below this." He continued,

I think understanding the history can help in better understanding the actions/reactions of women (both White women and women of color). The tough part is holding individuals accountable while also recognizing the systematic issues that affect behaviors (and approved behaviors, at that).

Raymond also wrote about two ideas, both related to putting these ideas into practice as a student affairs professional and both related to his experience reading Teaching to Transgress. The first idea, as he described it, related to how some student affairs professionals engage others in sharing their perspectives. He wrote, 
I think those of us who want transformation, and have some experience with social justice can get preachy. We send a singular message that can be difficult for some of our students to understand, let alone embrace, and we don't always give them the room to try it on.

The second dimension he described was related to the need to be liked,

I think many professionals in student affairs became involved in the field because it provided them a sense of belonging. This extends, often, to the desire to be liked. But we have to be able to look beyond the need for immediate affirmation. Raymond connected these ideas to his experience in conduct and working closely with colleagues in residence life, "I think that stronger learning is often tied directly to the feeling of community. And it is about safety but combined with vulnerability. We have to recognize that safety is not about not being challenged or critiqued." Raymond wrote, towards the end of his journal, about how being able to challenge people can be difficult for him for a number of reasons, "I think I'm often viewed as the enemy, related to both my social and professional identities."

In our post-interview, Raymond spoke about experiencing a connection between the values of the student affairs profession and the approach to education described in Teaching to Transgress. He said, In many ways the idea of engage pedagogy that is what we feel like part of our job is all about, that we're there to work with students and assist in their development. Not to make their development happen, but to be there along the way. 
He continued, describing how the field may still be working to live out these espoused values,

We're open to the idea that we are also still developing and still figuring out who we are and how we connect with each and with the world. We might have the knowledge and skills and strength that the teacher [does] but we do it in a way that is more, or at least it's supposed to be more, [about] connecting and involving of the students that we work with.

Raymond spoke to how this connected him to his own experiences as a student affairs professional, saying "I think it is something that I do already, so I don't think this book started me to do something that I was doing before." He continued, "I think that it is not something all the time, so reading the book definitely jump start some of those thoughts." Raymond continued to reflect on what putting his experience into practice might look like in his role:

Within the boundaries and rules that I can implement, and at the very least keep in mind trying to figure out how I can, when an innocent has occurred, work with the student on how we move forward as opposed to coming from a place [of] "I am a person about is educated about conduct issues and about potential sanctions and here's what I think will help you the most."

He returned back to his idea of working within the boundaries, saying "there are some restrictions and structures that I am bound by but I think there is room within that to try to incorporate that kind of idea of engage pedagogy more."

In our final interview Raymond spoke about trying to create a bridge between himself and students who might resist his approach, especially for students who see him 
as someone who will likely enact his privilege upon them, "when I have those conversations those students tend to be resistant, sometimes I feel like I'm able to make a little bit of a bridge, and use analogies or stories." He also spoke about how that resistance has shifted to appreciation, "sometimes those conversations I've experienced some appreciation that I'm acknowledging that in the meeting with them that there is some understanding of what else may be going on beyond just the direct actions that are result of the meeting." He connected this back to his experience reading Teaching to Transgress, saying "it helps me to process more and understand more of what might be going on especially for people who don't have the same social identities that I have."

\section{David}

"[I] bring my full self to my teaching that my students are engaged in a way that is not just sage on the stage." David spoke in our first interview about the ways in which he envisioned transgressive teaching and engaged pedagogy being connected to his work as an Assistant Dean of Students. He spoke about advising student organizations and presenting workshops in ways that he hopes draw more people into a conversation, "having everyone sit in a circle and stacking um stacking everyone who want to speak in a more modern way and create an environment that feels less formal and more open."

In his journals, David began by writing about the feeling of excitement that he felt when having his approaches and practices validated, "hooks opens with a lot of my own thoughts and biases. Of course, I love this." He also posed questions to himself, reflecting on the difficulty of putting some of the ideas expressed into daily practice. He began by journaling “Are our safe spaces really safe?” He continued, wondering about the type of space required to undertake this sort of thing with students "How do we allow for the 
high emotion of anti-racist and feminist work in our spaces. In our lecture halls, in our offices?"

Later in his journal, while reflecting on a quote from hooks about the ways in which White women who act in ways that challenge racism alleviate the fear of racism felt by Black women, writing, “This makes me wonder how much I signal my commitment. I attend a ton of events, speak at events fairly often, and, I hope, demonstrate my commitment. But not as much as I ought to." He connected this reflection to the experiences his students were having, at the time there were protests across campuses of a controversial right wing speaker doing a college campus tour. David wrote, "Certainly with the current attacks on feminist scholarship, I need to be vocal." He continued, noting that while he did not think it was a good idea to go after the speaker, "I ought to be out there with my ears closer to the students as they go through their understandable processes dealing with such nonsense."

During our second interview David spoke about the aspect of the book that he felt most resonated with him: "I think the notion of the validly of the lived experience is probably the biggest take away." He continued,

In the book hooks made such a great case for how valid, how important, how essential, how our levels of privilege, our history, our people, and the main thing, how important [it is for] educators [to] respect people's lived experience and our own lived experience.

He further reflected on the ways in which he could apply that value to his own work. In his role he oversaw several departments within the university, and of all of the participants has, objectively, the widest ranging decision-making power and authority. He 
spoke about the career center on his campus, the office in which he began his own student affairs career:

For example, career reports to me, and I thought thinking about lived experiences in our resume workshops. What does it feel like for say African American female in a resume workshop at career services? How can we, or what modifications can be made to a resume workshop has so that has a positive impact on a particular group? Can our resume workshops be delivered in our student organizations for example could we doing resume workshop at the black student union or should we be doing a resume workshops at these ethnic identified Greek organizations? He also recognized the locations of these offices may be another way to engage students differently, saying that he would likely not hold these workshops in the career center because "that feels probably less welcoming and probably less sensitive to one's experience" and he wanted to continue to consider what ways he might be able to influence change in the areas under his supervision.

David also spoke in this interview about the ways in which the book encouraged him to examine his own lived experiences and understand himself better. He described it as "my reawakening to the importance of differences and the experiences of have brought, I'd say, a positive crisis where I feel like I don't have time.” He continued, I have not given myself time to listen to individuals. While running from meeting to meeting, while completely not keeping up with my email flow, while um dashing from teaching team meetings to lectures to goodness knows what, I have very rare occasions to sit down with students and colleagues and friends to just to 
have deep conversations. So one sort of pact I have made myself, to take time to listen and particularly to the perspectives are outside of my own.

He reflected further, again connecting this reflection back to reading Teaching to Transgress and how the experience offered him a new way of looking at his work and what things to which he does and does not pay attention, saying "this experience has me feeling maybe I'm not as mindful as I need to be about my lived experiences." David also spoke to this pattern being, in part, connected to how long he has been in the field of student affairs, and how much time he believes he has left in his career:

I am at the back end, I think at the earliest I have 10 more years in the field and so it's gotten me feeling [less] like "coast to the finish" and more like "Wow, I have so much more to learn and so much many more skills to develop to do this to work with our modern students in the best possible way."

He went on to say that he examined the choices he made in relation to his learning from the experience of reading Teaching to Transgress, "So I am constantly trying to think of practical applications in the back of my mind, would this be hooks approved or if it is a way to make sure that their values where people come from."

In our final interview, David began by saying, "[This] experience got me to look up more critically at how I teach and how my division works with students." He continued, focusing on his own interactions, "I am kind of thinking of ways that I can authentically be an ally and through actions signal than just symbols." In doing that, he said that a practice on which he is working "I think I am kind of quieting my own noisy busy mind a little bit more listening harder." David, at the end of this final interview, spoke about what he believes being able to listen to the experiences of students can offer, 
also offering a summary of his perspective on transgressive teaching, "bell hooks

describes creating spaces that are spaces for students to share their experience and honor their background and experience."

\section{Ronald}

Ronald, in our first interview, spoke about how he believed there could be a very clear connection between transgressive teaching and the work of student affairs professionals, saying,

I think about the training that we, we [do] and how often that's a list of things you need to do or memorize these important protocols and we miss, often in my experience here, we miss the opportunity to have dialogue and engage students in more reflection and conversation about their identities and how their identities play out.

He spoke about this observation actually being an inspiration to shift the focus of staff meetings away from these sorts of interactions, "one of the things that I do in my practice is to move away from staff meetings that are information downloads but just use those as professional time."

In his journals, Ronald wrote about the connections he saw at the beginning of the book, "I think the concepts here are applicable to the ways that student affairs offices operate. From my experience, there is often a holding on to the old ways of doing things. These old ways are rarely transgressive or engaged." He continued, making a specific connection between his own experience and one described by hooks, "the notion that teachers should be self-actualized stuck out to me as I realized where I am in my own understanding and development. I am thinking about what ways I can continue my 
journey to self-actualization." Ronald connected to this idea again later on, writing in his journal "some of the connections that stood out to me were about how education is necessary for liberation and that this liberation is not just for students." He continued, "I see myself in a role that allows for that liberation to happen if I engage with it."

Ronald noted change was a topic that stood out to him while reading Teaching to Transgress, and this change could be experienced as part of the process of liberation. He wrote, "while that need for change was connected to the classroom for hooks, I thought a lot about how that need for change goes beyond classroom settings." He continued, "I was reminded of the ways that my practice as a professional was from such a selfish and limited scope. I have done things like rely on folks from marginalized identities to bring up issues of injustice." He brought up a specific example to mirror examples given by hooks, writing about the tension he experiences between wanting to challenge and to be liked, "I would like to push students to explore their identities, but also want them to trust me and come to me as someone they enjoy."

In our final interview, which happened after Ronald had finished about half of the book and needed to stop because of other time commitments, he spoke about his experience with the book as having "brought me back into a place of human related to do some more of my own work and continue encourage others to engage." He also brought up a new idea, one that he said had stuck with him from the pieces of the book he had read, "I think reading Teaching to Transgress allows for a little bit more feeling and reflecting and self work needs to be about how compassion one of the things that came up was this notion of compassion." 


\section{Jerome}

Jerome began our first interview by posing a series of questions, both to himself and to student affairs professionals about how they take up their work:

Digging into the content that we are teaching and where does that come from, what kind of mindset does it support? Are we supporting a dominant narrative or allowing more narratives to exist? Are we supporting narratives that exist are not currently in the conversation? Are we challenging students to bring their whole selves into the classroom when we talk about history? Are we talking about they and how it relates to the individual and relates to the social identities?

In his journals, he reflected on how difficult it can be to feel comfortable with the answers to those questions. He wrote,

Do we teach so that students are more open to the content or so that we are challenging power structures directly? This is a difficult question to answer for me because making the content more accessible often means making it more accessible for privileged people and thus means valuing their education over marginalized students in the space.

He continued, recalling one of the ways this tension has shown up in his own work, "I typically lean towards using the language of oppression, even if it leaves a bad taste in some people's mouths. I'm trying to uncouple the language from the propaganda tied to it."

In a later journal entry the topic of language returned for Jerome. He wrote, "I think Chapter 11 has a very important message about creating space for students to use 
their own language and being validated." He continued, reflecting on what it would look like in his work,

I need to find means to create spaces for students to use their own language without feeling inferior or out of place. I also need to do more to engage White students who use non-dominant vernacular as a means to be "cool".

Jerome also wrote the experience of reading this book was helpful for him in doing some of the work he described in earlier entries. He wrote "Many of the sentiments bell hooks writes on in these chapters are not new thoughts to me, but they feel like the language for which I have been looking." He continued, "It has offered me some space and language to engage in these conversations with colleagues who have similar identities." He also acknowledged his own work, "Not to say that I don't have a lot of decolonizing to do in my personal and professional life, that it was not solely something for other student affairs professionals to do." He concluded this journal with an appreciation of Teaching to Transgress, "This is but the book did a better job of taking a lot of thoughts, conversations, and experiences I have had and collecting them in one space."

Jerome recognized that reading Teaching to Transgress had given him space to reflect on decisions he had made with which he was not comfortable or he felt did not align with his own values, similar to the experiences described by Raymond. Jerome wrote,

When she spoke of White people who do not take on the full burden of holistically engaging in anti-racist, anti-sexist, anti-classist, etc. struggles, I am forced to reflect on the times that I do not, for whatever reason, put myself on the line and join in community anti-oppression work. When she speaks of herself 
side-stepping the conflict with the Toni Morrison-bashing professor I think of the many times I avoid the hard conversations and try to comfort myself with "they're not willing to hear it."

Jerome also recognized the importance of challenging himself and pushing against some of those feelings. He wrote in his final journal entry, almost as a call to action since finishing the book, "I need to do a better job working with staff and faculty to either explicitly state their expectations or, preferably, create a space welcoming students to come as they are." He continued, "This gets to the idea that classrooms should not be overly concerned with making sure everyone speaks, but that everyone is welcome to speak and that when they do so their voice is valued."

In our second interview, Jerome described the part of Teaching to Transgress that stayed with him. He particularly connected to the "sections were she was directly thinking about teaching pedagogy and how to actually practice and integrating it into the classroom." He continued, expressing appreciation that these readings had helped him work to understand "how that could lead into programming and different kinds of both co-curricular and extracurricular places and spaces."

Another concept to which Jerome felt a connection was to what he called "detangling the brain and mind from the body." He described it as wanting "to be seen as individuals and oftentimes recognizing our bodies and our identities especially those that give us privilege make us feel we are representative of a group of our own self." $\mathrm{He}$ continued, "[We] try to distance ourselves from those identities, each try to only embody our personal selves and think that apart from deal with the realities of life almost." He spoke to why this stuck out to him, saying, 
We are bringing a lot of baggage, but when we try to detangle ourselves from our bodies we want to act like that has not impacted on how we are address our class or to the subject, we want to act like impartially can be the thing we can actually reach.

He continued to unpack this thought "I think a lot of ways we are taught to ignore our social identities, ignore our biases, instead of being aware of them and taking them into consideration when we are interacting with students." Jerome described the reason for this part of the book standing out had to do with how familiar other aspects of transgressive teaching were to him. He said,

A lot of what I do is facilitating conversation and creating programs to create dialogue and discourse so I think a lot of the teaching tools Bell Hooks talks about I also try to put it into practice when I'm facilitating. I share myself, I participate in the group rather than trying to take myself out and be a part in it and not be disconnected from in the space.

He concluded, "I think I need to do a better job of that at times and really not let myself disembody really take myself away from my identities and my body as part of the conversation."

Jerome connected this experience to hooks' reflection on Freire's misogyny and sexism within his earlier writings, saying, "One of those reflections I had was today there is a very consistent trend of being able to throw out ideas, theories, based on someone's actions or their missteps or saying something that is offensive." He offered the example of R. Kelly: 'I can say 'I'm done with listening to say R. Kelly.' And I think there's something to be said for that idea, holding artists accountable for their work." He also 
realized his own connection or lack of connection to R. Kelly might mean he was willing to dismiss his work and how that might be a function of his identity as a White, heterosexual, male. He reflected, "I think what that means for me going forward is the idea of having to temper my indignant outrage of my self-righteousness around some of these issues and look at it a little bit more complexly."

Toward the end of this interview, Jerome reiterated his appreciation for the experience of reading Teaching to Transgress, describing it as "an affirmation of a lot of things I have learned through my teaching education and years of doing my social justice research and things like that just a little bit more I guess collected into this one space." He spoke of the ways in which it recalled his teacher training, that his work was to "work with students to fill knowledge rather than give it to them." He connected this to his work in student affairs, especially as someone who does a lot of facilitation as part of his role:

I have learned a lot that as a facilitator. One the biggest and most important things to do in a space is to make sure to give of yourself as you are asking students to give up themselves, because if you don't show your own vulnerability and willingness to contribute then being like that might not be comfortable and also becomes a power dynamic. You're asking them to become vulnerable and give knowledge when you're not willing to participate in the process.

Jerome did not complete the final interview for this study, so there was not an opportunity to follow up on these ideas or to examine what, if any, ways these ideas had continued to develop after more reflection and experience. 
Seth

Seth, like many of the other participants, began his experience reading Teaching to Transgress by feeling a connection between the way hooks describes transgressive teaching and the work of student affairs professionals. He wrote in his journal, "Initially, I am seeing clear connection between our work in SA and the concept of an engaged pedagogy. Both focus on inviting more individuals into a space of growth and learning while honoring who they are." He continued, recognizing that while student affairs espouses these values that it often does not meet them, "Both—and SA when it is working from its highest self-emphasize the relationship between the teacher and student as critical but recognize that this relationship must demonstrate a mutuality where traditional notions of power and authority are questioned." He wrote further:

I see connections between Hook's understanding of an engaged practice as action and reflection upon the world in order to change it and our work in SA that focuses on experiential learning or engaging with an experience and reflection on it as a primary strategy for development. This is especially the case with some popular approaches to leadership development in SA.

Seth also reflected on the difficulties of putting these values into practice and how that experience might be different for a student affairs professional than for a faculty member:

The administrative structures that one needs to navigate during the change process can be daunting. For instance, as someone who is in charge of physical space in a student union, I struggle to ensure the space reflects the interests and identity of our diverse students while also navigating challenges of budget and university design standards. 
He also reflected on the ways in which power is used: "I was thinking about the challenge in SA of exercising power in the lives of students and how we can exercise power without perpetuating systems of oppression." He continued, also recalling his own history with student conduct, saying, "We are often making decisions around the development and enforcement of policy that can serve to keep students in a role or within a boundary."

In our second interview, Seth felt an excitement, similar to many other participants, about the connections he saw between transgressive teaching and student affairs. He said,

I found the book exciting in some ways and in some ways the idea of Teaching to Transgress and education from liberating perspective to be very connected to what we try to do in student affairs at least what my experience in student affairs and at a university that is faith based and focuses on holistic education.

He continued to explain the excitement and its origin, in a way similar to David, "The excitement was 'oh here is some language in that gets me,' what drives my work." He continued, "My work is always about me and the students and I learned as much as I hope students get and try to practice that version of themselves."

Seth spoke to ways in which reading prompted him, like many other participants, to ask reflective questions about how he might put these ideas into practice. He said "I found myself thinking at one point, 'How do students see themselves in the Student Union?' And not just in the physical space that might be designed like a multicultural center or women's center for them but throughout." He told a story about an interaction, through his role in planning staff development for the division of student affairs, in which he held a space of dialogue for members of a different department. He recalled, 
Somebody in that department is often thought of as a difficult person and I found myself, in preparation for that mediation, thinking about the nature their difficulties. How related to their identities that might be, how them being difficult is more about them not conforming to an institutional standards that have been set up over the years.

He summarized his feelings on the power of bringing personal narrative into learning: The connection with hooks, that's really being able to name your experience have it held in the space even temporarily so that they can examine it, so others can receive it, and appreciate it. It's sharing that narrative as part of the transformational process.

Seth concluded this thought with a broad idea about the ways the learning students were doing in all parts of college could be beneficial for them beyond the college experience, saying, "The education process needs to be transformative if we want the people to go out to the world and transform versus sort of reinforce what's going on." He also expressed a connection, similar to a reflection offered by Jerome: "The mind-body concept; that's something stuck with me, in some ways affirm something I already believe.” He continued, describing his own conception of it, "Education is not just about dumping into our mind and I think was we do in student affairs, or seek to do is to really connect the mind and the body and given my own faith-based Institution I probably would being spirit into that."

During our final interview, Seth spoke again to the connections he found between his work and transgressive teaching, "when I read Teaching to Transgress from a director of a student union hat, I think about my role is to create space for people to practice in 
becoming who they want to be in the world." He also spoke, similar to the how many other participants spoke to their experience reading Teaching to Transgress, as a call to action, saying "I've been feeling that more and more this responsibility to say something, and to do something. I don't know what that is, but that's been something I've really been in touch with." He went further, connecting it a particular dimension of his identity: "I'm still trying to work through the types of responses I want to make with that, and how I want to use that Whiteness for something that is constructive."

\section{Gene}

Although Gene did not finish reading Teaching to Transgress, he still found some connection to his work with students in the passages he was able to complete. In his first journal he wrote, "The author acknowledges that education in general should be liberating, exciting, and individualized, which is something that I have always adapted in my higher education career." He continued, explaining what it means to be adaptive in his work, "I do not give them the cookie cutter advising treatment that many advisors at [this university] do." He also described the way in which his work holds a deeper significance to him than simply as a job, saying, "My work is a lifestyle, and I value my students more than a nine to five relationship. I craft their advising experience based on the individual."

\section{Synthesis}

This section collects the variety of ways in which reading Teaching to Transgress offered participants an opportunity to both reflect on their practices as student affairs professionals and connects the ideas of transgressive teaching to those practices. Both the interviews conducted and the journals kept by participants while reading were designed 
to, in part, elicit reflections on the experience of reading the text and asked participants to identify connections between the practices described in Teaching to Transgress and their work as student affairs professionals. These connections arose from the reflections, and collecting them in the narrative form allows for a deeper connection among them to become clearer. These reflections and connections ultimately had helped the participants understand more clearly the ways in which these theories could connect to their practice.

Each of the connections made by the participants had specifically to do with the work they did in their particular functional area. They all spoke specifically about how the ways of engaging with students described in Teaching to Transgress offered them an opportunity to reflect on how they either currently utilize a similar approach or how they may begin to use a new approach more aligned with what hooks (1994) described. Many of the participants also reflected on the ways in which the broader field of student affairs and its general values and mission aligns closely with the ways of engaging with students in which transgressive teaching is rooted. This often meant participants could also reflect beyond their own positions, also reflecting on the work of their peers and colleagues within and beyond their own departments or institutions. Each of the participants also spoke to the ways in which finding these connections offered them a sense of validation, and that feeling was an exciting feeling.

Many participants, however, felt challenged by the experience. Some felt pulled to challenge the ideas presented in Teaching to Transgress. These challenges are also important as a way to provide a more nuanced narrative of the experience had by the participants, and will be reviewed in the next section. 


\section{Challenging}

While the participants of this study all found many opportunities to reflect on their experiences and explore potential connections between transgressive teaching and their work as student affairs professionals, they also experienced challenges while reading the text. Some experienced these challenges as an invitation to examine new possibilities for their work, while others to these challenges as critique. These challenges were multidirectional, in that there were instances in which the participants felt challenged by hooks and also instances in which the participants wanted to challenge hooks. These occurrences sometimes were and sometimes were not directly connected to one another, in that the desire to challenge hooks sometimes did and sometimes did not come as a response to being challenged by the text.

\section{Fred}

Fred spoke to challenges in reading on two occasions. The first was during our second interview. In describing some of his experience reading Teaching to Transgress, he mentioned he often had the urge to speed read or skim the text. While he spoke to rationalizing that feeling as the sections he was reading not being relevant to the research being conducted, he also reflected on the ways in which it may have been connected to the emotions he believed hooks was expressing in writing about her own experiences. $\mathrm{He}$ said, "A visual in my brain right now is almost like a hammer; she's really trying to beat it over the head. These read [as] anger from her. These are negative experiences that are existing in the classrooms." 
He recalled this again in our final interview. He also described the experience more deeply, as if the time since the experience offered him more insight through reflection. He said,

The frustration I told you I had, finding her chapters about feminism to be the hardest ones to digest, because representing the White patriarchy, it's always difficult to think of yourself as the oppressor or someone who literally occupying space or someone who might be a barrier to women or women of color getting into a similar space.

Fred also spoke to gaining some new insight into his own purpose as a result of that reflection and the feeling of being challenged, saying, "I think that has allowed me to consider maybe, hopefully not simplifying it, trying to use my White privilege for good, trying to identify it in the room."

\section{Terrance}

"It challenges me, having open eyes when dealing with people who are blinded." Terrance also experienced challenges throughout reading Teaching to Transgress. He first wrote in one of his journals, "I also felt reading chapter five the need to wrestle with my identity as a White man. In observing the inner conflict between White feminists and black feminists and feminists of color." He continued to reflect on what his wrestling with his identity as a White man might offer him: "I wrestled with the concept of theory being viewed with a patriarchal lens - and how much of it is dismissed without a critical exploration of what is transferable and what is not."

After he finished reading Teaching to Transgress, Terrance reflected more on this idea. He said in our second interview, he particularly connected to the division between 
Black and White feminist women, saying, "There were a lot of things in there that I had trouble wrapping my mind around. That wasn't for me a reality that I had really thought about or encountered." He continued, "When she talked about the challenges of White women and black woman to me those were things that were new, hadn't thought about, mainly because I'm not a woman." Terrance also spoke about the experience challenging his perceptions of strength and weakness in others. He said:

Sometimes I look at people as being strong and that discounts the impact of the negative things that they've experienced and how they may have perceived themselves. A lot of times I'm like "oh, that person is strong," so I'm going to treat them as if I don't have to worry about hurting them because of their strength.

He connected this more directly to his view of his Black-identified colleagues and friends, saying they have "gone through a lot in our country. They have gone through a lot in in society, you know, and so that raises them up in my mind in terms of how I perceive them." He continued to unpack his new realization that came out of hooks' (1994) challenge, "in doing this, it does not recognize the impact of those experiences."

During our final interview, Terrance returned to the challenge to something he had discussed in his journals and in the post-interview. He spoke about the experience challenging him to better understand his identity as a man and how that impacted his interactions with others. He said, "I think for me the area outside my comfort zone is kind more of the my masculinity looking at the role my masculinity plays with other people." He also spoke to having begun to explore that more, saying, "That is where I've leaned into that discomfort." 


\section{Ernie}

"One of the things that I did not understand or talk about on a day to day basis. I struggle with reading the book." Ernie offered a number of examples of challenges he experienced during the process of reading Teaching to Transgress. In his journals while reading, he wrote about his experience with the chapters in which hooks tells of her educational experience: "It makes me feel ignorant and ashamed of 'doing what I was told' as I pursued my own education and now, how I educate others." In a later journal, he returned to this experience:

The section on the "oppressor's language" made me think of my own upbringing understanding, reading, and writing since I was in Kindergarten, the English language. I never had to be corrected, at home or at school, that my way of speaking or writing was "wrong" because I grew up in the dominant culture and came from a family of high school-educated parents.

He also reflected on what he would have felt if someone told him the way he had always spoken was wrong and needed to be corrected rather than appreciated or understood.

Ernie pushed back against some of what hooks shared in Teaching to Transgress. He offered in a journal entry that some of what he was reading "comes across as a rant but against the same system she is part of and I think that the changes she suggest are too bottom-up to make a difference (indeed she did write the book 25 years ago now).” He spoke more directly to the idea of a classroom as a democratic space: "Is the classroom really a democratic space? We pay for the educator to be knowledgeable in their field and are seeking insight into materials that they have studied." He continued, offering some agreement while still pushing against hooks' assertion, saying he does believe a 
classroom is "a place where the students should be seen as partners in the process." Where he disagreed was around the idea of the classroom being democratic, with a concern about the ways students could disrupt the learning of others: "What if the students that always speak up are wrong? I'm not paying to hear them speak or to contribute to confusion."

During our second interview, Ernie reflected more on his own educational experience and how that shaped the way he was interpreting Teaching to Transgress. He spoke to his own educational expectations and assumptions, saying, "I've been taught by predominantly White instructors here, and I am a White male, so there's so many different times when she's talking about in front of the class and all I'm visioning is the PowerPoint." He admitted, "I have no idea what her classroom experience is like." He continued to reflect on this challenge and how his lacking a reference point made sharing her vision difficult: "When they talk about, you know, getting everybody to talk in class and everyone in the classroom have to act responsibly, I'm thinking, 'What does that look like?" He continued, asking more reflective questions, "Does she allow them to disagree and yell at each other, or does she allow them to use language that I wouldn't use? $\mathrm{He}$ also wondered about the responsibility of authority in this type of classroom space: "What is that responsibly, is it to everybody sharing and they're actually providing their opinion, or is it making sure they are contributing?" Still, he expressed an interest in leaning into the challenge presented to him. In our final interview one of the things Ernie spoke about taking away from this experience was "bell hooks' experience with the White college educators, White high school teachers, even going to her classroom and telling her what they think and how to respond That's what I'm trying to avoid." 


\section{Raymond}

Raymond began his experience reading Teaching to Transgress with feeling challenged and spoke of it with some excitement. He wrote in one of his first journals, "Sometimes it is just considering/reading about possibility that encourages/enables making a change. Maybe it is a combination of feeling subtly called out but also pushed down the path that I want to tread." Raymond did not always approach the challenging aspects of the experience with the same positivity though. In a later journal entry, he wrote about two different chapters saying, "I did not find much value in 'A Revolution of Values.' It seemed like something that could have been covered more quickly and did not have a practical application," and "Maybe it's because I have done some work around educating myself in the social justice arena, but the 'Embracing Change' chapter seemed like nothing new."

Raymond reflected on what might be bringing some of these things to the surface. At one point he wrote in his journal,

I feel guilty, because I don't think I've been very effective at being transgressive in my teaching. It does remind me of one part of the values chapter where it talks about how people decry some of the main values that seem dominant in our society. If things like bell hooks talks about mesh with my values, why am I not doing them already?

He returned to this point in a later journal entry, "I keep finding myself wanting to point out what is missing. I think I want to be able to demonstrate that hooks isn't always right, probably out of fear and guilt." 
Toward the end of the book, Raymond wrote about experiencing a tension within himself, saying, "I don't disagree with the things that hooks is saying in this chapter. White people (especially White men) have used language as a weapon to control and hurt targeted groups." He continued, "but doing so back doesn't seem to me to be the answer, but something that I see happening a lot. It's the eye for an eye principle.” He connected this to his own desire to share a common language: "I struggle with the idea of a common language not being a benefit. I want there to be some way we can effectively communicate with each other without it being oppressive."

While there were a number of moments while reading Teaching to Transgress where Raymond spoke about experiencing challenges, they did not seem to stay with him past the experience of reading the book. In our second interview, Raymond spoke to one challenge, and it was one that Ernie also expressed, the lack of direct action or translation. Raymond said, "But [there] wasn't necessarily a lot of action, there were some action-type things and I think that there is value for both but I think it is harder to translate her philosophical piece to direct action." Raymond did, however, offer much more insight into another aspect of the experience, which will be covered in the next section.

\section{Gene}

Gene experienced a challenge very early in reading Teaching to Transgress. While reading the first few chapters, he wrote in his journal about a passage in which hooks speaks to encountering many folks who espouse values of diversity, justice, and so on, all while acting in ways that are counter to those values. Gene wrote "[While this] 
may or may not be true, the author seems to suck the wind out of recognition." He continued,

I think acknowledgement needs to be made to people who at least recognize that racism, sexism, and classism exists. Decades will go by before humanity, possibly centuries, especially in the United States, for total lifestyles, total values, and cultural actions can be changed.

He went on to write that when hooks spoke these actions, she removed the possibility of being presumed innocent from White people: "I believe she herself demonstrates some sort of intolerance and lack of appreciation." However, because he was not able to continue in the study, we did not have an opportunity to explore these ideas through the rest of his reading and reflection.

\section{Jerome}

Jerome wrote a number of reflections on the ways in which reading this book challenged his view and learning around what higher education and student affairs were. In one instance, he wrote, "It... brings about the importance of contextualizing our work within the history of higher ed. Higher education is a historic system of power that further privileges White, wealthy, heterosexual, Christian, cis-men. It still does." He continued, realizing that he is a part of the system he speaks about wanting to dismantle, "We work for oppressive systems while we are trying to decolonize education."

Jerome wrote about being challenged to be honest about how well he does and does not express his espoused values through his work: "I found myself reaching for examples of when I enact the strategies she talks about, especially on being open and sharing with students." He continued, issuing a challenge to himself, "I have to push 
myself to look past the times I meet the bar and see the many times that I don't do enough do decolonize the space." Like Raymond, these ideas were not returned to in our second interview. Unlike Raymond, though, Jerome did not participate in a final interview, and so we did not have the opportunity to explore ways in which these ideas may have been part of his reflection later in the process.

\section{Seth}

Seth, like Raymond and Ernie, spoke to feeling challenged by not being offered a step-by-step process to practicing transgressive teaching. He wrote in his journal, "In this section of reading I finally started to realize that we were not going to get clear instructions of how to teach to transgress." Seth returned to this idea in our second interview. We were discussing what, if any, connections he saw between the ideas described by hooks and the work of student affairs professionals, and he offered, "I think the book leaves it somewhat open around what the links can be and are for the reader to make." For Seth, this seemed to be the only major challenge he experienced. Like Raymond, he did speak to another dimension of the experience that will be covered in the next section.

\section{David}

David, in one of his initial journal entries, spoke to the expectations he had about hooks and her work going in to reading Teaching to Transgress. He wrote, "From the little I have read about hooks, I was thinking that her writing was going to be somehow militant beyond my threshold. I don't even know what my threshold is for militancy." He also wrote about having difficulty engaging with hooks' description of the difficult interactions between Black and White feminists. Like Terrance, David described that 
experience: "I really slogged through chapter five. I was not keenly aware of the rift in feminism. It was enlightening to hear this from hooks' view." He attributed some of his difficulty to a lack of expertise, saying "There is a lot of specialized language and a pattern of thinking - threshold concepts in feminism that I am not facile with." David also wrote about the ways in which this chapter brought up resistance from him, finding himself thinking "Don't you have anything good to say about these academic warriors who have made such great strides in their deconstruction of the patriarchy?"

David wrote about the challenge of being willing to attend or put on programs that seek to address the issues about which hooks writes in Teaching to Transgress. He offered that at the sorts of programs that seek to offer the kinds of liberatory spaces hooks described, "Things might get pretty intense. I find myself resisting events that might end up with students yelling and crying. Hooks might argue that this is what needs to happen." He continued, reflecting on the necessity of these spaces and his own unwillingness to participate, "With time and resource constraints, I'm at a loss about how I could do this work - the deep, emotional, mass therapy that I think it might take for us to really move forward." In a later journal entry, David wrote himself a few reflective questions, taking some inventory of how he uses what is available to him to work in a way hooks describes:

How often do I use my lucky position to help my fellow humans to deconstruct these unfair systems? How often am I quiet when I ought to be that guy who speaks up around something that ought to be fixed?

During our second interview David returned to many of the challenges about which he wrote in his journals. He described his experience reading the text as a 
conversation, and one in which he often felt comfortable interjecting, "Ok, bell, I get that and I don't think I agree particularly here." He also spoke with some appreciation of the challenges the book offered him, one of which was to continue to engage with new ideas. He said, "It was also a challenge to me to do more reading, so, this one book, this one obviously luminous individual has got me to thinking a deeper level than its time to sort of take a sabbatical."

David returned to his reflective questions, speaking about what continuing to reflect on the challenges offered to him by Teaching to Transgress. He began by saying "I am just meeting my basic commitment and rest as much as I can when I am offline and so the balance is for the balance of survival." He continued, while also again showing appreciation for the experiences saying, "Reading this book was really giving me a deeper level than I normally do about who I am." He continued, "It got me thinking 'Wait, this is not okay.' I should probably figure out a way to keep looking at myself and finding a way to keep growing even though I am under water with all these commitments." He concluded the thought, saying, "It's sort of a challenge. It opened up a challenge for me to not just survive but carve out enough time to be a better professional." He also spoke about feeling defensive while reading and where that defensiveness might have originated. He first said, "I was sort of defensive for White feminists, and, in a way, they didn't know better. I bet they are on board now. So there was an area where I was kind of defending my folks." He continued, "Wondering if I'm filtering what she is saying through my own experience and my knowledge and respect for, you know, all activists who are looking for social justice." He concluded, saying that 
while reading Teaching to Transgress he "kept thinking about my own biases while I was also feeling it."

\section{Ronald}

Ronald, who was also not able to finish reading Teaching to Transgress, spoke to challenges in one of his journals. Like several other participants, connected to a challenge with the chapters on theory. Ronald did have his own challenge, which was different than the ones experienced by others. His challenge was less about understanding theory. He wrote, "The chapter about theory also made me think about the need for theory and how I have struggled with theory and its implementation in the past." He revisited this thought in a later journal entry, writing, "The need for combining theory with praxis also made me think about the ways that I've put theory into practice in my life."

In our final interview, after Ronald had stopped reading. He again addressed a theme similar to other participants around challenges. He spoke to the ways in which the experience had also offered him an opportunity to engage with the thing on which he felt challenged. For Ronald, the challenge was putting theory into practice. He spoke to his new thinking on the topic: "One of the things that stood out to me there is also this complacency in addressing issues when they are brought up and how can I be more of an agitator." He continued, describing one way that this agitation could be taken up, "to point out the things that need to be changed rather than waiting to be support for someone else."

\section{Risks}

In the same way that many participants experienced challenges in the book, many also spoke to the risks they believe were associated with practicing transgressive teaching 
as a student affairs professional. In many ways, the theme of "risks" can be connected to the larger theme of "challenges" in that when participants spoke about risks, many spoke about feeling challenged to take risks. Also, many of the participants spoke to the fear that comes with taking risks, while others acknowledged the role that privilege plays in the ability to take risks.

Fred. After finishing Teaching to Transgress, Fred spoke to a hesitation that he felt around connecting with students in the ways described in the book. He offered, when reflecting on what it would take for each member of the community, including himself, to show up as their full, authentic self, "I think the first thing that comes to me is there would be a lot of hesitation and there would have been a lot of risk of vulnerability."

Raymond. "It's easy to make rationale for not taking action and that I find myself falling into that at times." Raymond spoke most often about risk and his fear of the impact of those risks. He first wrote in one of his journals that there can be risks that one can take that impact his family, for whom he was the sole income at the time of this study. "For others," he explained, "their willingness to go outside the lines is a potential risk for their entire family. I think the idea of transgressing is a good one, but not as straightforward a choice as she makes it seem." He went deeper into the risk that he saw in taking up the challenge to do more presented in Teaching to Transgress: "Still, I think for me, and others in this field, we want to have the radical effect on students hooks talks about, but are limited both by systems and by time."

Raymond expanded on this thought in our second interview, where he said that he saw naming these risks as being part of confronting how he has rationalized not acting to address instances of injustice, saying, "hooks is at a position where in large part she can 
do what she wants. She can lose the job but mostly herself will be directly affected and her reputation would most likely land her another academic position." About his own situation, he offered, "I am not. I am provider for my family and I do not have that kind of reputation." He continued, "Going outside the acceptable range of behaviors for my institution has potentially more negative impact for me as an individual." He concluded, "My ability to create change in the system is also hampered by my reliance of the system to provide me with livelihood and my family with food, and shelter, and clothing."

While experiencing this sense of fear, Raymond spoke to the ways in which his identities can be an important factor in taking risks. He reflected on what it might mean for him as a White, heterosexual, male to take these sorts of risks, saying, "Sometimes my voice carries a little bit more weight." He continued, even expressing the new possibilities this risk taking might offer to others:

I am part of the system and I have some expectations of upholding the system but encouraging students about how they can think about how they can call they can challenge and what even if it is sort of within the system they can challenge it.

In our final interview, Raymond revisited this idea that there are risks and that they can be valuable. He began, "I feel like those issues of social justice are incendiary to include in my position." He continued, seeing that in taking those risks in his interactions with students, "We can potentially grow in their understanding and knowledge around these issues."

Terrance. Terrance spoke about the ways in which taking up his work in this way could present a risk. In our second interview he said, "I can choose very easily to ignore this topic, and achieve success," instead of, as he put it, "run[ning] the risk in my 
department of lowering my stature; like when positions become available, and because I am ruffling feathers of people of power." He spoke about having to have that conversation with his wife: "You just need to know because I'm making these choices it could negatively impact us."

Terrance also spoke to the ways in which he is able to choose to take those risks because of his identities, saying, "I need to do this because this is the right thing to do, not because it makes me a better professional, not because it makes me more marketable." He continued, reflecting on the ways in which his choices can also impact his co-workers, "If my colleagues—who don't have these privileged identities—are not going to be successful it means I have to sacrifice some of my success to make that happen." He went further, as if to let this point sink in, "it's not like there are infinite jobs out there. As we go into this field there are less and less jobs at the top and so I could be losing financial compensation because of the choices I'm making."

Jerome. Jerome spoke about his identities being a part of his ability to take risks. In his journal entries, he wrote, "As a White, heterosexual, cis-man I get the freedom to integrate my beliefs around social justice into my work without an assumption of it being selfish and angry. This gives me the freedom to push against the unjust policies." $\mathrm{He}$ continued, reminding himself about his expressed values and the responsibility that may come with them:

I have so much more freedom in every facet of my life because of my privileged identities. People associate my actions with me and not my whole identity groups. If I run a workshop on a social issue it isn't seen as a personal vendetta. My 
passion isn't relegated to jealousy of selfishness. All of this means that I have to do the work of challenging myself and doing my own decolonizing.

Jerome, like Terrance, acknowledged working toward his goals of justice and equity might have consequences: "There will be sacrifices to make in order to challenge systems of oppression and I know that I still don't realize the extent to which I would have to sacrifice in order to have equity."

Seth. Seth wrote in his journal about the ways in which these practices feel risky, "I connected with the feeling of risk and discomfort of teaching in this way." He continued, connecting to other things that he has learned through teaching, "Yet, also knowing from my own experiences that these really uncomfortable moments are the opportunities for deep learning." He concluded with a guess at the place from which this feeling arose: "I could sense the risk being connected to my identity."

David. David was the most certain of the safety with which he can take risks in his work. In his journal he wrote about the safety he had within his career to take risks: "Many of the risks I have taken are right in bell hook's pedagogical playbook. And I get away with these risks, most likely, because of my gender, class, education, and good looks [he inserted a smiley emoji after this]."

In our second interview, David spoke about this ability to take risks, at least in part, being connected to his role as a faculty member. He said, "I feel gratitude for my teaching/faculty role because that is a place where I can make instant changes. For example if I am reading bell hooks and seeing how important it is to make sure every voice is heard." He spoke about there being a different process in his administrative work, saying, "It might take a full year to change like how do we divert our workshops or 
how we work with our partners in housing or something like that." He still was certain of his ability to take these risks, which also may relate to his senior level administrative role. He continued to reflect on his abilities given his position later in the same interview: "I can put chairs in a circle. I get to spend on topics or chuck half of my lecture because there is a question about the first part of the lecture." He reiterated that as a student affairs professional that experience is very different, outlining his thought process in some reflective questions: "Do I commit funds and resources to make this workshop happen or how do I support the team putting something on?"

\section{Synthesis}

Participants in this study were often challenged by the ideas of Teaching to Transgress, and they reacted to those challenges in a variety of ways. Some were able to use reflection to develop learning and new ideas from the challenges presented, while others expressed a difficulty incorporating the ideas they found challenging into their practices. The majority of the participants also spoke to the ways in which many of the challenges offered in Teaching to Transgress involved taking some sort of risk on their part. While many expressed fear about the consequences of taking these risks, others believed their positions (both identity and organizational) offered them a degree of safety to take these risks that might not be afforded to others with different positions. The challenges and risks named offer an interesting counterpoint to the excitement experienced around the connections the participants felt while reading Teaching to Transgress. This can ultimately be helpful in contextualizing findings on how the participants believed an environment for other student affairs professionals to experience the reflection and development could be constructed. The next section will present 
findings connected to that theme.

\section{Offering a Structured Environment for Reflection and Development}

One dimension of this study was an inquiry to understand if there could be any application of the ideas of transgressive teaching to the work of student affairs professionals. To that end each of the participants were asked, at the end of the final interview, if they believed that this experience would be helpful to other student affairs professionals. Some participants also offered other reflections that addressed this question at other parts of the process as well. Ultimately, the findings focused on the experience being a helpful one and one that would benefit from a structured, intentional space where reflection and discussion were also a part of the experience.

\section{Ernie}

During our final interview, when I asked Ernie about whether he believed this experience would be helpful for other student affairs professionals, he said, "Absolutely, yeah, any time you can get other people's point of view and their work with the clarity bell hooks' did." He continued, speaking about the ways in which the experience could be adapted into a professional development opportunity for a staff, a department, or a division, saying, "I would probably pull out segments and you know provide them as part of course pack rather than the whole reading." He continued, "You probably pull out like six good readings out of there and make it more concise." He went on to describe the a section on passion in Teaching to Transgress that he believed would be most helpful within a department or a division of student affairs to generate excitement and reconnect to the mission and values of the department or division. 


\section{Raymond}

Raymond spoke about the value of the experience in a similar way, saying, "Social justice and inclusion are highlighted in our field often so to be knowledgeable in our field, it's helpful to be aware of those issues and have a broader understanding of those issues." He continued, expressing that the experience could be helpful to people across a variety of levels of familiarity with social justice and inclusion in higher education, "It covers a topic that is important, for us to be effective as a student affairs practitioners." He continued, saying, "It's providing potentially a different perception and new information people might not already have." He also noted while this would not be a book that could completely replace other readings within a student affairs graduate program, it could offer an additional and more nuanced approach to much of what is core to the work of this field.

\section{Ronald}

Ronald shared similar thoughts on the helpfulness of this experience, saying "Absolutely, I think there are lots of areas where this is applicable to the work that others do, student affairs professionals are doing." He continued, connecting the experience to the teaching that goes on in a variety of spaces:

I think whether folks are in the classroom or not, at an institution of higher learning there's sort of a notion that there's always going to be a classroom existing in a lot of different ways and how we show up, how we participate with the learning with the students that we interact with is always going to be informed by our identities.

He also noted, based on his experience reading about half of Teaching to Transgress, 
"This book allows for a level of reflection but also illumination around the importance of continued self-work and community in the practice." He continued, sharing how he believed the experience could be helpful not just at the individual level but also at the organizational level, saying that Teaching to Transgress could help in "breaking through the power dynamics in ways that power shows up," and this could lead to individuals across a variety of identities to have a very different experience within their work environments.

\section{Terrance}

When I asked Terrance, during our second interview, if he believed this experience had impacted the way he thinks about being a student affairs professional, he said, "It gives me hope for the future." During our final interview he returned to this idea. When I asked him if he believed this experience would be helpful for other student affairs professionals, he spoke about how he had already begun to refer other to the experience, saying to them, "This is a book you need to read. I'd love to have a discussion with you, talk to you about it." Terrance continued, saying that it would be specifically important for White, heterosexual men in student affairs to read Teaching to Transgress, "Honestly, I think White men who read this book and can promote it, I think can go a long way. We really need to be reading this book." He concluded by saying, "I think this should be a required text book in grad programs for student affairs."

\section{Fred}

During our second interview, after he had recently finished reading Teaching to Transgress, Fred said the book "definitely feels like it could be a handbook for going into this profession or continue in this profession." He continued, "Teaching to Transgress as 
an instruction manual would tell me [to] really think about inclusivity when designing programs." He made a connection to an important part of his identity as a first generation college student and to the way he functions in his roles in student affairs: "Even I'm guilty of sometimes just assuming that everyone knows what I mean because I have been on a college campus now for 10 years." He continued, saying that this experience had helped him to be "cognizant of you know who is my audience and who am I trying to reach."

Later in that interview, Fred said, "I think I'm going to say it's a call to action.” He went on, saying, "We've really been, I hope, well prepared and trained to know that student affairs is more than just giving what I mentioned earlier, providing a service," but that often it feels as though "people have wavered or wondered from that, just because of the nature of our work." He concluded, saying, "This can be the reminder that in my connection with students I'm playing that role."

During our final interview, Fred responded to the direct question of if he believed this would be helpful by saying, "Short answer: 'Yes."' He expressed some hesitation with just that answer, and after a moment of thought he said, "Long answer, I think it could use in a way that you've done for me which is provide a little bit of a framework." He continued, "If a student affairs professional read that and then had dialogues or conversations with their teams and had somebody who facilitated the connections between your identity and Teaching to Transgress, I think that's the winning formula."

\section{Seth}

Seth offered a similar perspective on the utility of this experience. He said, "I think it would be helpful," while adding the caveat that "just giving someone a book and 
tell them to read it, it's fine for the research study. [That] is kind of the minimal ways for it to settle and take impact." He continued, describing the need for a structure to assist in making the connections rather than assuming that people will all make the connection, saying, "Some support in making sense of the material and looking for the connection, it's not directly related or written for student affairs people."

\section{David}

David shared a similar thought, that a structured way for people to discuss the book and make sense of the experience would be a helpful part of the experience. When asked, he said, "I think it would, particularly in small groups or the great luxury you provided me is I knew I had to check in with you and reflect so it helps me to stay on more of a schedule." He continued, "Yes, provided that it was in some sort of reading group or facilitated by someone. I could do a lot more meaning and reflection to it.” David also said this book might not immediately call to people in student affairs, and particularly to White, heterosexual men in student affairs, saying, "I would say that the Teaching to Transgress especially for the majoritarian dude like me is, not until you enlighten me to it, it was not on my short list of things to read." He continued, describing the benefits of it even if it was not something he was immediately excited to experience, "I think that there's definitely a broccoli aspect to bell hook's work. It's not it's not a delicious fast food."

\section{Synthesis}

Most of the participants in this study spoke to the ways in which they believed this experience would be helpful for other student affairs professionals. Of those who did speak to that theme, most said that simply reading the book would not be sufficient by 
itself, but that a process like the one this study offered, to reflect and discuss and dig deeper with another person, would be helpful in making connections between the theory and the practice. These findings only take on an importance when understood in connection to the other groupings of findings in this chapter, because each relates to the ways in which participants have experienced reading Teaching to Transgress and making sense of the question of whether it can be connected to the work of student affairs professionals.

\section{Summary}

This chapter shared findings related to the first research question of this study, which sought to understand the possible connections participants made between transgressive teaching and their work in student affairs. The findings were shared in themes. The first theme around which the findings coalesced was reflection and connection, where in the participants spoke about the ways in which their reflections throughout the experience of reading Teaching to Transgress helped them to see connections between the experiences described by hooks (1994) and their own work as a student affairs professional. They also spoke about challenges, with a sub-theme of risks, speaking to the ways in which the experience challenged the participants to think differently about their experiences, how they felt a desire to resist some of what hooks offers, and the risks associated with this potential new approach to their work as student affairs professionals. Finally, the participants spoke to the ways in which they saw future interactions with Teaching to Transgress being helpful to other student affairs professionals within the context of a structured environment for reflection and development. The next chapter will report findings on the second research question that 
guided this study, whether the experience of reading Teaching to Transgress offered participants an opportunity to connect to an identity as an educator. 


\section{CHAPTER SIX: FINDINGS ON IDENTITY}

The research questions of this study, as well as its design, placed a large focus on the social identities of the participants and how those identities shaped the ways participants engaged in their work as student affairs professionals. Given this focus, it was also important that findings related to those identities were considered. This chapter will focus on the different ways in which a variety of the participants' identities were or were not salient for them throughout their experience of reading Teaching to Transgress. More specifically, this chapter will present findings in three categories: the salience of identities, in which the identities that were and were not salient for the participants through the process will be reported; current events, which will present the current events that took place over the course of the study and how those events impacted the experiences of the participants and the salience of their social identities; and identity as a teacher, which speaks to the second of this study's research questions on how this experience may impact student affairs professionals' identity as a teacher.

\section{Salience of Identities}

Over the course of this study, a variety of identities held by each of the participants came into and out of salience. Some of the identities that were salient for participants at the beginning of the study, before they began to read Teaching to Transgress, continued to be salient for them throughout the experience and their less salient identities also remained not salient. Mainly, these were identities of Whiteness and maleness. Other identities, ones which were not salient at the start of this study became more so. Specifically for Ernie, Jerome, Raymond, and Terrance, sexuality became a much more salient identity, although Terrance also spoke to making the choice to put that 
aside to focus on another identity that had come to greater salience for him: his maleness. This chapter will discuss the ways in which participants spoke to the salience and lack of salience of a variety of their social identities throughout the process of reading Teaching to Transgress.

\section{Ernie}

Ernie began our initial interview by talking about how he did not feel particularly connected to his White identity, feeling as though he did not have any sense of cultural grounding to being White. He did speak to feeling a much stronger connection to his identity as a Christian, a first generation college student, and a person who grew up lowincome. He also spoke about not feeling as though he could not show up with any part of himself in his work place or in his relationships with others.

When he began reading Teaching to Transgress, Ernie wrote, "I have bookmarked several pages to come back to as she uses examples, analogies, and quotes from other sources that I want to dive into." He continued, noting the ways in which parts of his personality are also connected to his White identity, "I have such a loud persona in meetings that I have often witnessed my own White privilege appear in meetings where I feel comfortable on topics I have no experience with." He connected this to another, more broad behavior that he feels is connected to his privileged identities: "I also am guilty of asking others to share in an environment where I have the authority and wonder to myself if forcing those responses is creating animosity or a hesitance to continue collaborating." Still, throughout the experience of reading the book, he found it difficult to always connect with the identities on which this study focused. He wrote, "I fall into my identity as a Christian more easily than that of a White, heterosexual, male." 
After finishing the book, however, Ernie was much more connected to his own sexuality. He spoke about the ways in which a chapter on "Eros" spoke deeply to some of his own experiences: "I used to work in the recreation center, and I used to get 18-yearold females come in sports bras and yoga pants to go work out." He continued, reflecting on the ways in which the nature of student affairs work means that different relationships can develop between professionals and students, "We end up working alongside with students for like eight hours rather than one hour classroom sessions, so I get to know them differently than you would as a faculty member." Ernie did not, however, speak to the other parts of his identities during this interview.

However, during our final interview, after more reflection, he seemed to become more aware of these identities. When I asked him about any identities that were salient for him in his work, he said, "probably my Whiteness, not probably, definitely." $\mathrm{He}$ continued, telling a story about groups of students with whom he works and feels a strong connection, "They all complain about how White the university is and the lack of diversity and they share it with me as though I am one of them [a peer to the students]." I asked if he ever addressed this with the students, and he told me about one student's reaction when he pointed out his own Whiteness to one of these students recently, and Ernie said the student's response was simply, "You're different." Ernie went on to talk about how reaching Teaching to Transgress offered him not only an experience of being more aware of parts of his identities, but also of the importance of recognizing and name their impact. He said this experience had made him "aware that I need to address it and make sure if it's happening subconsciously that they are aware of my race and identities then I should just bring it out rather than minimize it, I'm definitely a minimizer." 


\section{Fred}

As discussed when introducing Fred, in his pre-interview he spoke about his Whiteness, his male identity, his heterosexual identity, and his identity as a first generation college student as being very salient to him in his work. His identity as an atheist was only salient for him some times, usually when events on campus focused specifically on religion or spirituality, and he was working to understand the ways in which his title and education interact with his own perception of his social class. When he began to read Teaching to Transgress, Fred immediately began to journal about the ways in which identity was part of how he was making sense of the experience. He wrote about how the book chapters "reaffirm a long held belief that folks with these privilegesWhite, heterosexual, and male identities - cannot be color blind nor can they sit idly by while people of color fight for racial and social justice." He continued, "We must be active change agents. We must acknowledge our power and privilege, consciously work against oppression, and use our privilege(s) whenever possible to do good and foster change in our communities." Fred continued to reflect on the ways in which his identities have shaped his own educational experience, writing in one of his later journals about how he does not ever feel invisible in any space, "I almost always feel present and that my true authentic self is available and accessible to those around me. I rarely feel afraid, alone, or ostracized."

In our post-interview, Fred spoke more about how his identities can impact the ways in which students interact with him. He said, in speaking about his role as a conduct administrator and what it might mean to practice transgressive teaching in his work, "I think there could have been a lot more opportunities for me to actually be critical of my 
intentional or unintentional impact on others." He continued, reflecting on whether those actions were related to a fear or an ignorance, saying, "Would it or could have been because I didn't want to know it, I didn't want to be open and vulnerable to hearing some critical thought on how my Whiteness, how my maleness, you know straightness could be intimidating?" When I asked him more specifically about how the book might have brought some of these thoughts up, he spoke both about how two of his identities came up in tandem to one another: "My race but my race has been White but also oddly enough that seemed — what's the word I want to use here —it would conflict occasionally with my being son of immigrants and a first-generation college students." He continued, speaking about the ways in which he connected to hooks' description of the ways in which often White women were able to connect more deeply with Black women if they shared experiences around class, saying, "I know the privileges of being White because I experience them and benefit from them." He continued:

I myself had experienced it in a different way, not being from a family who had parents who had gone to school, college specifically, coming from a more middle class family with a single income from my father and my mother stayed at home. Fred spoke about identities that are important to him, but did not come to salience during the book, saying, "My sexual orientation, I don't really feel that was salient in terms of being part of bell hook's focus" and "being an atheist and not having like a religious affiliation. I don't recall that it came up either."

During our final interview Fred also spoke about similar identities being salient to him through the experience. He said, "I think last time I mentioned that my Whiteness has been pretty much the most salient identity for a while now." He also said, "Maleness 
or biological sex or both gender and the sex have definitely right, right underneath being White." He spoke about why he believed those identities stayed most in his awareness, because those identities, he felt, were "extremely important to recognize and challenge or if not check could be very dangerous." He also spoke about what was not salient for him, saying, "I don't talk about you know religion or faith much." He added another identity, about which he had not spoken before, but that he was now aware did not come to salience for him in this process, saying, "I don't think about ability much, or the fact I don't have hopefully known disabilities or temporary disabilities."

\section{Terrance}

Terrance also spoke about the ways in which he spent a lot of time focusing on understanding his privileged identities in his initial interview. He referred to his religious identity, specifically the way in which he identified as both fully Christian and fully Jewish. Terrance spoke about the ways in which while being a father was very important to him, it did not come to salience for him in his student affairs professional role. Like Fred, Terrance wrote in his journal about the ways in which the experience of reading Teaching to Transgress helped him understand the ways in which his identities showed up in his work, writing, "I need to be aware that my words and questions will be met 'suspiciously or potentially be seen as an act of appropriation to enhance my own opportunistic agenda"” (hooks 1994, p. 131). He also spoke of the ways in which his identities offered him opportunities to not be viewed with this suspicion, saying, "The idea that the person who is most powerful has the privilege of denying their body was a new concept." He was able to make sense of the idea though, concluding, "As a man, I 
can get away with a lot when it comes to my body - I will not be judged as harshly in trainings, in the classroom, in one on ones - as female or Black colleagues would." In our post-interview, Terrance reflected on a realization he had in processing the experience of reading the book, saying:

I think the area where I need the most growth is my gender identity a man, looking at my lack of awareness around how my male identity can impact my relationship with others, so I think for me reading this the feminist stuff really was you know more challenging is not the right word, most engaging for me in terms of looking at new ideas and new concepts about how my gender operates on a daily basis.

He continued, affirming that during the experience "probably one of the most present, salient was my male identity." He also spoke of how this will be a part of how he approaches the issues he sees on his campus moving forward, saying, "Honestly, where my, where our, biggest need is around issues of race. And so, how masculinity plays in that conversation something that I have to be much more aware of" and also offered, "There's work to be done in every area but in terms of my journey I think my masculine journey is probably the one where not as far as long as I would like to be."

Terrance spoke about the identities that did not come into salience for him during the process, specifically speaking about his sexuality: "I think there was a couple of examples in the classrooms when she talked about this sexuality and the sensuality of classroom that they came in that chapter." He continued, "That's a bigger challenge for me as a man to fully engaged in sexuality in a classroom thinking about what that would mean for me. I think for me that made me a little uncomfortable." He also offered there 
were other identities that did not become salient for him during the process saying, “Obviously religion, you know there wasn't a whole lot, there was some on religion, but I think for me my Jewish identity really wasn't salient during the discussion, and ableism." He reiterated, "I think for me really there though the big ones were being White, being male, or the two big ones with the other ones kind of minimal engagement."

During our final interview, Terrance spoke similarly about the identities most salient to his experience. He said, "For me, skin color has been in the forefront of this book," and "My identity as a man and wading through male privilege has been more in the forefront, more salient, more deeper because for me I didn't ask myself a lot of questions about what role does my male identity play." He continued that he reflected on times in which his male identity was impacting his relationships, saying that he was not interrogating "how would a women take what I'm saying because it's coming from a man, as opposed to I took a very color blind mentality, not color blind, but gender blind mentality, before the book." He offered, similarly to Fred, that an identity he held helped him to connect with the experiences of marginalized people, saying, "I would say my Jewish identity to another degree has become more salient because it's the only real identity that I can connect with I think other people from marginalized identities because of that experience." During the final part of our last interview, Terrance said he still hadn't put much thought into his sexuality and the experience with Teaching to Transgress. He said, "I think that is how I offer that my sexuality is one that may become kind of I've put aside to kind of focus on masculinity and my Whiteness and being Jewish." 


\section{Raymond}

Raymond began this process feeling connected most to his identity at a father and as a Christian, and his Christian identity being salient was in some ways connected to how often he hears people making light of that identity and its symbols. He also spoke about the ways in which his identities interact in ways that my create some dissonance, like his graduate level degrees and mid-level university employment while also qualifying for low-income government programs at times and being a sole earner for his family. Raymond also spoke about a level of awareness of his identity as a mid-level professional, often feeling it impacted how people in entry-level and upper-level positions engaged with him.

Like Terrance and Fred, Raymond wrote in his journal that his experience reading Teaching to Transgress gave him insight into how others might perceive based on his identities and his role. He wrote, "I think it provides me a little better understanding about the potential for women of color to not trust me (whether students or colleagues), though this is not news to me." He also spoke about a clear connection to class from the readings and how it is often glossed over in his work: "Class isn't often addressed and when it is, it is often in superficial ways. For example, we aren't offering options other than paying a fine in sanctioning." He continued, "I think that the conduct system is modeled on justice systems put in place by the middle and upper classes. I think that the system is one most are used to."

Like Ernie, Raymond, too, connected to the chapter on "Eros," writing, "hooks talks about Eros covering passion beyond the physical, but I actually believe that one of the things we rarely confront in our field is the physical attraction that is likely to come 
with the territory." He continued, "It is not surprising that people in this field would be physically attracted to students. But we don't talk about this. Or when we do it is about sexual harassment and liability issues." Raymond also wrote about the ways in which class was present for him in reading: "Class is one area where I have, at times, possessed a targeted identity. However, given my White, straight, male status, it is difficult for me to accept or identify as being oppressed or targeted due to this status." He continued, expressing understanding and empathy, "I also understand the frustration that those from targeted backgrounds in relation to class experience when they are told they possess privilege in relation to their other identities."

During our second interview, Raymond spoke about the ways in which being aware of his White and male identities can help in the work that he does, saying that being able to "acknowledge and validate some concerns and issues that they bring forward and not have to fall back to a position of defensiveness and which I think is often where people who are White and male will go" was helpful. He continued, reflecting on the ways in which students will perceive him as a White man may impact "the student's interactions with me and how willing they are to share and how much they believe that I am willing to listen to them because they have no idea what kind of background I have." In this interview Raymond spoke about how these two identities, being White and male, were some of the most present for him in his reading. He said, "I would say predominantly my race being White gender being male. But I mean there were some, some issues related to um my identity being heterosexual, but I think those were very limited." He continued, speaking of how class also was present, "A little bit more related to class issues, but I think that is also related to my own research on class." He concluded 
by speaking about how in reading Teaching to Transgress, "I felt like her focus was on issues of race and gender so I think that was salient."

During our final interview Raymond acknowledged that his shifts in salience are, for him, connected to his privileged identities: "I think that for me salience tends to shift and I think it is that largely due to most of my social identities are dominate identities, so White male heterosexual Christian abled bodied." He continued, acknowledging the ways in which salience is connected to differences in identity with others, "What tends to be most salient when I recognize either a difference between myself and a student."

Raymond concluded by saying that his religion, while important to him, still rarely comes into salience in his work, saying, "Religion very rarely comes up. I consider myself Christian. I would not say I'm very out or evangelical Christian so that would not be something that is very obvious or clear to anyone who didn't know me."

\section{Jerome}

Jerome spoke in our pre-interview about how his first exposure to social justice was in high school and that he began to be aware of privilege and his heterosexual identity then. His White identity has been salient since he was in college, and he spoke about the ways in which he experienced a desire, during that time, to distance himself from other White people by calling them out on their racism. After teaching and returning to school, he was able to reflect more on how these identities impacted much of how he engaged in activism and with other people in his life.

While reading Teaching to Transgress, Jerome journaled initially about his sexuality coming into salience: "I think this is one of the first times that I have directly related the content to my sexual orientation." He also spoke about the ways in which his 
role requires that he be aware of many of his privileged identities, speaking about being a "White man in a role that is meant to promote diversity, inclusion, and social justice. I carry a lot of privilege with me into the work and dismantling colonialism from my teaching and facilitation is radically important." He also reflected on his own educational experience and how it is shaped in part by his own White identity:

One thing that I find when reading is the challenge to my White lens. I have experienced this often when examining my own education side-by-side with critical narratives. When bell hooks discusses her experience with desegregation I am again brought back into this space of feeling betrayed by my education.

Jerome also connected a passage in Teaching to Transgress to his own experience as an education major and his male identity, writing, "I remembering having a male professor in college tell our class that men had to be very conscious of their behavior because people are weary of male teachers." He continued, in related the ways in which he distances himself from his body and identities in a way similar to Terrance, "I am very hesitant to touch my college-age students. I don't like the distance I create because I am so hyper aware of what assumptions people may have based on being touched by me or seeing me touch someone.”

In our second interview, Jerome returned to the distancing of mind and body as it related to his identities, saying, "Some of the things that I took across were reflections on how you on, the privilege of being able to detangle your identities is very much more lodged with Whiteness and maleness.” Jerome continued, “As White, straight man I completely detangle myself from my identities and will not seem as though I have an agenda when I want to talk about race or if I want to talk about gender sexual 
orientation." He spoke more about this, saying "I think in many ways privilege seeks to normalize and become a non-identity, so Whiteness often seems to be just normal not a real race not an identity." In speaking about class, Jerome reflected on his town growing up, saying, "I am constantly am wrestling with how to identify when it comes to my social economic status and I think that came up several times during the book." He continued, recalling the area in which he grew up, "I grew up in a community that was very wealthy and it was a very weird kind of dynamic because we moved into this community and my parents got this house and wealth kind of build up around us." Jerome continued, “Looking back on it, I wasn't working class. I wasn't impoverished. You know, my parents were able to help me a little bit in college and things like that. We had enough. We always had enough.”

Jerome expressed a reflection similar to one offered by Raymond, how White, straight men are often not even spoke of when talking about identity. He said, "We don't expect much from White, straight men because we are you know we don't have a whole lot. We don't have rights that we still need to gain or anything like that." He continued, “So because we are less vulnerable, we don't expect a whole lot from White, straight men when it comes to this work." Jerome also mentioned that religion continued to be salient for him, attributing much of that experience to his experiences in high school. He said, "You know, identify as an atheist in in high school growing up in a very right wing Christian conservative area in this country, you kind of have people to try to convert me and things like that." Because Jerome did not complete the final interview, there was not an opportunity to revisit with him and to explore the ways in which reading Teaching to Transgress offered him more opportunities to reflect on these identities. 


\section{Seth}

Seth, during our first interview, spoke about the ways in which his position and the privileges of that position were salient for him in addition to his Whiteness, his heterosexuality, and his maleness. He said, like Raymond, he was particularly aware of those things when they were different than the student or the staff member with whom he was interacting in the moment. He also spoke about the salience of his identity as a father, particularly as someone raising three sons.

While reading Teaching to Transgress, Seth connected his experience to the ways in which privileged identities often do not have to consider how other aspects of identity also influence experiences. He wrote, "The privilege I hold is that I can, at some level, chose to not pay attention to the intersecting dynamics." He continued, connecting the experience to reading Teaching to Transgress, "I found the review of feminist scholarship and dialogue helpful in modeling how I might continually engage in working with intersecting identities and collusion in upholding traditional pedagogies."

This aspect of the experience stayed with Seth. When we spoke after he finished the book, he returned to this idea and connected it to the chapter on mind-body separation. He spoke about how that experience "was recognizing that education is both about advancing knowledge and understanding insights but not doing it that is not disconnecting personal history and merit and experience that's often represented visually by our bodies." Seth continued, reflecting more on a chapter in which hooks dialogues with a White identified colleague, reflecting on "how his White body and brings a sense of power into the classroom and it's that impacts students and their experience and their learning and his need to be aware of that in the education process." Seth also discussed 
the ways in which he needed to be aware of how his voice as a White heterosexual male with a Ph.D. was taken up in these spaces even when he challenges systems of dominance around race, gender, or sexual orientation. He said, "The shadow side, if I'm sort of just advancing these things, but not naming the fact that I am able to advance it because of my identity, doesn't really address the whole issue of oppression within the whole system." He continued, reflecting on how that realization also helps him understand more about his identities, "It does get me in touch how easy it is as a White, heterosexual male, cis-male, how easy it is for me to neglect personal narratives and part of the underlined as a binary it's shared in some way.

Seth spoke more about how his privileged identities, particularly his experience as a White, heterosexual, male also interacted with one another in shaping his experience. He said, "Those identities would be very aligned with the dominant narrative and therefore that is just a narrative that is more pervasive it sort of forget it sometimes I guess just part of the way things are." He continued, connecting this to what he sees as the purpose of his work and education, "The educational process, needs to create space not only really just name my narrative but then for others to have that space to sort of bring in their narrative and experience into it."

Seth provided another insight into the ways in which the dialogue between hooks and her colleague highlighted for him the interaction of his identities: "The intersection really was quite clear so it's hard for me to think about the dialogue of bell hooks and the professor has as a dialogue between a male and female and as a black and White person, it's a black woman and White male." In this same part of the interview, Seth spoke to being aware of how at least one of his identities was not very salient for him: "I don't 
know I was really connecting with my sexuality or sexual orientation at the time in reading it. I don't felt that triggered at all." He added, after having that realization, that there were actually a few individual identities that were salient for him, saying, "You know, so I think, I can recall that at times my middle-class identity was present." He also spoke to his identity as a father of three boys and the choices he makes about their lives staying present for him, saying, "Over the last six months, short of noticing the environment that we're putting them in and who they are in contact with, what types of identities they don't see in their classroom and on their soccer team.” During our final interview, Seth spoke much less about which of his identities were feeling more salient to him. The one that he did mention, his White identity, he connected closely with some of the current events in the United States at the time rather than connecting that salience to the experience of reading Teaching to Transgress.

\section{David}

David, at the beginning of this study, spoke about his identity as being White, heterosexual, and male as all being salient for him. He spoke about his particular awareness of his heterosexual identity when deciding how to decorate his office and being unsure how non-heterosexual students might experience seeing pictures of his partner and family. He also was very strongly connected to his identity as an atheist or a humanist and also spoke to keeping that out of a lot of his interactions with students for fear of its impact on their potentially already targeted experiences.

As he began reading Teaching to Transgress, David wrote in his journal, "hooks reminded me of my privilege." He continued, reflecting on what his role and its connection to his identities, "hooks got me thinking about my role as a leader in a 
Hispanic Serving Institution.” He also wrote in his journal about his atheist identity, specifically saying, "My freedom from religion is attributable to my privilege. Because I have a warm, safe bed and access to books and smart people, I don't need to have imaginary friends." He continued, writing, "In my teaching and administrator roles, I feel a duty to obfuscate my godless philosophy. I trot it out now and then but with a qualifier that I respect a wide variety of worldviews."

During our second interview, David expanded on much of what he wrote in his journal. He spoke about the experience of reading Teaching to Transgress as if he were watching himself from outside of his body. He said he was becoming more mindful of how privilege influences the ways in engaged with other people, saying, "Sometimes I will make a comment in a group or say something somewhat carelessly and surprised at the reaction and then realize, wow, this group is hearing me as, how they perceived my identity."

Like many of the other participants in this study, David mentioned his sexuality was not particularly salient for him throughout his read: “I don't think I thought a lot about my heterosexuality during the book um at least I don't remember invoking my gender expression and identity." David spoke about his atheist identity being present in the same way that Raymond spoke about class, saying, "I identify as an atheist, fairly strong atheist, and sometimes, you known sometimes I feel that my only marginal identity is my denial of a higher power." He continued, "I think there were a couple times during the book where I was thinking about challenges of different populations and [atheism was] the only way I can empathize." 
During our final interview, David returned to the ways in which he has continued to develop an awareness of the ways in which his identities can interact with how his words and actions are perceived by others. He spoke about giving a lecture to a group of graduate students studying to be student affairs professionals, and the topic of the lecture was about rules and policies within the field. He reflected that during his lecture, "I became very aware of my identity has an administrator and then along with that my identity as middle-aged, White guy, heterosexual, and administrator and started to lose my momentum." He also spoke about the ways in which while he is very aware of some of his identities, that he may also still be missing other aspects and not understanding how they are also a part of his experiences. He said towards the end of our last interview, "I just feel so much of my identity, the personal aspects and how I see myself feel like it's on my sleeve that I can't think of." He seemed certain that they were there, but that he had not yet had a chance to bring them into salience for reflection.

\section{Ronald}

Ronald began this experience with his identity as a White male, and a connection to what that means as a student affairs professional, as very salient. His class also was something about which he was mindful, acknowledging that his class experience also interacts with his ability in that he does have a health condition that impacts his life but his class means that he can afford the care necessary to not have to worry about those impacts on a daily basis. Ronald also has a particular experience of his heterosexual identity being salient, noting that most people assumed him to be gay because of the amount of LGBTQ affirming signage and decorations he had in his office. 
As he began to read Teaching to Transgress, Ronald wrote in his journal about the need to manage the difficulty of being White, heterosexual, and male while engaging students in difficult explorations of identity and systems of oppression. He wrote, "All of this is connected to my privileged identities and the White supremacy that surrounds me." He also reflected on his desire to be liked by students and the contradiction that can arise from those experiences: "I can see these things at odds, as I would like to push students to explore their identities, but also want them to trust me and come to me as someone they enjoy."

Ronald was not able to complete reading Teaching to Transgress within the timeframe of this study, and so he did not have the chance to reflect more on his experiences and identities through the rest of the process. However, when we did a final interview after he had stopped reading, he still offered some reflection on the ways in which his identities were brought to salience through the reading experience. He spoke specifically about his maleness, saying, "Some of pieces around gender step out a lot and thinking about the ways hooks talks about feminism and critiques of feminism and what that looks like as a man." He concluded by articulating some reflective questions, to continue to try to understand this more deeply, "What does that mean for me to be a man in the field and my masculinity when I perform and my masculinity impact my work?"

\section{Synthesis}

Ultimately, each of the participants was very aware of their White and male identities throughout this experience. Sexuality was less salient for the majority of the participants. Ernie, Raymond, Jerome, and Terrance spoke to it emerging for at least a portion of their experience. Terrance spoke to making the choice to focus less on that 
identity; whereas Raymond and Ernie felt there needed to be more attention to the impact of that identity on student affairs professionals' work. It is also important to note that the salience of identities can also be impacted by events occurring in other parts of the participants' lives. The next section will address how a host of current events also played a role in bringing some identities to salience.

\section{Current Events}

As participants were reading Teaching to Transgress, many connected their experiences to events taken place around the United States and how those events often provided clear examples for the participants of dynamics hooks describes playing out, opportunities to reflect on how their identities shape their experiences in the world, and ways to engage both of the previously named experiences with others. Many of these events offered context for the participants, and for many of the participants these events also brought different aspects of their identities into greater salience. It is important to acknowledge that the occurrence of reading this book did not take place in a vacuum and that the salience of identities experienced by the participants can be influenced by other factors as well. Over the course of the study there were a number of national events in the United States, some were regular occurrences in that they happen on a regular schedule, while others were events that were shocking to many of the participants. One of the participants, Seth, actually spoke to this directly, saying, "It's never isolated so there are other things that are happening in my life. You and I should, this outside context where we've had some incidents going on with students that have helped me rethink [some things]." As they were reading and journaling, or as we were conducting interviews about 
their experiences with the reading, often it was in the days and weeks around those events.

The United States presidential election of 2016 was the most spoken about of the current events impacting the experiences of the participants. It was an example to which different participants were drawn at different times, and the connections that they made to their experiences were very different as well. Still, it was a common experience that seemed to continually come to the surface for participants throughout the process, and also one to which many found personal connections and connections to their work as student affairs professionals. There were also references to the Pulse nightclub shooting, Mizzou concerned student 1950 protests, and the killing of Philando Castile and Alton Stirling. While these events were very different, all of them were spoke about as it related to bringing certain identities, most often Whiteness, into salience for the participants.

\section{Terrance}

Terrance did not bring up the election until our last interview together, about five weeks after he had finished Teaching to Transgress and 10 days after the presidential election. In summarizing his experience reading the book and what aspects of it had stayed with him, he likened it to a new pair of glasses. He also described the experience as a challenge to think more critically about his environment and his meaning making around events. He then filtered these experiences through the example of the election. $\mathrm{He}$ began by saying, "Before the election I wanted to have conversations with people about what's our game plan for post-election. Like there are three outcomes here and we need to be prepared." He did not get a lot of traction for those ideas, saying, "A lot of people were around me were like, 'You don't need to prepare. Once the election happens, it's 
over." He again related to the metaphor of new glasses and how the critical thinking he took away from the experience helped him to be differently prepared to engage members of his community. He said he was now more "willing to critique and criticize the environment and not get wrapped into what the current. Kind of questioning outside the box a little bit, I think, has helped me be more prepared and be ahead of the game." He connected specifically to the election, saying, "My staff had already processed for a week before the election. When Hilary lost we appreciated that we had game plans in place. We had programs in place because that was one of the possibilities to prepare for."

Terrance summarized the connection he made between the election, his work, and reading Teaching to Transgress: “...Basically challenging the echo chamber of higher education. A lot of my White, progressive, liberal friends, this was a reality that they had not considered, that America is really racist and misogynistic beyond their bubbles." Terrance expressed gratitude for the ways in which this experience had helped him to challenge his own echo chambers. He said, "The notion of the book is "where are my echo chambers that I live in,' 'how do I bust through those,' and 'how do I listen to people and speak to people in a manner that challenges their [comfort].'”

Terrance also spoke to other ways in which the book challenged him to engage with others in the world, and he saw those experiences as being connected to the presidential election as well. He spoke to the ways in which he felt challenged to hold multiple truths, as well as the understand how those truths can challenge structures of power, and how his identities often push him to react in defensive ways. He said, "There is something new to this, that I've learned from post reading the book our last interview, is this concept everyone is entitled to their own truths." He continued, recognizing there 
were ways in which that could be used to uphold systems of oppression, "When marginalized colleagues speak their truth, myself and other people say they are entitled to their truths but I'm also entitled to my truths and I don't have to accept it. I think you see that in the elections." He connected this idea back to Teaching to Transgress, however, saying, "Whereas [reading the book] leads [to an] ability of living and seeing their truths and where we're come to this post-truth world we live in." He continued, reiterating the ways in which the world in which we are existing emphasizes subjectivity of truth, and in a way that makes it much easier to devalue the experiences of those different from one's self.

Ernie

Ernie spoke about the election in our second interview. Ernie's connection to the election had internal and external elements to it. There were some feelings he was noticing within himself, and he felt those were connected to his identities. He was noticing a dynamic within his staff. Internally, he described feeling guilt about the ways in which the election of Donald Trump would not directly threaten much of his way of life: "I have a numerous friends that this presidential election touched a nerve because [their rights are being threatened] and so being straight, heterosexual, White male, I feel as though I have this guilt that I did something wrong." He continued on to describe the ways in which he saw the outcome of the election impacting other staff members in his office. He spoke about the dynamics of their weekly staff meeting, especially for two recently hired Black staff members, wondering "how are they feeling supported being Black or a person of color at our university with this ongoing narrative of Trump supporters vs. Hillary Clinton supporters." He went on to make the connection between 
his awareness of these experiences and his experience reading Teaching to Transgress, reflecting on the ways it offered him an opportunity to reflect on how people whose identities are different might be experiencing these events differently. He said the experience "helped raise my level of awareness that might be the first thing on their mind when they first enter a room, being a person of color on a campus where there are Trump signs everywhere." He continued, reflecting on how he employs this awareness, "I tried to go into it more open-ended [being aware of] what's everyone dealing with and to see if there's any positive or negative that come from that and go from there."

Ernie revisited this reflection on his experience reading Teaching to Transgress in our final interview, which about three weeks after the election. He spoke about how the experience of reading the book has prompted him continue to apply the ideas about which he spoke in our post-interview to meetings and spaces he shares with colleagues and students, and what realizations that was bringing to him, "I'm talking in more settings about my beliefs and that wasn't something I thought was going to come out of this election." He spoke about one way that he was putting this into action as well, saying that he is starting to approach their staff meetings as "brave spaces instead of safe spaces. I have to recognize for others to speak up, it's brave, so just saying it's a safe space where they can express their opinion doesn't necessary allow them to."

\section{Raymond}

Raymond, while reading Teaching to Transgress, found resonance in a quote from the text and shared it through his social media. About this he reflected, "I feel like it's especially relevant in the current election cycle." Later in his journals, Raymond wrote about his observations of the way others were engaging with the election on social 
media and again found resonance in hooks' writing on the ways ideas are shared and valued "Over and over, I read on social media my friends condemning the racism, sexism, ableism, heterosexism, and other issues that resulted in Trump's being elected, and imparting those concerns on everyone who voted for him." He continued, "They have essentially deemed that there is one way to be and not being in line with that makes you a bad person" and noted this was a tactic that helped to catalyze a variety of people to vote for President Trump.

Raymond spoke more to this idea during our post-interview. He felt very connected to a desire to not approach public discourse on the election in that way, but also worried about subconscious motivations for staying out of those conversations all together, he said, "Part of my rationalization behind that is that I look to myself to be a bridge that I want to help increase the understanding for folks who don't." He continued, expressing concern that if he were to "focus on taking articles about how bad things are or what people who support Trump must be like because this is what he is doing that it will limit my opportunity to be a bridge." He continued, however, that often he did not take the action of trying to be the bridge he described. He recalled a section of Teaching to Transgress in which hooks spoke directly to this, and Raymond was keenly aware of this, saying "how we've become a culture that accepts lies, and lies to ourselves, and that makes it hard to resist the sort of lies that those in power gives to us. It is just sort of pretend things are okay." This helped him to connect to his concern around rationalization, saying, "It's easy to make rationale for not taking action and I find myself falling into that at times when I should be doing more or could be doing more, but then I rationalize why that is not happening." 
Seth

“The times we are in, my Whiteness is really present to me.” Seth, like Ernie, expressed that the outcome of the Presidential election as being connected to a part of his identity that was salient for him during out last interview, about four weeks after he finished reading Teaching to Transgress. He began by reflecting on "a decade plus of really intentional effort working to manage how I exercise my Whiteness," while acknowledging he has to manage what it means to hold those identities when interacting with other people on his predominantly White campus: "It still gets lots of projections, you know, like, especially when I walk into a room as an authority figure." He spoke to the ways in which having his position and his identities met those expectations in the wake of President Trump's executive orders banning people from countries whose populations were predominantly Muslim from entering the United States: "The Whiteness kind of feels like it's available in that and it's not just about the authority and the director." He continued, "I've been feeling that, this responsibility to say something, do to something. I don't know what that is. That's been something I've really been in touch with. I want to use that Whiteness for something that is constructive."

\section{Fred}

Fred first wrote about the election in his journals. He described it as one of the first connections he made between the readings and his work: "The first connection I made, almost immediately, was between hooks' description of our society in 1994 (when her book was published) and how similarly it sounded to today, especially given this year's presidential election." He then copied a quote from Teaching to Transgress, a quote in which hooks writes about the ways in which the current environment of the time 
normalizes the difficulty and uncertainty of building community. He continued to reflect on this topic's connection to his work and to the environment of college campuses, writing, "This deeply impacts my work on college and university campuses. What's worse is that it deeply and negatively impacts students from minority, disenfranchised, and underrepresented groups.”

These thoughts stayed with Fred through the process, and were a point to which he returned in the interview after he finished reading Teaching to Transgress. He spoke with some nervousness of what this feeling could mean for the students with whom he works, while also recognizing that the discomfort he was feeling was an important reminder of the work he had ahead of him. He said, "It was unsettling because I'm thinking a lot of my reflections, you'll see, I keep wanting to say, 'This isn't connecting' or, 'It's 2017 soon.' I really don't like the fact that this sounds so relatable to today." He continued, imagining a conversation between the two of us and bell hooks about the way the world seems at the moment and how the he felt about the election of Donald Trump as President of the United States may have resembled how students, faculty, and staff of minoritized identities were and had been feeling on campuses: "This is more relevant today than ever." He continued, saying, "The college classroom and the whole university experience, regardless of institution type, should be this larger piece of putting together who we are as people and how we live in this world and are received in this world." He concluded that all of it "comes together at this point of learning and understanding and making sense of what's in front of us and we can't do that if we are not being our true authentic selves to this table." 
Fred, while journaling about connections he made between reading Teaching to Transgress and his work in student affairs, also reflected on the Pulse nightclub shooting and the impact students might have felt in its wake: "How many of our faculty and staff thought to pause their teaching and assignments for one day and ask their students, 'How are you today? How has this tragedy impacted your lives? This is how it has impacted me..." Fred connected this to the ways in which hooks described engaged pedagogy and how Fred orients his approach to work in student affairs, that both require "the ability or willingness "to teach in a manner that respects and cares for the souls of our students"" (hooks, 1994, p. 13).

Fred pondered in one of his journals the ways in which those working with students were expressing care for those students. He related a story about students taking up action around the climate on his campus at the time. Fred's campus, and many other campuses around the United States, experienced students walking out, protesting, and issues demands, which was sparked by students at the University of Missouri under the name "Concerned Student 1950." Fred reflected, asking, "How many of us in Higher Education (faculty, staff, and administrators) considered the impact on our students?" He related this back to how hooks (1994) defined engaged pedagogy as a desire to care for these students' souls and reflected on how he could express that care for the souls of his students in his work.

\section{Jerome}

Like Fred, Jerome made reference to the University of Missouri student protests in his journals. In speaking to his appreciation of hooks insistence that teaching is a political act, he framed his current work experience: "I also highlighted a section of the 
second chapter about the political nature of all teaching." He connected this to the climate at his current institution, writing, "This is an extremely prevalent ideology at my school as we have many professors ignoring content and context in an attempt to be apolitical, all the while making political decisions in avoiding certain experiences and viewpoints." Jerome also highlighted this was not behavior exclusive to the faculty. He reflected on the ways in which he has had to navigate what he sees as the responsibilities of his position while also operating within an institution that places value on this illusive or illusory neutrality: "I have been at my institution for about 8 months and been told multiple times that I am being too political or engaging in topics that are not mine to discuss because they are politically charged." This is when he offered the specific connection to the University of Missouri (referred to as "Mizzou”), writing, "I am prohibited from sending out a response letter from school stating that racism has no place here after the events at Mizzou because that would be asking for trouble or asserting that racism exists on our campus."

\section{Gene}

Gene, in the journal entry he wrote before having to stop his participation in the study, made a connection between his experience reading Teaching to Transgress and the ways in which the book pulled his identities as a White man into salience and the killing by police officers of Philando Castile and Alton Sterling. Gene wrote, "The shootings of Philando Castile and Alton Sterling occurred. These types of events make me feel guilty as a White man, and reading chapter two of this book began to stir up those feelings." Similar to the ways in which Ernie and Seth spoke about the election of Donald Trump while reading Teaching to Transgress bringing their White identity forward, Gene's 
journal spoke to the salience of an identity being connected to both the experience of reading the book and being contextualized by a current event.

\section{Synthesis}

The participants of this study all spoke to the ways in which a variety of events in the world brought some part of their identity to salience. For most of them, the various events mostly enhanced the salience of their White identity, an identity that already was rather salient. Much less often, these events also connected to identities around being a man and being a student affairs professional, and all of these events were connected to the experiences of education described in Teaching to Transgress. These events are important to note as they help to illuminate the ways in which participation in this study did not happen in a vacuum, and other influences can impact how identities came into salience over the course of this study.

\section{Identity as a Teacher}

A number of the participants in the study spoke about themselves as educators, feeling as though their role as student affairs professionals provided them an authentic claim to an identity as an educator. Many participants started this process already viewing holding this as part of their identity. There were a number of ways in which these participants' experiences of already recognized the different ways in which learning and teaching happen both in and out of the classroom on college campuses were connected.

One of the ways in which participants found themselves making connections between their experiences reading Teaching to Transgress and their conception of themselves as educators was by connecting to their own experiences in teaching classrooms or learning about teaching. Some of the participants had been elementary or 
secondary school teachers before moving to work in higher education; other participants had majored or taken course work in education as undergraduate students; and still others had taught classes at the undergraduate or graduate level.

\section{Education in Teaching}

Some of the participants in this study had taken undergraduate courses in teaching and/or had worked as teachers. Jerome worked as a teacher after graduating college. Fred held an undergraduate degree in art education and also took teaching coursework while in graduate school. Seth also held an undergraduate degree in education but decided to pursue a career in student affairs while still in college. Each of them spoke to the ways in which this experience helped to make a connection between their understanding of teaching, the concepts of transgressive teaching, and their work as a student affairs professionals.

Jerome. "I think that often it's easy to forget that, at least in my personal view, we are educators," Jerome said, reflecting on how reading Teaching to Transgress might have impacted whether or not he saw himself as a teacher. He continued, "I think it reaffirms some things and reminded me of some things but I don't think it's changed my view of what it means to be a student affairs professional." Jerome's background in teaching — his history as an elementary school teacher and as an education major — played some part in this connection. Jerome wrote in one of his journals that he recognized much of the framework of Teaching to Transgress from reading Paolo Freire's (1979) Pedagogy of the Oppressed, and this was a text and an approach to teaching with which he was familiar. 
During our first interview, when I asked Jerome about any connections he might see between ideas of transgressive teaching and the work of student affairs professionals, Jerome said, "I think student affairs professionals are educators.” He continued, offering context, "Educators are different, in the sense of the word, we are not always necessary in the classroom. We work with students, they learn through their experiences within res life, and within student affairs, through campus activities." He also offered that this meant student affairs professionals also have an understanding of historical dynamics and systems of oppression, saying, "It is important to make sure that the teaching practices that we have are not reinforcing colonial structures and structures of institutionalized racism, sexism and so forth." He also made the connection to an experience he remembers from his undergraduate years. A friend was telling Jerome a story of a class in which, while discussing race, a White woman in the class began to cry. When members of the class started to console that student, the professor, who was a Black woman, asked the class members to stop and examine why they felt compelled to comfort this person, what was informing that desire to prioritize the feelings of this White student.

Jerome reflected, during our interview, after he finished reading Teaching to Transgress, on how this dynamic played out on college campuses, in and out of the classroom: "We don't hold White people accountable for their feelings, and they push them out to people and middle of classroom space and common spaces." In his own work engaging his campus in social justice through programming, trainings, and dialogue, and especially as a White, heterosexual, man holding that position it remained important to be aware of how he lifted of the voices and embraces the emotions of the students, as well as the staff and faculty, with whom he worked. 
Jerome continued to reflect on this story's connections to his own work, especially as a professional tasked specifically with incorporating multiculturalism and social justice into the experiences of students on his campus

How you make a safe space for all if somebody is crying, how do you react to that? What if that person is a White, of color, how do you kind of manage that in a classroom environment or whatever space you are in you are and I think it's very interesting the idea of someone's emotions having so much power in a room that they can shut down a conversation whereas I've seen students like have extreme emotional connections to and be completely shut down because of the first thing people color coming from an oppressed position and talking about how was subject material relates to their personal life experience and get shut down because they're not talking about the book specifically, or they're not talking about facts, they are talking about their experience so they are completely shut down. To try to address some of the questions Jerome posed, both to the field of student affairs and also to himself as he continues to navigate his own work, Jerome came to the idea of balance and how he can use this meaningful story and these practices to inform how he creates space with students in the future. Toward the end of our interview after he finished reading Teaching to Transgress, he reflected, "I think one of the things she challenges me on is the idea of it's not either all concrete facts or all experience but this ability to find a balance between the two and honor and validate that."

Fred. "As a former education major and certified teacher, this seemed obvious to me," wrote Fred in one of his journals while reading Teaching to Transgress. Even before he started to read the book, he seemed to have a sense that his experience in education 
would be a link between these ideas and his work in student affairs. In our first interview, when asked about whether there might be a connection between the concepts of transgressive teaching and his work in student affairs, he said, "We are constantly working with students to break down barriers to reexamine parts of their life." He also expressed some anxiety about whether he was getting the ideas right or making the correct connections. Still, after thinking about what he believed the ideas to mean, he offered, "I would hope there are any kind of truth in that transgression, teaching the transgression, transgressive learning, that it's kind of reevaluating, reexamining, I hope that we are fostering that on a daily bases or being good stewards."

While reading Teaching to Transgress, Fred was struck by the way hooks spoke about the broader concept of engaged pedagogy. He then put this phrase into his own words, which seemed to enhance the gravity of the concept for him, saying, "To respect and care for your students was placed above all else, even your subject matter." This approach had been particularly important to Fred in his work in student conduct, a role that puts many of the students with whom he would have to interact in a defensive position.

He also expressed some frustration about the possibility this was not a commonly held perspective among student affairs professionals. He pondered, "Where is our emphasis in today's higher education? I can't help but feel like, I'm starting to feel more and more that we might, as a larger field of higher education, be losing our focus from the education." Fred continued to address the ways in which his experiences learning about teaching connected to his experience reading Teaching to Transgress, saying, "I feel like I had already some framework in some grounding in that teaching was supposed 
to be, is, or can be, um about relationships and about the connections with the student or students.”

In our final interview, Fred spoke to the ways in which this experience helped to remind him of his connections to being an educator. He had just started a new job, the Director of Student Life, at a new institution, an open access community college. He spoke of the experience reading Teaching to Transgress offered him, "Teaching to Transgress did have a nice reminder we are teachers because if you read it, the audience might be faculty but I've always considered myself a teacher. I've always considered myself an educator." He expressed a curiosity about the ways in which he believed Teaching to Transgress might impact how student affairs professionals could see themselves as educators, saying, "If this book was more widely distributed and read, would people feel empowered to see themselves as teachers and their offices are classrooms or their student unions are you know forums?"

Seth. "I think of us as teachers, as educators in student affairs." Seth's experience can be seen as a bridge between the two ways in which many participants found themselves connecting their roles as student affairs professionals to that of a teacher. $\mathrm{He}$ had an undergraduate degree in education and also taught classes in the graduate program from which he received his masters and doctoral degrees as an adjunct faculty member. In our first interview, before reading Teaching to Transgress, he spoke about using a number of the same approaches in student affairs work and teaching, saying, "I have always thought about being a well-rounded educator that just doesn't have one trick that they lean on, rather what is appropriate for the situation, creating a tool kit." 
Seth, similar to Fred, spoke in our pre-interview about hopefulness that there could be a connection between the ideas of transgressive teaching and his work as a student affairs professional. Continuing his reflection on the ways in which different approaches to engaging with students can lead to a great impact on students' experiences, he said, "If it is something to choose from, so if it is something to help inform the way we think educating the students, then I'm sure it could be helpful or informative." Seth's work in student unions can be a point of connection, as he often spoke about a desire for students who might not see themselves represented in the aesthetics of the university to feel as though the student union was theirs, to feel a sense of connection to the place.

While reading Teaching to Transgress, Seth made connections between his experiences in student affairs and as an adjunct faculty member and described the approaches described by bell hooks to be a helpful in making that connection. He wrote, "As a former student conduct administrator and currently leadership faculty member, I really resonated with the understanding that students will not always accept our guidance." He continued, "There can be joy in this experience as important to education as the practice of freedom and allowing students to assume responsibility for their own choices and learning." In our interview following his completion of the book, Seth shared a story about his own experience as a student learning about education. He talked about the experience of reading some passages as transporting him back to a moment in college, when he first read chapters from Freire's (1979) Pedagogy of the Oppressed: "The connections around banking, of sort of regurgitating knowledge, and I was having these experiences in student leadership that felt-I don't know if I have the term back then but I do now—of I felt more liberating." He continued in relating these experiences 
to his work with students: "As a student affairs administrator I go to work every day trying to think about students can do that type of work for themselves and become what they want to become or practice that future version of themselves."

In our last interview, Seth reflected on how his identity as an educator has been a part of how he sees himself throughout his career. He also reflected on how it can be very easy for student affairs professionals to lose that sense of themselves through the course of their career, and that reading Teaching to Transgress may help for other student affairs professionals to make, deepen, or remake that connection. He told me, "I think it also goes a long way to helping student affairs professional really think their roles as educators." He continued, saying that while many people come out of their graduate preparation programs with a sense of themselves as an educator, "It's easily lost as you move into your career and you forget an educator and administrator or because you always hear yourself refer to as a staff member that somehow the identity of educator is lost."

\section{Experience Teaching College Students}

While some of the participants were trained as teachers, others developed their understanding of teaching through their experiences as members of the faculty at colleges. While this still lead to those participants having a sense of themselves as educators, there were also some distinctions in the ways in which that sense of self did or did not connect to their work as student affairs professionals.

David. "It is a challenge for me to distinguish my teaching work from my general student affairs work." David's role came with a partial appointment as a lecturer, and he had both undergraduate- and graduate-level teaching responsibilities each year. In reality, 
David's role kept one of his feet in the worlds of in- and out-of-classroom learning, and it could be hard for he and I to make clear distinctions between when he was acting as a student affairs professional and when he was acting as a faculty member. He wrote in one of his journals while reading Teaching to Transgress, "Our work, because it is outside of the classroom, gives us a closer view as students interact with each other." He articulated a number of specific connections between environments described in Teaching to Transgress and the environments of student affairs professionals, the most clear of which he described by saying, "We also have the same struggle that hooks addresses in the opening of her book. We have a pattern of managing student groups that is much like the patterns in the classroom." He drove the point further, saying, "It is a pattern that rewards the complacent student who studies hard, follows directions, and does not rock the boat." David spoke a great deal of the validation that hooks' work offered to his approach to teaching. "As a human, I picked out all of the bits that support my own teaching style and felt like I would pass the bell hooks test if she observed my teaching." Feeling this validation charged him to wonder how he could find ways to use these approaches in his out-of-classroom work as well. He wrote in a journal entry a list of questions, almost as if imagining the possibilities. There were two that really moved to the fore, as if he were prepared to start revamping processes the next day, "Can more of my workshops be in a circle?" and "How come our resume workshops, our study skills workshops, etc. are mostly led in the same way with PowerPoint decks carefully read by nervous undergraduates?"

David veraciously connected what he did in the classroom, and the ways in which he felt hooks affirmed his approach to engaging students, with the work he did outside of 
the classroom. David continued to reflect on the ways in which he could empower those whom he supervised to take up this approach in their work with students. In his role he supervised 30 teaching assistants (TAs) and talked about how his position, in many ways, protected him from backlash if he rocked the proverbial boat to which he referred. He wondered, in a way that almost seemed as though he was asking bell hooks for guidance, "How do I give my TAs permission to do this work more closely to the student's experience?" He also acknowledged that his position afforded him space his TAs may not have had, saying, "I don't really have to care about teaching evaluations. I have 30 years of seniority and the freedom to try out most anything. My TAs are just starting out. They really feel a need our students to like them." Since David also had directors of offices reporting to him, he could also continue to see the people who work for him expand their practices. He spoke more directly to not just changing himself but using his position to enrich the practices of others and to impact the students with whom they interact.

In our final interview, David spoke about taking these questions and actually moving them into action. When we spoke, he would make reference to preparing for his spring course, and in our last interview he said, "I'm presently sort of tearing apart my writing of my best course, which is a student affairs values course." He also spoke about the ways in which he believed this experience inspired him to approach the ways he interacts with students, in and out of the classroom, in new ways as well as challenging the systems to try new approaches as well. He also spoke about student experiences as if the in- and out-of-classroom experiences as if they were all a part of a single system rather than separate experiences, saying, "Our educational delivery system, as it currently stands, it can have a lot more sensitivity to differences, it could have a lot more different 
structures." He continued, giving more specific examples which start to blur the lines between what is traditionally thought of as a classroom and a student affairs program, "It doesn't have to be linear it doesn't have to be during the daytime, it could be blended with technology and there's so much to fix about how we talk about important things."

Terrance. "This is already my teaching method in the classroom:" Terrance only mentioned having experience teaching once during our interview after he had finished reading Teaching to Transgress. He spoke about how his approach to working with students in a classroom had always been similar to how hooks describes her approach to classes, saying "I've been teaching classes you know for 10 years now-2003, so 13 years, I've been in a classroom, and the way she described her classroom is always been how I approach teaching." He continued to describe how he approaches teaching, engaging students in the process of designing their learning experiences, asking them questions like, "What do you want learn?" and "What do you want to get out of this course?" He also involved them in constructing the course: "Let's build this syllabus together. Here's my syllabus, but I want to build a syllabus with you," and "What are some of the things you want to cover?"

Still, this experience offered Terrance new approaches to his work outside of the classroom in how he supervises staff, how he supports his colleagues, and how all of these things support students. He spoke about the ways in which his experience gave him the ability to reflect more on how he can bring the experiences he was worked to create with students in his classes into his work in residence life: "It was very affirming in many ways things that I really believed codified and made concrete some of the thought process I have lived with for a while and I just haven't been able to put terms or names." 


\section{No Experience Teaching}

There were two participants who never indicated having any experience teaching or having any training as a teacher. Still these two participants, Raymond and Ronald, saw themselves, and student affairs professionals in general, as educators. These two participants spoke to ways in which reading Teaching to Transgress affirmed and solidified this perspective.

Raymond. Raymond had spent his career working within student conduct, first within a residence life department and then in the student conduct office at the same university. He expressed some interest in teaching once he finishes he Ph.D. but had never spoken to any direct experience or background in teaching in his past. In our first interview, he mentioned already having a sense of himself and his work as a way of teaching: "Part of the reason I am in this field is a desire to be a positive difference in the lives of students." He lamented the ways in which that changed, "Over the course of my career, how that gets affected has changed. I feel like I have moved farther away from informing/instructing students and toward education as liberation."

He shared a similar thought in one of his journals, speaking to the teaching that happens in the relationships between student affairs professionals and students by saying, "In student affairs, our teaching is seldom in the classroom." This echoes a thought Jerome shared. Raymond continued, reflecting on the ways in which his position limits interaction with students, "If real education only happens with getting to know students, this is fairly difficult when we sometimes have only one interaction. We do try though." So it seems as though the experience of reading Teaching to Transgress, for Raymond, 
helped to bring these thoughts closer to the surface and perhaps concretized them in ways he may not have had the chance to before.

When we were conducting our last interview, about five weeks after he had finished reading Teaching to Transgress, Raymond expressed a very similar sentiment to many of the other participants around the viewing student affairs professionals as educators who could be helped by using the book to understand transgressive teaching and their work. He said, "In student affairs we sometimes actually do teach. We often don't teach in the same manner as a doctor she is talking about in her book but some of the same issues." Raymond gave some further context to the connection he was making, in ways similar to those described by David, in that the experiences of students run throughout the classroom and the rest of their experiences on campuses with injustice and inequity and are isolated to one environment. Raymond said, "I think [reading this book] will help because she is talking about the field of education, again have some direct stories that [student affairs professionals] can have understanding more about those institutional inequalities that happen in the educational field." Raymond's experience in student conduct always involved some degree of engaging students in their own learning, and also their resistance to that learning, an idea that both Fred and Seth had spoken to as well.

Ronald. Ronald did not speak about any experience teaching or teacher training, except noting at one point he hoped to "get into the classroom as an instructor" in the future. Still, he, too, spoke about the ways in which he saw student affairs professionals as educators. He also believed the ideas of transgressive teaching would serve student affairs professionals in their work well, saying, "I think there are always ways that we're 
always teaching." He continued, "There's a level of teaching that seems to be happening, as we are connecting with students, and I think there are ways that we can teach the messages." This sense of connection stayed through his participation, even though Ronald was not able to complete the book and journals within the timeframe of this study. While only having finished about half of Teaching to Transgress, he still spoke about the connections he made between the concepts in the book, his work, and his sense of himself as an educator. He stated, "I think there are lots of areas where this is applicable to the work that student affairs professionals are doing." He continued, "There's always going to be a classroom existing in a lot of different ways and how we show up, how we participate with the learning with the students that we interact with is always going to be informed by our identities." He concluded by speaking of the ways in which Teaching to Transgress can help student affairs professionals continue to do that work: "This book allows for a level of reflection but also illumination around the importance of continued self-work and community."

Ronald's connection to his own ongoing learning was contrasted with the stress of his new job, having to learn the basics, adjusting to new work styles and expectations, and understanding how he could bring himself and his experiences to the work. These can be difficult things to work on simultaneously, which Ronald experienced and which lead to his needing to step away from the project before completing the experience.

\section{Synthesis}

Based upon these findings, it appears the experience of reading Teaching to Transgress did not create or instill an identity as an educator in a student affairs professional. However, if a participant already held an identity as an educator, the 
experience offered them more upon which to connect the experiences of participating in this study and their work as student affairs professionals. While this identity was often connected to experience with teaching, either through teacher training or serving in a teaching role on a college campus, two participants also cultivated the identity without those experiences. Ultimately, it appeared the experience of reading Teaching to Transgress was effective at bringing this already held identity into salience or facilitating a connection between the teaching described in the book and the work of student affairs professionals through that previously held identity.

\section{Summary}

This chapter presented findings on the identities that were and were not salient to the participants of this study. The participants all experienced their White identities as being the most salient, and the majority experienced their male identities as being salient as well. Four participants spoke to feeling their heterosexual identities as being salient, thought two said that it was only connected to one chapter in Teaching to Transgress, and one of those chose not to focus on that identity further. Additionally some contextual data around what brought certain identities to salience through their experience reading Teaching to Transgress was offered in the form of current events. The 2016 United States presidential election, the Pulse nightclub Shooting, the University of Missouri Concerned Student 1950 protests, and the murders of Philando Castile and Alton Sterling all brought participants' identities, particularly their White identities, into salience while participating in this study. The findings in this chapter addressed some dimensions of this study's second research question on the ways in which reading Teaching to Transgress may impact the participants' identity as an educator. The findings suggested this identity 
was more closely connected to past experience identifying as an educator and would be more greatly impacted by this past experience than the experience of participating in this study. As this chapter sought to address research question two, the next chapter will address findings related to the topic of leadership, which relates to research question three. 


\section{CHAPTER SEVEN: FINDINGS ON LEADERSHIP}

\section{Introduction}

One of the core questions guiding this research project has been to understand if there can be any connections made between a group of White, heterosexual, male student affairs professionals' experiences reading Teaching to Transgress and their understanding of practicing leadership. All of the participants were asked questions about their understanding of leadership and what they believe practicing that understanding looks like as a student affairs professional. While many of them used many different words to describe their own conceptions of practicing leadership, a number of connections did emerge. Similarly, the connections they made between these conceptions, their own practices, and their experiences reading Teaching to Transgress were described in a variety of different ways, however connections and themes did become apparent.

\section{Leadership as Communal Participatory Change}

While each of the participants spoke about leadership in a variety of different ways, a recurring theme across all of their conceptions of leadership and its practice was that leadership is enacting change in ways that are communal and participatory. When referring to this concept of change, all of the participants spoke about it in ways that framed it as a thing which positively benefited the people experiencing it, either at an interpersonal, group, communal, or even a global level. Also, while speaking about leadership in different ways and with different language, each participant spoke to the ways in which they viewed leadership as something that the people for whom the change or goal is directed are involved in the process rather than simply being recipients of the 
results. While other dimensions of how the participants spoke about leadership took the form of specific actions or ways of taking action, in speaking to this aspect of their understanding of leadership through the process of reading Teaching to Transgress was more oriented toward an underlying value or orientation.

\section{Fred}

"I've been really trying to redefine this." Fred spoke about the ways in which a conversation about leadership and what it actually means had been a part of many conversations in his life at the time of our first interview. He spoke about the explanation to which he had arrived after thinking about it for some time: "I feel like I have subscribed to this thought leadership is really kind of giving power to others." He went on to describe this more deeply, saying that in his mind real leaders are "folks who are engaging, empowering, motivational, they are coaches, they make others better. That is what I view leadership and that is how I have been trying to channel leadership." Fred spoke more about the way in which he was hoping to put this into practice in his work as a student affairs professional, saying, "There are so many great things I can do individually, but it is about who I bring with me, who I push up and give more room and space too." He continued to speak more about what that would like in his role as the Director of Student Conduct, "I am really willing to bring students to the table for an active role in the conduct process." He spoke to how he believed this could be a possibility to really change the way students engage with the process, by "giving students power in a space where traditionally they think they are powerless."

Fred continued to express a desire to practice leadership in this way in our interview after he finished reading Teaching to Transgress. He spoke more about lifting 
up others and measuring the impact of his work by who it brings to the table saying, "I want to be a leader who leads from the middle or even, some mentioned, behind" and also being someone who "brings other people up and motivates them, excites them." Fred continued, saying he hoped he was being a leader who valued "autonomy and, you know, participation." He further reflected on the ways in which he saw himself doing that in his role. In recalling his own identity as a teacher and an educator, he made a connection between teaching and practicing leadership. He said, "Leadership and teaching can be one and the same." He continued, thinking more deeply about this idea, "Maybe we think of leaders as leaders of organizations or leaders of divisions, but are good leaders not good teachers? You know, in terms of how they facilitate, you know, empower their staff, or their teams to succeed?" He returned to his own personal definition of leadership when reflecting on an experience he had been able to have when the campus at which he worked hosted a national leadership training summit at which he was able to be a participant. He said, "Leadership, to me, in practice is the modeling the way, how we want to make our communities look." He also described leadership as "encouraging an exchange of ideas, allow people to challenge the process of what we do and how we do it, and why we've done it like that." He concluded that he believes leadership was "not a role or position but as a, if not a process, an ongoing experience that leadership is a thing that we do."

This was still a conception of leadership about which Fred was thinking when we spoke again about five weeks later. He had started his new position as the Director of Student Life at a community college in the Southwestern United States, and he spoke about leadership using a new phrase, which is that of being in service to others, in 
addition to returning to his conceptions of leadership practice from earlier interviews, saying leadership is "giving them power and empowering them." He also came to a new approach to leadership, "Being a servant to others, having a real philosophy that the work I'm doing is to improve relationships, communities, programs, environments, and that it is from a place of mutual benefit."

It was within this part of Fred's conception of leadership that he found the most connection to transgressive teaching. During our initial interview, before having read Teaching to Transgress, he expressed hope for a connection, saying, "If it provides for individuals who are leaders or inspiring leaders to be more introspective and cognizant of their power or their privileges, it allows us to be more critical of the work we do, then of course. He continued to unpack this thought: "How we view ourselves as leaders probably has a really big impact on how we employ those leadership skills or how we do this work on a day to day basis."

During our post-interview, Fred spoke about the connection he experienced between his approach to leadership as participatory and communal and the concepts he read about in Teaching to Transgress. He also spoke to the ways in which it affirmed what much of his current approach and "has added the layer, all those qualities [of leadership] while good, hopefully also requires that the breadth and depth to include people." He continued, reflecting on that connection and his own approach to leadership more deeply, "I think I've been doing this well already but the context still permeates because of these factors. They [would] probably allow people's core self to be front and center." He concluded, offering again how the experience had affirmed his approach to leadership and solidifying how he hopes to practice leadership in his work, "I think 
finally leadership is about the sense of, connecting to bell hooks, it's about, always forward progress. Leadership is about making things better for your community or the next generation or whatever you are working towards." He then paused and decided to reword that assertion, offering, "Leadership is the collective need for positive change and to make our experience, however long we are on this planet, better."

During our final interview, Fred spoke more to the things he believed the book offered him to continue exploring: "The connection I see from Teaching to Transgress [is] you've got to do this self-work continuously." He continued, "[hooks] continues to write about life learning, reading, putting herself in places with these other thinkers and theorists and really trying to grapple with her own stuff too." He went further, connecting this to his own practice of leadership: "When I consider leadership, I can only be as good as I also allow myself to be." He concluded his thought, saying, "If I get stuck in a rut or if I just rest on my laurels, I can't be my true authentic self if I'm not finding out who I am, exploring change as I age, and if I'm not building good relationships." This new aspect of leadership, the inner work or self-work, was an aspect that arose from many of the participants' experiences reading Teaching to Transgress.

\section{Terrance}

"For me leadership is really about changing the world." During our first interview, Terrance mentioned two theories of leadership to which he feels most connected: "For me relational leadership model is number one; social change model would be my secondary." Still, he described in greater detail his own approach to leadership as a student affairs professional, incorporating similar ideas as those mentioned by Fred about self-learning being important. He said, "I engage with 
leadership as a way for me to expand my open spaces and close my blind spots." He continued, saying that he also sees this as something that can be done in community with others rather than just individually. He said he wants to engage "with other leaders to engage their blind spots and help them discover things about themselves they do not know to be more open and be more aware of who they are and their identities." $\mathrm{He}$ continued, describing this process of discovery and engagement as being an important part of how student affairs professionals can practice leadership. He said this process "comes in helping others discover their nature as a leader, because I am a firm believer anyone has the ability and the potential to be a leader."

Terrance described leadership as a way of viewing and understanding his work. He described leadership as a lens, one that helps continue to develop his own work and that of others while also still connecting leadership to a participatory process: "When I am interacting one-on-one, the questions I am asking myself are 'How can I help this person unlock their leadership potential?' And that includes empathy. 'How do I empathize and get in a place of understanding first?"' He returned to his earlier idea that leadership is something people can discover within themselves, and his excitement about being a part of that discovery for others. He said of his questions and his empathy, "That may help you discover for yourself what leadership means to you. Because what leadership means to me is my own personal thing, I want you to discover what your leadership is."

In our interview after Terrance had finished reading Teaching to Transgress, he spoke about an approach he puts into practice when being asked to speak about leadership. He said that he saw this as a way to both lift up the voices of other 
practitioners while also challenging a hegemonic perspective of leadership in those learning about it: "I try to involve colleagues from marginalized identities so it's not just some White, heterosexual guy up in front of the room." He continued, saying it is important for those learning to see "I'm working in partnership with other folks to talk about [leadership] from a different perspective and to acknowledge that I am approaching leadership from a White, heterosexual, male perspective.” He said this strategy had helped him and those with whom he worked to "not be afraid to engage in what might [leadership] look like differently from our other colleagues." He continued, expressing a hope that the thinking that this approach represented for him would become a practice throughout student affairs: "My desire is that student affairs becomes a much more inclusive field, meaning that your success is dependent upon your knowledge skills and abilities and not on what you look like, how you dress, who you know." He connected this idea back to how he believes he is practicing his own approach to leadership, saying, "I think for me that's where I had the power I need to do with the power that I'm given and do everything I can to give it away."

During our final interview, which took place about six weeks after Terrance had finished reading Teaching to Transgress, Terrance started out by saying about his understanding of and approach to leadership had not changed through the experience. "I think it's still people coming together to accomplish positive change. To me that is still leadership is, we're trying to make the world a better place." He continued, "I think how we get there is where you got to be inclusive and bring voices to the table that are different than our own don't agree with us and really trying to listen to instead of dismissing them." He concluded by speaking about the desire to redistribute power rather 
than consolidating it: "We've got to really empower people and give our own power away, and I can't empower somebody if I'm trying to hold onto my power." This idea, that power needs to be distributed rather than consolidated, was at the core of Terrance's approach to leadership in community with others and as a change process.

This was also where Terrance made his connection between leadership and transgressive teaching. "Engaged pedagogy would probably be really aligned with, you know, my philosophy and my belief system and how I practice it." Terrance had some familiarity with other theories of engaged pedagogy before he began participating in this study. Given that, he already saw the possibility for some connection between these ideas and how he understood leadership. Throughout the process, he continued to return to his original definition and approach to leadership, even saying during our final interview, "I don't know my definition of leadership changed because I've actually leaned into the models I've used and talked about before."

\section{Ernie}

"There needs to be a reason for leadership." Ernie, who had spent a large portion of his career working in campus recreation, used teams as a metaphor and a point of reference when describing leadership. He described leadership in ways that involved participation and community, saying during our initial interview, "Leadership's the ability to cast a vision and to coach and encourage the team to reach those goals." He also acknowledged that creating buy in to goals and vision is a part of the process:

"Sometimes it involves having them share those same goals and visions. Sometimes it's helping the group to understand why they need to get there and not help them get there without ever joining in that shared vision." Ernie also described some of his 
understanding of leadership being shaped by experiences of bad leadership, speaking to the impact of being uninvolved or withholding participation and the contrast when observing these approaches: "You can recognize poor leadership when you get poor communication, poor vision." He continued, "You can see absentee staff, faculty, deans that are coming in for a paycheck." He balanced this with the observations of behaviors that are positive and contribute to the mission and the community, saying, "You can see engaged strong leaders that communicate what their values are and what their vision of the organization is and then chart a path to get there and bring the group in along."

Ernie returned to this notion again during our interview after he finished reading Teaching to Transgress, even referencing his previous statements about framing leadership as creating a shared vision: "I am someone who strives to find a shared vision, and I was harping on that earlier. For me, it's how do you get everyone in the room passionate?" He spoke more about the different ways that can play out on college campuses, referencing the students with whom he worked as examples: "They want to correct what they have seen as racism on our campus, so leadership means, to them, forming a tight-knit community with the people that they live around and inspire that shared vision." Ernie also expressed an a consciousness of his role and the power that comes with it in situations working with students on their own leadership: "I don't want them to ever feel that as though they are being guided or their work is being changed or corrected by me." He came back to this idea later in our interview and brought the idea of students being empowered more the core of how he was seeing leadership practiced in his work as a student affairs professional, saying, "Above all else, be student centered and 
create an environment where they can direct and create what they want to create through their education experience."

In our last interview, which took place roughly four weeks after Ernie finished reading Teaching to Transgress, he spoke more about the importance of shared vision. He also spoke about this being something available to people in any position, rather than simply those in positions of authority or control: "You have a vision when you are working, you know, what your work is going to look like, and that's what people gravitate to. That charisma draws people no matter what level of organization you are at." He concluded, reiterating the value that vision played in creating buy in for the members of the community was key to practicing leadership: "Making sure you have an effective vision I think is crucial for any leader, that you have a vision of what the community you want to be in looks like."

Ernie, like Terrance and Fred, found his connection between transgressive teaching and leadership within this perspective, saying "[hooks] talks about, keeps on talking about passion." Ernie found a connection between his own understanding of leadership and transgressive teaching through the idea of passion. He connected it to empowerment in our second interview just after he had finished reading Teaching to Transgress, saying, "I think that all of her teaching really related back to the passion and empowerment and how did you help students recognize that this process will get them get to where they want to go." He also connected to challenging the process, a similar thought to one shared by Fred, saying that it invited everyone "to challenge the process as they go through it." When describing his experience reading Teaching to Transgress and considering its connection to leadership, Ernie said, "It's been helpful as I related to my 
leadership and my role as an adviser, to make sure [the students] can have some reason to relate to their involvement." He continued, reemphasizing the importance of a more communal sense of participation rather than one based in authority, "if I give them one way of doing things if I tell them what we want them to accomplish, it defeats the process of the leadership."

\section{Raymond}

"I think of leadership, I think of taking the opportunity to sort of help others push the world to a better place." Raymond held this core idea very closely when speaking about leadership in our first interview. He tried to expand upon the idea, but kept returning to this concept "I think of it as something that is forward thinking, pushing, helping to make things better." He continued, saying he also believed "there is a wide variety of things that make it happen but that's the nutshell, trying to figure out how we are helping other people and not just ourselves." He spoke more about this idea in a way that connected to much of the perspectives on leadership to which Ernie and Terrance had spoken as well, describing leadership as "helping a group to work together to determine goals and vision, where you want to go, and then helping the group move towards that." He continued, describing leadership as being, in part, "figuring out the areas you are struggling, as individuals or as a group and helping to address those, and then helping the group sort of continue to consider the goal and how you are getting there."

In our post-interview, Raymond spoke about the ways in which reading Teaching to Transgress helped him to see some of his ideas of leadership being articulated. He began by describing it as "be a part of the process and look at what's going on and what 
doesn't work." He expanded on that notion: "Looking at what works and doesn't work and trying to go beyond. For me one of the big pieces is trying to go beyond this sort of surface level." He also connected this to his work in student conduct: "Looking at a policy and trying to determine how our policy are or not inclusive in the language used, the things that they can and cannot do." He also saw this as a point of frustration, saying "I think for the most part we come at that from a surface level perspective." He spoke to practicing his idea of leadership in his role as "trying to think deeper about how the systems that we create and systems of conduct work to help us in helping students develop and to be engaged more."

This particular dimension of Raymond's conception of leadership continued to be alive in our final interview. He began by describing his own approach to leadership as "being able to think broadly on a topic and think about ways to move forward um but also working with the people you are working with to um, bring the group together on a particular path." He extended that idea further, focusing specifically on those often not brought into decision-making or included in assessments of desires and possibilities, "I also connect it with other ideas of justice and thinking about how the choices we are making are impacting those with the least advantage." He continued, "So it's more critical to think about that and not necessarily the majority who have more advantage in the situation." When describing how he might put this understanding of leadership into practice, Raymond spoke to one aspect of it as "having the focus I think that is beyond you as an individual, but it is for both people you work with but also student focused." He continued, "You are not just looking at the group that you are a direct leader of, but you're looking at how that group impacts and effects the students that you serve." Unlike 
many of the other participants, Raymond did not directly speak to an immediate connection between his understanding of leadership and Teaching to Transgress.

\section{Jerome}

"I have a very broad definition of leadership, I think." Jerome immediately spoke to examples of the ways in which students practice leadership in a variety of ways. One example he offered was in the ways that students who may often be called "followers" are actually leading, as he said they "are often students who are aware of their surroundings and are able to support better from a position that is not dictating the plan, but supporting someone else's vision, gathering people around it, being the leaders of action." He continued, "I think leadership can take many different forms, but in general, I think that leadership is knowing when to kind of take lead and fall back and let other people lead." He connected this to a more broad orientation around leadership, which in many ways echoes the way Fred, Raymond, and Terrance spoke about the concept: "True leaders are the ones that can help people grow in areas they need to. They are understanding of their strengths and weaknesses." He also described an aspect of leadership being people who can best utilize resources available, as he described it as knowing "how to use a team, or act within a team that the goals are met not necessary about ego and who does what, but use that team to get the job done in the most effective and efficient way." He also added that participating in a team in this way can also create space for "teaching everyone within that space how to grow from that experience," which aligns with perspectives on leadership offered by other participants.

When speaking about a group of students with whom he works, Jerome offered an approach for putting this perspective on leadership into action, " $[\mathrm{I}]$ try to get them into 
positions where they can see their own strengths and feel like they can fall, or feel can um they can trip and try again." He continued, offering that he sees this as an important part of his own work to develop the skills and strengths of his students, "I also try to recognize and encourage students when [I see that] they are challenging themselves outside their comfort zone and offer different exposure and experience that will encourage students to grow in that way." One example he offered was around students who also hold dominant group identities: "I challenge a lot of our more traditional leaders to think about ways they are supporting or not supporting marginalized students within our community." Jerome also spoke about putting using this approach to leadership with his colleagues around campus: "I definitely challenge a lot of our professionals to think outside the box and to think more about how our current roles and our current structures are supporting students." He continued, "I try to work in collaboration with a lot of our professionals around campus." Jerome described one way that he tried to create environments where these sorts of challenges could happen and could bring about good work on his campus, saying that he tried to create non-hierarchical working groups because "that is where we have the most ability to collaborate [focus less on] who owns what within this process, but [focusing on] what the output is and making sure we get there in the best way possible."

In our post-interview, Jerome referred back to the idea of working with colleagues and challenging them to think outside of the box, asking them to examine ways to engage students that are "not about being the source of power and knowledge in a space, making sure the community you are leading has a say-so." He described one way in which he puts this into practice in his work, "I think often times it means helping others that are 
marginalized in different ways learn to use their voice instead of me trying to speak for them." He continued to describe why this is important: "In an institution that doesn't respond to what staff are being told by students, to have students who view themselves as having a voice and power is really important especially having skin of color in a very White environment." He continued, saying that when students "have that self-authorship, understanding themselves as a power, as someone who can make demands of the institution is really important for this type of leadership to work."

Furthering this point, he said, "It's very easy to lead top-down it is very difficult to lead in an nonhierarchical way, and in order for that happen, students need to recognize themselves as a power and as someone whose opinion that matters." Jerome connected this to the work that he does with students more directly, saying, "I think it also means creating a space for students can disagree with you." He continued, "It is very important for students to feel they can say, 'You are wrong,' especially when I'm a White straight man talking about issues of injustice within communities I don't belong to.” He believed this was important because in those instances, students needed to "feel like their experiences are validated enough that they can stand on it and disagree with whoever because their experience are important."

Jerome had some exposure to the broader concept of engaged pedagogy before participating in this study. When asked if he believed there could be a connection between engaged pedagogy and transgressive teaching to how he understood leadership, he said, "I think wanting to look at leadership as less hierarchal definitely changes my perspective, or has a lot to do with my perspective on education." He continued, "The idea that the teacher should not be the source of knowledge but it should be in the 
creation of knowledge, I think that's directly related because the teacher is a leader within the space." He clarified this assertion "does not mean they are not the only leader, but they should be a facilitator of that instead."

During our post-interview, Jerome spoke to the ways in which the experience offered him a clear example of putting this approach to leadership into practice, without drastically altering his own understanding of the concept. He said, "I think it's giving me a good example of how bell hooks approaches leading, but I don't think it's dramatically different from how I think leadership should be." He continued, connecting to some of the challenges he has faced attempting to practice this approach to leadership in his work, "It's easy to preach a nonhierarchical community based leadership style when in actuality that's more difficult to pull off then it is to talk about and theorize about." He said that ultimately Teaching to Transgress was helpful to read with this in mind, saying that it "gives a great example and she really provides some more concrete ideas on how to do that."

Seth

Seth responded to my question about what leadership means to him during our first interview with a chuckle, "Honestly, you can't ask someone with a Ph.D. that and think you are going to get a straight answer." Still, his answer was not as complicated as he even believed it might have been: "holding space around others to be at their best to become what they want to be that as an individual or as an organization." He added that another aspect of his definition of leadership is "addressing the more sticky issues in our organizations and our society and working with people side by side in order to resolve some of those things." He spoke about how his position, working with student unions and 
activities, offered him opportunities to put that definition into practice, saying that his role is "creating an environment where others feel they can work in a way they are called, help themselves and others to work to become [who they want to become], provide resources, empowerment, and time."

Seth brought in a connection to the second part of his definition: "In the space management that I do and when thinking about creating space I mean try to co-create it with others." He continued, also speaking to the ways in which he works to recognize those who may not feel welcomed or a part of the spaces he worked to create, he tried to "bring in others in that space illicit ideas, [that] sort of approach. I don't consider myself as sort of wildly creative person, but I do think of someone that can illicit creativity from others." He continued, "I think about how I bring students in around what do they want to do here and what matters to them, how can we provide the options and opportunities for that [creativity and co-creation] to occur." Seth also spoke about the ways in which student affairs as a field defines leadership: "I think in student affairs there is an emphasis on leadership for some sort of the social good. And thinking about leadership that supports social change, social justice, development, learning of students, and access into those opportunities."

In our interview after he finished reading Teaching to Transgress, Seth was drawn back to this idea of co-creating. He spoke of the ways in which identity and experience can play a part in how that co-creation happens: "Co-creation can't happen if you can't bring all the themselves." He continued, "My approach to leadership is always wanting to do more co-creation and so in some ways [reading Teaching to Transgress] expanded that understanding of co-creation about when it would allow for the co-creation other 
stories and experiences, holding more." When I asked him what that might look like in his role he spoke of dialogue, saying it "is something, something that I often do with students and is just as important with our staff. He continued, saying that since much of the direct interaction he has is with other staff rather than students, "I have found some of the fruitful engagements with staff have been when dialogue is the foundation." He continued, thinking in the moment about how dialogue could be a part of his work as the Director of the Student Union, which requires a great deal of attention to logistics and planning, "How do I bring more of that dialogue into that part of the process? For instance, how are we thinking about the best scheduling system for students."

During our final interview Seth offered his definition of leadership in a way that recalled one part of his first answer: "I see leadership as a function of groups and the exercise of leadership from individuals is about mobilizing groups to address some of the complex muddy problems that we're facing." When I asked him about what he believes that looks like in his work, he spoke about how the student union can be a place where students explore that: "We create an environment where students can have some choice over the types of challenges they engage in, maybe the ones they don't, and how to engage." He continued, saying that the spaces he works to create can help "to clarify values, gain insight into themselves, and take those insights and those values and put them into the world." He also spoke to the ways in which much of the work that student affairs professionals do can be viewed in this way. He spoke more to how he practices leadership as a student affairs professional by saying, "Almost any student affairs function area in my mind is about managing the environment whether it's policies that inform the environment, the physical environment itself, the communities people can 
engage in, types of organizations they can engage in." He continued, "We set up these environment where they can run like a gauntlet, they're much more intentional, but it's what we do, and that's what leadership looks like in student affairs. Setting up that environment where students gains some insight."

Seth connected this idea back to the concept of co-creation, speaking more about how the environment can be a part of the interaction rather than just the venue for the interaction between Seth and the students: "When you are trying to lead by the environment primary, by focusing on the environment you are creating for the students then you're in some ways letting go of control from an individual perspective." $\mathrm{He}$ continued, reflecting that while he does not "jam [students] into these routes that seem to have been best for many other students, instead [I] give some students some choice, some agency around how they want to move through that environment." He saw his role, and the role of student affairs professionals, as being to "coach them, reflect along the way, give them some feedback, but ultimately they (the students) are the ones determining where they are going to move through that environment." It was with these ideas that Seth made his most direct connection between his understanding of leadership and transgressive teaching.

Seth also found his greatest sense of connection between leadership and transgressive teaching within this theme. "Engaged in learning others and alongside them, I certainly think that would be my leadership style.” Seth, like Jerome, Terrance, and Fred, believed there could be a connection between how he understands leadership and what engaged pedagogy and transgressive teaching are. He continued to speak to that possibility, saying, "Questioning some of the assumptions we have about our work: that 
is what I define as part of transgressive teaching." During our interview after he had finished reading Teaching to Transgress, Seth spoke about a new aspect of transgressive teaching that had occurred to him, "The first thing that comes to my mind comes around holding more of the whole, you know and especially around people's stories and experiences. How can I leadership create space for those can be made available?"

During our final interview, Seth spoke more about the holding space for stories and experiences as a part of how he practices leadership. He also spoke about how doing so can contribute to students finding that space. He said, "If you underlay hooks' work, Teaching to Transgress, I see the similarity." He continued, saying that in student affairs and within a transgressive teaching framework, space is co-created "to do some discovery around themselves, you are exposing them to multiple methods and voices, they have choice which ones resonate, which ones they want to investigate, and what ultimately their truth about that experience is going to be."

\section{David}

"I like the modern, the more modern looks at leadership." David spoke to a theory, the only person other than Terrance to name an author in their discussion of leadership, as a grounding for his definition, "I really like Kouzes and Posner and their conception of leadership as a, the art. Can I quote them from memory or not? I am imagining myself on my lecture stage." He stopped to chuckle, then continued to describe leadership as an art, motivating people to struggle towards shared goals. He said, "I like the idea of a leader is not necessary accomplishing the goal but getting others engaged that they want to struggle along and for, actually put together a shared goal, and then struggle together." He also spoke about leadership as being able to identify problems, 
saying, "I think our leaders are as simple as the folks that I admire look for problems, so they have a good ear to find what needs to change and they are active in making the change."

During our interview after David had finished reading Teaching to Transgress, he told a story of a meeting he had attended, in which he saw a practice of leadership that resonated, "it was one of the best meetings I have been in the last five years, and it was largely because these two powerful and wonderful humans allowed for silence." He continued, "This was a room with a lot fancy people, and we're looking at really big questions and I loved that we sat in silence. I think they were doing 10 seconds at a time, but that was super impressive." After reflecting on that experience some more, David said that it "gave me sort of new motivation, I can work on my inner game and think more deeply in the moment, I could be like them, comfortable with silence even in a taskoriented meeting so yeah an aspiration of mine."

David spoke to the ways in which this experience connected to his larger view of leadership. He spoke to feeling called to do more "listening to others and value their lived experience" as part of how he hopes to practice leadership. In our last interview, which took place about five weeks later, David spoke about the ways in which student affairs professionals can continue to practice leadership in a number of ways: "Our educational delivery system, as it currently stands, can have a lot more sensitivity to differences, it doesn't have to be linear it doesn't have to be during the daytime, it could be blended with technology." These two areas, internal comfort with and thinking about the value of others' lived experiences, were the places from which David made his connection between leadership and transgressive teaching. 
David, like Terrance, had a specific theory of leadership that he used to frame his approach. In our initial interview, he spoke about how he hoped that he engaged people in a way that creates connection, saying, "Motivating people to struggle with you forward, I am hoping that my students and my teaching team feel that we are all on the same team and feel we are all kind of growing towards enlightenment." In our second interview, David spoke to a different kind of resonance between his understanding of leadership and transgressive teaching. In connecting it to the story he told about sitting in silence in a meeting, he said, "Post-hooks my leadership is a little more interior. Am I reflecting on this week enough? Am I reflecting on my identity in a way that helps me to become more effective and engaged?" He continued, also reflecting on what this interior work might offer him in moving forward, "This kind of experience has me doubling down on empathy and so I think, I think that in the next 10 years, possibly my last 10 years in the profession, get better at empathy."

David spoke to the ways in which this approach might be important for the field of student affairs and how leadership is practiced within the field. He said, "I think the next level of leadership is the ability to be more aware of identity, maybe more important than that is listening to others and value their lived experience." These ideas stayed with David. During our final interview, he spoke to the depth of this resonance as we were concluding. He said, "hooks handled it so much better." He unpacked that further, saying that while he continued to read technical articles about teaching technology and that those were good for staying aware of what is in the moment, "but Teaching to Transgress was much more, it's helping me to think about how I teach and do my job in a way that will last longer." 


\section{Ronald}

Ronald, in a way that seemed almost to contrast Seth's initial response to how he defines leadership, started out pretty simply: “[acting] in a way that furthers and moves the group forward towards a goal." He continued, describing the many ways in which student affairs professionals could do that by "challenging yourself, learning about who you are is one aspect of leadership in student affairs that I think is important." He offered another, describing it as "engaging with peers, working to improve the world around you and make connections with the world outside of the university." While he did not finish reading the book, it was around some of these ideas that Ronald found a connection between his understanding of leadership and transgressive teaching.

Ronald was not able to complete reading Teaching to Transgress, which meant that we did not have as many opportunities to discuss more about how he thinks about leadership. He did offer some additional thoughts about leadership and its connection to the parts of Teaching to Transgress that he was able to read. He reflected on the ways in which his hooks gave him the opportunity to examine how his identities show up in how he practices leadership, and how that can impact the students who whom he works. He said that the way "hooks talks about leadership and power and the connection between those two things in a hierarchical setting a working office or university in general and how that form of leadership is produced is oppressive, and it is White patriarchy." He continued with this connection saying that the roles I play on campus and my leadership comes through a White, patriarchal [lens]" and that an awareness of this is important to making change in communities. 


\section{Synthesis}

This section reviewed the findings around the most prominent perspective on leadership presented by the participants, that leadership is a communal or participatory change process. Each of the participants spoke about leadership around this theme, while using different language to describe a similar concept. Each spoke about empowerment, particularly for those whose power is taken or stifled by systems of oppression. This also included talking about empowering themselves to act in ways that support and lift up others and themselves to create the kind of positive change of which they described leadership being in service. There were other ways in which the participants spoke about leadership, and in many ways they connected back to the idea that leadership is communal and participatory. One such idea was that leadership is about building relationships.

\section{Leadership as Relationship Building}

While every participant in this study spoke to at least part of their understanding of leadership being connected to a communal or participatory change process, some expressed a perspective that included other dimensions as well. A common theme was that leadership is done through relationship building. In many ways, those who expressed this conception spoke about it in a way that connects to their understanding of leadership as a communal or participatory change process. Often, the relationships built would be the foundation upon which the collective change could come about.

\section{Fred}

Fred spoke about building relationships in our final interview. While he had spent much of our discussion of leadership connecting to the ways in which it was about 
empowering people and sharing power, he spoke to how developing relationships with people was what enabled him to share his power and lift up others. He said, "Leadership, to me, is relationships. It's how we connect with other people, how we learn about them and hear from them." He continued, saying that being a "good leader is investing in people, it's giving them opportunities to shine, giving them the encouragement and empowerment to do things they want." He spoke about how this aspect of leadership had been very present for him in the recent months, since he had started his new position in a new state and a new college. He had spoken about putting a great deal of effort into developing relationships with his new colleagues.

\section{Terrance}

Terrance, while centering much of his conception of leadership on a relational leadership model, focused much of his application of that model on how it is a process through which communal change can come about. Still, in our second interview, after he had finished reading Teaching to Transgress, he reflected on the ways in which the experience of reading the book, and what it had offered him more capacity to do, enhanced his ability to develop relationships. He said, "I think what this does is help me be more relational in an authentic way around issues of race, where as I may not have engaged with those issues in the past." He continued to describe the experience, saying that the book "has produced much deeper, authentic relationships, especially with my colleagues of color."

Terrance continued to build upon this connection in our final interview. He spoke to the ways in which this experience helped him to clarify his purpose, and part of working toward that purpose involved the relationships he built with people so they could 
work toward change. He said, "If anything, my purpose has been enhanced but the model hasn't changed." He also connected his understanding of leadership and his experience reading Teaching to Transgress with his understanding of social justice, saying they all orient around a process. He said, "I love, you know, that definition of social justice is a process. That is still real for me, to understand people are in their own processes and people are in their own spaces on this journey" as a way of describing the different ways in which he built relationships with others.

\section{Ernie}

Ernie spoke about relationships as a part of his understanding of leadership as well. In our first interview he spoke about them in the most general sense as it related to leadership, saying, "To be to a good follower, because I do understand the need for other people to hold the leadership role but then providing leadership within the role that I am given on the day, a task at hand." In our second interview, after he finished reading Teaching to Transgress, Ernie brought his examples a bit closer to himself and his work. He spoke about the relationships he could continue to develop with students and how the book offered him something to help engage "as a straight White male, to recognize the racism that exists and to have to rely on the students to tell me when they perceive that and that is a dangerous place to be in." He continued, saying he hoped to offer students space to be able to speak about their experiences and to believe those experiences were valued. He wondered, "How do you get students to speak up when they feeling they are being oppressed? How do you really change that relationship?" This also made him reflect on his identity as a White man and what it might mean for him to try to speak for the students rather than opening space for the students to speak for themselves, saying, 
"Every time I open up my mouth, I'm aware that I might be adjusting how they view any of these issues." Ultimately, he spoke about wanting to foster relationships that empower students rather than continue to silence them, much the same way that Fred spoke about relationships being connected to the communal aspects of leadership.

\section{Raymond}

"I think of leadership, I think in relation to other people. So, I don't think of it as a thing, but something, interaction and connection with other people." Raymond spoke about the part of his approach to leadership that involved building relationships as "getting to know people you work with. Student staff, if you work with faculty, community, whoever. Getting to know them." He continued, "I do try to get to know the people I'm working with beyond just, hey, we are colleagues. I do this work. You do that work. Okay, great, we are done." A bit later in our interview he spoke more specifically about how he also tried to be aware of how power and position were a part of those relationships. This was similar to how Ernie spoke about his own awareness of his identities and their power when forming and maintaining relationships. Raymond said, "I think I try to come from a perspective of letting the other talk first especially when there is positionality and I am talking to someone considered an entry level professional or someone that I supervise." He continued, saying that if he encouraged a newer professional to speak first they could work to find their own professional voice, rather than "feeling like they are just parrot what I have to say or follow my lead, but they feel have an opportunity to share their thoughts without being influenced by what I have to say." 
Raymond reiterated and expanded on these ideas at the end of the interview. He spoke about leadership having a component of the connections that are formed with other people, "not because I have a higher position and or have more authority or because I may have more information. I try to come from leadership with the idea of working together and having mutual goals and also mutual paths." He spoke to viewing the working relationships as being two people on a path together and needing to resist the urge to treat each person as if they were on their own journey that would never interact with his own. During our post-interview, Raymond returned to the idea of leadership involving relationships. He spoke more to how the experience of reading Teaching to Transgress helped him to continue to think about how he built the kinds of relationships of which he spoke earlier: "I think it has been encouraging for me to be more engaged in the areas of connection with students and staff, trying to incorporate [that relationship] more than it has potentially been done in the past," which Raymond spoke about as being part of how he believes a greater degree of participation and empowerment could be encouraged between himself and the staff and students with whom he worked.

\section{Gene}

Gene spoke about an aspect of leadership, within the frame of it being about building relationships, which also made it less about a relationship between one person and a group, but about how that person developed and supported other relationships. He said in our first interview that a real leader was someone who "learns and respects the people they are leading and their different styles of working and how each person would work with each other." Gene continued, saying that another dimension of leadership is developing an appreciation of people and what they bring to a team or a situation, saying 
that a leader "is not necessary leading people, [but rather] being able to be adaptable in situations and being practical and unbiased and how described earlier, not immediate putting people in boxes and labeling them." He extended this though more directly to the ways in which leadership can be practiced in the field of student affairs, saying, "In student affairs, my definition then would be to show students, to embrace tolerance, to show respect to all people." Given this perspective on leadership, Gene might have been able to find some connections between these ideas and those described in Teaching to Transgress; however he was not able to complete the book or his participation in the study.

\section{Synthesis}

While not as extensive as their thinking on leadership being a process that is communal and participator change making, several of the participants of this study still spoke very directly that there is a component of leadership that requires relationship building. While somewhat diverse in how they describe these relationships being cultivated, each of those who spoke to leadership being at least in part a process of relationship building spoke specifically about how leadership is not done in isolation, and has to do with the general ways in which one person interacts with another person. This was, in essence, the description of human relationships. Participants also spoke about leadership as being connected to the ways in which people act more specifically when they are in relationship, and those findings will be discussed in the next section.

\section{Leadership as Setting an Example}

In addition to building relationships, another action or way of taking up action to which many of the participants spoke is setting an example. These actions often focused 
on what people who are practicing leadership did in their relationships with others, making them related but distinct from ideas that leadership is relationship building. While not all of them used the phrase setting an example to describe the concept of leadership, over the course of their experiences many of the ways in which they did describe practicing leadership centered on this theme. Two themes often made up this larger framing of the participants understanding of leadership: acting with integrity and role modeling. Based on the way in which the participants spoke about these concepts, the distinction that is being drawn is that role modeling can be seen as showing others the behavior that one expects to see enacted. Acting with integrity, when spoken about by the participants, was more closely aligned with acting in ways that are consistent with espoused values and expectations. Since these concepts were also interconnected in the ways they were spoken about by the participants, I chose to write about them in that way, as being distinct and related concepts. For this reason, I will first present the findings that spoke to leadership being a process of acting with integrity, followed by the findings that spoke to leadership being a process of role modeling, because while acting with integrity can inform role modeling, role modeling can also be done without acting with integrity.

\section{Leadership as Acting with Integrity}

A number of the participants spoke about leadership as being related to acting with integrity. While each participant's definition of integrity varied, their central understanding of it was very similar and was connected to similar ideas, most often the concept of being accountable to others.

Fred. In our initial discussion, Fred spoke to the ways in which those who make decisions within an institution of higher education stayed accountable to their students. In 
our first interview, he spoke about the ways in which this idea had been emerging in his work, which at the time was as the Director of Student Conduct at a small private liberal arts college, saying, "[something that has been] coming up a lot now, is accountability and how it pairs with transparency." He continued, speaking about the ways in which people at his level can often exercise a great deal of influence, saying, "We know that we have tremendous influence over who gets funded or who gets opportunities." He further said, "I would hope that leaders in student affairs, myself included, we're calling attention to that, we're asking folks to reexamine why they do what they do." He also spoke about the transparency and accountability not only being for the students at the university, but also those students support networks. Fred reflected, "I think today's parents and families, and the folks that are helping in the process or contributing want to know what is actually happening and want to know how decisions are being made."

While the concept of integrity did not emerge in his journals or in our interview immediately following his reading of Teaching to Transgress, Fred did speak to it again in our final interview, which took place roughly six weeks after he had finished his reading and also was about two weeks after he had started his new position as the Director of Student Life at an open access community college. He still spoke about being accountable to students, this time demonstrating how he might make his decision making process visible for those impacted by his decisions. He said, "I don't make them in a vacuum. I ask for feedback. I check in with folks. I'm transparent where I am struggling. 'It's a tough decision. What do I do? This isn't an easy decision for me. This is, you know, this is difficult. What should I do here?"' He connected this approach to his 
personal values and to his perspective on leadership: it should empower and engage people in the process.

Ernie. Ernie also spoke about being accountable to others as part of practicing leadership while speaking about the ways that can be done by student affairs professionals at any organizational level. During our first interview, he said, "It is always being accountable and effective with your time and resources, and if you can do those things, you can improve leadership at any level in student affairs." He continued, noting that leadership also involves "consistency and that comes with accountability, just bring that same answer to the same group or a different group regardless of who's in the room." He finished that thought by noting, with some frustration, "I don't think you see that a lot."

During our second interview, which took place after Ernie had finished reading Teaching to Transgress, he spoke again about consistency; however, this time he connected the concept more closely to a consistency between values and action. He said that to him leadership involved holding closely a set of ideas and traits that could be counted on and depended upon by others. Ernie described his own characteristics, saying, "I am accountable. I am empathetic. I am positive. Above all else, [I will] be student centered and create an environment where they can direct and create what they want to create through their education experience."

In our final interview, which took place about four weeks later, Ernie again returned to integrity as a theme. In this interview, he spoke very directly to it, saying, "It's making sure how you present yourself and the actions you take represent the values that you have." He continued, speaking both to being "intentional about how interactions 
impact others" and "being consistently true to your principles and values, making sure your actions reflect them." When I asked him about how this could play out in a work place, Ernie spoke about having stayed at his current institution for such a long time, and aligning his institutional memory with the experiences of the students he served. He said that this has a lot to do with his personal values aligning with those of the university at which he worked: "That's why I worked here for so long." He described those values as a series of maxims: "It's be inclusive and be welcoming and approachable." He continued, describing a perception of academia and academics being cold and uncaring, which could be particularly damaging at Ernie's institution because "we're a primarily first generation, low-income school, and that's the background I come from. It's making sure the way I speak and the way others see me is approachable no matter what position I'm going to be in." He connected this idea back to the relationships that he built: "They should know that they can rely on me and my judgment and I'm here for them."

Terrance. Terrance only spoke about acting with integrity during our postinterview, immediately after he finished reading Teaching to Transgress. In that interview, while discussing his approach to leadership, he spoke about the ways in which he can practice leadership in situations where he, as a White person, still needs to be bringing up conversations about race on his campus. He said, "For me, being more real and being able to talk about race and not feeling like I have to be perfect and not feeling like I got to worry about you know how this can impact my career," referencing a previous part of our conversation in which he spoke about the ways in which he understood that being vocal about oppressive behavior could limit his opportunities for career advancement. He continued, reflecting on how he was still learning how to better 
talk about race but placing an importance on doing it even as he learned, saying that be believed it was important to make the effort and be open to receiving feedback on the effort, "It really comes down to how do we deal with feedback and are we somebody who is so egotistical we can't handle critical feedback, or are we somebody who owns that this feedback is true?" This, he said, was how he and others could continue to be the kind of "real" about which he had spoken earlier in that interview.

Raymond. Raymond spoke about the concept of integrity when speaking about the ways in which he practiced leadership in his workplace. He also spoke to the importance of both creating thoughtful policies and enacting them in ways that were thoughtful of those whom they impact. During our first interview, Raymond spoke about how he said he put a lot of thought into "trying to make sure in the policies and procedures that I am responsible for creating, updating, and enacting in a way that is inclusive of all the people in the group." This was, however, the only time that Raymond spoke to integrity as part of his understanding of leadership. Raymond did speak about the ways in which practicing leadership connects to role modeling, and these concepts do show up in connection to one another. Leadership as role modeling will be covered in the next section.

Jerome. Jerome, like Raymond, only made one reference to integrity when speaking about leadership, yet it still fit within the larger frame around which Jerome spoke about leadership as being in part about role modeling. Jerome's mention of integrity stood out because it was the only time when any of the participants wrote about leadership in a journal entry. Jerome wrote, "Much of Chapter 12 reminds me of the idea of doing a thing with integrity, i.e. practicing peace when preaching it, teaching about 
justice in a just way, or teaching about pedagogy in a pedagogically sound way." This, still, was aligned with the other ways in which Jerome spoke about leadership, which was consistent with this and other findings on leadership. The participants did not speak about these things as independent ideas, but as interconnected pieces of a larger idea.

\section{Leadership as Role Modeling}

Unlike integrity, "role modeling" was often the language that participants would use to name this concept. There were variations on the theme, in that not all participants spoke about the concept of role modeling in the exact same way. These definitions, however, all centered around concepts and approaches that, when closely examined, were connected around the idea of role modeling beyond simply having the same words used to describe them.

Fred. Fred spoke about his conception of leadership as being put into practice by role modeling. He spoke in our first interview of the ways in which he, as the Director of Student Conduct, made efforts to do this in his work, saying that role modeling is key to his work because "I think about everybody who I reach. [Am I] living in the principles of the institution, living in [my] values and really portraying that." This highlighted the ways in which participants spoke about integrity and role modeling being distinct but connected. Fred continued, reflecting on a question that further articulated his view of the relationship between integrity and role modeling, "If you are talking about being collaborative, then actually, you know, crossing the aisle and building partnerships with folks on campus, folks in the community." This conception was the thing upon which Fred built to speak about leadership as acting with integrity and so while he did not return 
to the concept of role modeling throughout the rest of the process, he did return to the idea that leadership is acting with integrity.

Raymond. "The first thing that comes to mind is role modeling." Raymond, differently from Fred, came to role modeling as a dimension of leadership later in the process. During our interview immediately after he finished reading Teaching to Transgress, Raymond spoke about role modeling as being a key part of how he understood practicing leadership. He said, "I think about leadership. I often think about it sort of the idea of role modeling and then taking the actions you think need to be taken."

Role modeling was also where Raymond found a connection between his understanding of leadership and his experience reading Teaching to Transgress. He spoke about seeing hooks write about how role models, saying that the he sees it showing up "around questioning, its questioning how things functioning and whether functioning the way we really want them to do and leading to the outcomes we would like." He also spoke about turning those questions inward on oneself: "Questioning if we are the ones needing to be looking at that or who else needs to be involved on the table and when we're having those kind of discussions." He continued that thought and also recalled another dimension of his understanding of leadership: leadership as a communal or participatory change process, saying, "I would say yes. Again my leadership is often more around role modeling and being a part of what you want to see happen." He continued, describing hooks' approach to role modeling, "I feel like part of what she is doing is in joining, to be a part of the process." This was the most direct and clear connection Raymond made between concepts of leadership and Teaching to Transgress. While it was less common for other participants, this connection was still substantive in 
that it articulated a direct connection between the experience of reading the book and understanding the concepts as practices of leadership.

Gene. Gene, during our first interview, spoke about leadership in a way similar to Ernie. He spoke about modeling the kinds of behavior that one hopes to see others enacting. Gene also spoke about this concept in a more future oriented way, in that he spoke about what potential role modeling offers for people within a community. He spoke about the students with whom he works and what seeing someone who is like them in so many ways modeling behavior can offer, saying it can be a way "to help them open their mind, expand their mind, and to tolerate what may be down here at [my university] which they never experienced." He gave a number of examples, including meeting people from different religions, different gender identities and sexual orientations, and a variety of political belief systems as well. He said he believed it to be important for students to see other people, to whom these students could look for guidance, interacting with and appreciating "things that they are not used to, be open minded and [have] respect for and think about ideas. When they see it they can model that kind of behavior." Gene continued to expand upon that idea, seeing it not just as how he practices leadership, but how leadership is and can continue to be taken up by student affairs professionals. He spoke about a belief that "student affairs and people in charge demonstrate the right behavior and embrace the behavior." While he believed there was still a lot of room for growth around practices of leadership in student affairs, he saw role modeling as "a different way to demonstrate or a better way to illuminate [behaviors and values to] students." Because Gene did not finish reading Teaching to Transgress, and also was not able to do any of the follow up interviews, there is much less data with which to work on 
understanding what, if any, connection he may have made between his experience reading the book and understanding leadership.

Jerome. While Jerome spoke a great deal about his perspective of leadership being very centered on communal participation and change, he also spoke to part of his understanding of leadership also being about role modeling. Building upon what he wrote in his journal about integrity, he, like Gene, spoke about role modeling as it related to what potential it could awaken for the students with whom he worked, saying that while important, "it can be very difficult when students are married to an idea what education should look like." He continued, acknowledging the importance of also modeling support through that challenge of pushing to change, "I think it's really important things to still help them and embrace that change, role model that things don't have to be as rigid for education to happen.” This is an idea that, had Jerome completed the final interview, would have been interesting to continue to explore with him as it developed through his practice after finishing Teaching to Transgress.

Ronald. Ronald, during our interview, he told me he wasn't going to be able to complete reading Teaching to Transgress for this project. He spoke about the importance of having students see him supporting colleagues and challenging systems of oppression in his work in university relations. He wondered, "How do they see me not showing up and what do they have if they have this [view of me as the] White patriarchy? Do they, does it land on them and that way? And probably yes." Ronald was the only person to explore the ways in which not role modeling behaviors can also contribute to the perpetuation of other behaviors, and still it offered a connection, some greater definition as to why modeling behaviors can be important in the practice of leadership. 
Synthesis. Some of the participants of this study spoke about two different aspects of setting an example as part of what they believed it meant to practice leadership, an internal dimension and an external dimension. Internally, it was important to these participants that those practicing leadership have an internal compass of values to which they were willing to remain true. This, for the purposes of reporting these findings, will be called "integrity" (a word that many participants used to describe this concept in their own practices of leadership and those of others). Externally, it was important to these participants that other people, often with whom they were in some kind of relationship, observe their behaviors and those behaviors be consistently aligned with both espoused personal and institutional values. This was called "role modeling," again a word many of the participants who spoke to this aspect of leadership used to describe the idea about which they were speaking. Together, these concepts can be combined as the notion of setting an example as a practice of leadership.

\section{Summary}

This chapter presented findings that focused on the topic of leadership. Specifically, this chapter offered the variety of ways that participants of this study describe conceptions of leadership. The vast majority of them describe leadership mostly as a process in which communal participation in creating change is the essence of leadership. This conception of leadership was by augmented descriptions of leadership that acknowledged the importance of role modeling, acting with integrity, and building relationships. Each of these pieces, when added to the conception of leadership as a communal and participatory effort to make change, created a framework upon which the participant's understanding of leadership was built. These findings directly addressed the 
third research question of this study: What, if any, impact does the experience of reading Teaching to Transgress have on how the participants understand leadership? The next chapter will discuss the findings presented in the previous three chapters in relation to the historical bodies of literature around the topics of transgressive teaching, identity, and leadership. The following chapter will also offer an assessment of the significance of this study, and implications for future practice and research. 


\section{CHAPTER EIGHT: DISCUSSING IMPLICATIONS}

\section{Introduction}

This chapter discusses the implications the findings for this study can offer to three fields. First, I discuss implications for transgressive teaching in the field of student affairs. Those implications are divided into three sections: affirming practices, engaging challenges, and supporting future development. I discuss these implications both as they relate to professional development and graduate preparation programs in student affairs. Next, I discuss findings for transgressive teaching and identities. This section, more specifically, offers implications for ongoing understanding of White identity, male identity, and heterosexual identity, and also other identities that came to salience during the process of reading Teaching to Transgress. This section also discusses how these dimensions of identity can all be a part of developing practices of allyship that acknowledge intersectionality. Next, I discuss implications for practicing leadership within the field of student affairs. Finally, I discuss what future research can be done to more deeply understand and offer greater nuance to the experiences explored with the participants in this study.

\section{Implications for Transgressive Teaching in Student Affairs}

First, I discuss the ways in which the findings of this study contribute to the greater understanding of transgressive teaching in the field of student affairs. I discuss the ways in which the findings offer the field of student affairs insight into the ways that practices can be affirmed, how challenges can be engaged, and how to support future develop in both student affairs graduate preparation programs and in ongoing professional development. 


\section{Affirming Practices}

Participants in this study spoke to a number of ways in which they believed their approach to student affairs connected to transgressive teaching as described by bell hooks in Teaching to Transgress. These connections took place both on a personal level, when looking at their own philosophies and approaches to their specific jobs, and also at larger, systemic level, when connecting the ideas to what they perceive to be the values and goals of the field of student affairs.

Many of the participants spoke about the ways in which transgressive teaching offered an approach to teaching in a holistic way that engages the entirety of each person more fully, which is a core value of the field of student affairs (ACPA, n.d; NASPA, n.d.). In many ways, experiencing this affirmation was also an outcome of transgressive teaching that hooks (1994) described as excitement and giving new voice to things which feel as though they have yet to be given space to exist (Bradley, 2009; Edwards, 2008; Labbe, 2010; NASPA, n.d.). This excitement was particularly generated in the beginning of the book, which can also be seen as a way of maintaining engagement throughout a process that also proved to be difficult and ongoing rather than clearly bounded (Chavez et al., 2003; hooks, 1994; Levtov, 2015; McLaughlin, 2017).

This affirmation is important for a number of reasons as the field of student affairs continues to grow. As social justice becomes more deeply embedded in the values of the field and as institutions continue to espouse values of diversity and inclusion (ACPA, n.d.; ACPA \& NASPA, 2010; NASPA, n.d.), offering affirmation when student affairs professionals take up the difficult work of addressing both individual instances of injustice and the ways in which many of those systems of have been codified into many 
of the systems with which people interact every day (hooks, 1994). Some participants shared there was a feeling of being one of a few people, or the only person, at an institution or in a department that was taking up the work in this way. In moments such as these it is additionally important for White, heterosexual, male student affairs practitioners to have this sort of affirmation, as a way to empower their voices and maintain their engagement (Aguilar et al., 2016; Ashlee et al., 2017; Berry, 2010; Grace \& Benson, 1999; Quaye \& Harper, 2007).

Many of the connections made by the participants were deepened by the experience of critical reflection. These processes were aided, according to the participants, by the journaling and interviews throughout this process, giving them the opportunity to examine their own experiences and how they may have shaped their approach to their work as student affairs professionals. This is critical to the ongoing, iterative work of understanding and practicing transgressive teaching (Chavez et al. 2003; Danowitz \& Tuitt, 2011; Edwards, 2008; hooks, 1994; McLaughlin, 2017). In addition to these affirmations, the findings also offered insight into the challenges faced and presented by the participants.

\section{Engaging Challenges}

Even though many felt the experience of reading Teaching to Transgress affirmed their understanding of and approach to the field of student affairs, there were still times throughout the process when the participants experienced challenges from the reading. These challenges were similar to what hooks (1994) described as resistance, a natural part of teaching in a way that pushes against much of what people have been taught about the world for much of their lives (Bullen, 2012; Edwards, 2008). Although the notion of 
challenging can have a negative connotation, it is also an opportunity in which learning can happen and is a meaningful part of the process of growth (Vera \& Speight, 2003). White, heterosexual, male student affairs professionals need to be able to engage honestly with the times they have fallen short of their own values or when their work has fallen short of their institutional and professional values (Bullen, 2012; Nicolazzo \& Harris, 2014). They also need to be able to manage the feedback they receive related to their impact on students and the learning taking place, rather than only expecting complete affirmation at every step of the way (Bullen, 2012; Edwards, 2008; hooks, 1994).

Much of the same can be said for the ways in which student affairs professionals challenged the ideas and experiences that hooks (1994) described. The process of reflection often involves some honest examination of the ways in which new information challenges what one believes about the world (Bullen, 2012; Edwards 2008; Vera \& Speight, 2003). Even as it continues to emerge that the practice of transgressive teaching is a way to expand the impact of student affairs practices of White, heterosexual, men in the field (Chavez et al., 2003; Levtov, 2015; Nicolazzo \& Harris, 2015), there will still be desires to push back against the challenges it offers, such as a desire to defend other White people when negative impact is observed, which can, as the findings offer, raise guilt and shame within student affairs professionals. For these reasons, it because important to also examine and understand what these findings hold for the future of student affairs professionals in addition to what it illuminates about the present.

\section{Supporting Future Development}

Many of the participants spoke to ways in which they believed this experience would be helpful for other student affairs professionals. Previous literature has offered 
suggestions for the benefit of these practices being employed by student affairs professionals (Chavez et al., 2003; Levtov, 2015; Nicolazzo \& Harris, 2014; Stewart, 2008), and in many ways the findings speak to affirming that recommendations and also offer ways to deepen them, particularly for White, heterosexual men in the field.

Student affairs graduate programs. While the connection and affirmation of these principles has and continues to be a part of student affairs graduate preparations programs, often it takes the form of informing that way faculty members teach their students how to be student affairs professionals (Danowitz \& Tuitt, 2011; Hubain et al., 2016; Jones \& Stewart, 2016), and while still not be a required aspect, but a suggestion that is, in fairness, continuing to build momentum. Because this literature only suggest these practices inform the way faculty teach their subject matter, the findings of this study build upon these assertions in that they speak to actually teaching transgressive teaching as a way of engaging students. The connections between the work of student affairs professionals and transgressive teaching were clearly experienced by the participants, a great deal more could be offered by an environment in which these reflections can be reinforced and integrated within other learning about the practice of being a student affairs professional. If these programs are, as Stewart (2008) suggested, training guides who need to be able to build trust with those whose journey they are shaping, then these practices could, as the findings suggest, impact the ways in which the White, heterosexual, male guides take up their roles.

The findings of this study offer examples of ways that reading Teaching to Transgress, along with directed, critical reflection on the ways in which the ideas connect both to the work of student affairs professionals and what the text offers about the 
dynamics that exist on college campuses. While most programs offer at least one required course on diversity topics in higher education, offering more opportunities for students not only to learn developmental theories that relate to a variety of identities but to engage in reflection about their own experiences, and the ways that those experiences may shape the ways in which each person takes up their work with students, could offer great promise (Danowitz \& Tuitt, 2011). These experiences could supplement the formal learning about theory, rather than be pitted against it, creating a theory informed practice (Bullen, 2012; Danowitz \& Tuitt, 2011). It also provides an opportunity examine the education that White, heterosexual, male student affairs professional has received, and can create an opportunity to ask questions about what impact that may have on their work with students (Bradley, 2009).

Finally, the environment of a student affairs graduate program would offer a different environment in which White, heterosexual, men can engage the impact of that experience. Rather than reading the book individually, if participants were able to have a group from whom they could receive support and with whom they were able to debrief their experiences as they were having them, new and deeper possibilities would likely emerge (Aguilar et al., 2016; Ashlee et al., 2017). While some participants did express an appreciation of me, and the ways in which their journals and interviews were helpful in making greater sense of the experience, the ways in which I was able to engage them, offer empathy, challenge, and support were limited by my role as researcher. Because I was not also a participant in the study, I could not take on that role.

This, of course, would also mean that both attention and intention would need to be given to ensuring that the practices of transgressive teaching continue to be 
accountable to the liberation that is at their core rather than to simply appease the experiences or coddle the feelings of those holding dominant social identity positions. While the experience offers great potential to examine and understand the experiences of privilege, doing so must be oriented towards changing those dynamics, and an environment in which future student affairs professionals learn their craft with a liberatory perspective needs to refuse to perpetuate the dynamics transgressive teaching works to address. This will require a great deal of feedback, reflection, and examination on the part of the faculty designing courses and programs (Edwards, 2008; Quaye \& Harper, 2007) and also means that White, heterosexual, men must be in discussion with others across identity dynamics to examine the ways in which these concepts are being used. If White, heterosexual, men in these programs are continuing to feel good about their experiences, but students of color and members of other minoritized groups do not feel as though they are being served by the experience, then transgressive teaching is not being effectively used.

Professional development. While there are many opportunities that this experience presents for evolving the ways in which White, heterosexual men learning how to become student affairs professionals can be taught about the field, it is equally important to address the ways in which these experience can be meaningful for White, heterosexual men who are already a part of the field and who still have opportunities to engage in ongoing professional development. While the participants of this study spoke to the ways in which reading the book was, in and of itself, helpful to their experience as a professional, there is still a need for support from their professional environments if these individual experiences are to begin to shift the larger scope of how student affairs 
work is taken up (Chavez et al., 2003; Nicolazzo \& Harris, 2014).

In fact, the reason for some of the participants not being able to complete participation in the project had to do with a difficulty in finding support for both continuing to participate and also for experimenting with new ways of approaching their roles. Because there will continue to be more work to do, the supportive network of a departmental professional development opportunity would offer a variety of ways in which individuals could find support in their experiences reading Teaching to Transgress. In many ways, this is a way in which the larger systems resist change. This would offer many of the same benefits that introducing the experience to a graduate program in student affairs would offer, in that a cohort of people could support one another, challenge each other, and deepen ideas through dialogue and discussion (Aguilar et al., 2016; Ashlee et al., 2017).

Utilizing this experience as a professional development opportunity within a department could also offer opportunities to examine the ways in which supervisory relationships and organizational power structures impact the work of student affairs professionals. Just as the demographics of students are ever diversifying (Chavez et al., 2003), so will be the demographics of student affairs professionals, and student affairs professionals need attention to be paid to how their environment contributes to sustaining their engagement in the same ways that students do (Levtov, 2015), and provide opportunities for departments, rather than select individuals, to put the values of their university and the field of student affairs into practice not only with their students but also with their colleagues, supervisors, and supervisees (Nicolazzo \& Harris, 2014). 
These experiences, like those that could be employed within a student affairs graduate preparation program, need to center an accountability that is outside of the perspectives of Whiteness, heterosexuality, and maleness. While transgressive teaching is designed specifically to challenge the historical power dynamics that benefit those who hold White, heterosexual, and male identities, it is still possible for those holding those identities to normalize their experiences within a social setting such as a professional development opportunity (Cabrera, 2012; Evans \& Broido, 2005; Keisling, 2007). Again, if the professional development experiences designed using a transgressive teaching framework, or designed around reaching Teaching to Transgress embolden and empower White, heterosexual, men but student affairs professionals who identify as people of color and members of other minoritized groups do not feel as though they are being served by the experience, then transgressive teaching is not being used for its intended purpose.

\section{Implications for Transgressive Teaching and Identities}

Transgressive teaching offers a variety of opportunities for anyone reading the text to examine their own identities and the positional experiences that are, in hooks' (1994) view, shaped by those identities. Teaching to Transgress, as a part of this study, gave the participants opportunities to examine aspects of their identity that included their Whiteness, heterosexuality, and maleness in the context of their work.

\section{Whiteness}

Participants in the study spoke to a variety of their identities being salient while reading Teaching to Transgress. All of the participants spoke to their White identity being salient for them throughout the book and many, even those for whom it was not a particularly salient identity before the initial interview, spoke to a different level of 
awareness of that identity in their work since reading Teaching to Transgress. Because it was a continual point of inquiry throughout the interviews and the journal prompts for the participants, and an identity about which hooks writes a great deal, participants had an ongoing opportunity to actively reflect on their own experiences and understandings of the world through the perspective that bell hooks (1994) offered in her writing (Reason, 2007). This also means that reading Teaching to Transgress can offer White people a different level of insight into the impact of systems of racism on non-White people, disrupting normalization and articulating the ways in which Whiteness shapes experiences in the world (Cabrera, 2012; Cobham, 2011; Evans \& Reason, 2007).

Many of the participants in this study spoke to the ways in which the experience of reading Teaching to Transgress brought to them not only a great degree of reflection and awareness of their White identity (Evans \& Reason, 2007; Reason, 2007), but also an understanding that they had an opportunity and some degree of responsibility to use that social position to influence events on their campus (Crowfoot \& Chesler, 1996).

Participants also noted that this experience offered them new, whether for the first time or simply in addition to what they had previously taken up, opportunities to explore these identities and find support in working to engage in discussions with colleagues, which is important to sustaining this reflection and development (Reason et al., 2005).

\section{Maleness}

Much in the same way that the participants spoke to the experience of reading Teaching to Transgress heightening the salience of their White identity, they also spoke to the ways in which the experience heightened the salience of their male identity. Like their White identities, maleness was an identity of which the participants had a level of 
awareness at the beginning of this study, so it was not completely invisible to them at the outset (Connell et al., 2005; Harris, 2010; Keisling, 2007).

Participants spoke about ways in which the experience provided them opportunities to explore the ways in which they show up at male in their work (Swain, 2005) and an increased awareness not only of the privilege of their identity but how it may influence the way they act in their interactions with others and how those interactions are experienced by others (Connell et al., 2005; Keisling, 2007). They spoke of the ways in which the experience of reading Teaching to Transgress helped to expand the ways in which they negotiate their expressions of maleness, to hold a greater diversity of possibilities for how they express their identity in their work as a student affairs professional (Anderson, 2007; Harris, 2010; Harris \& Edwards, 2010). This was able to take place, in part, because of the ways in which hooks (1994) actively named many of the ways in which societal expectations of maleness (as well as Whiteness and other dominant group identities) have been internalized and unquestioned (Harris, 2010).

\section{Heterosexuality}

The findings presented in this study offer that heterosexuality was one identity of which the participants were aware, much like they were aware of their identities as White and male; however, it was an identity that was less salient for them as they read Teaching to Transgress. Several mentioned it arising for a moment, specifically in the chapter in which hooks (1994) spoke to acknowledging sexuality (in her case, in the classroom). One participant said that on some level he actively made the choice to put that identity on the proverbial back burner to focus more on understanding other dimensions of his identity, and others spoke of it not being salient at all. This is worth examining because, 
like all of these identities, it is one that those holding it can chose to examine or not (Evans \& Broido, 2005; Worthington et al., 2002).

Three participants spoke to the chapter in which hooks (1994) mentioned sexuality to have been a moment in which that identity came into salience and stayed with them after the experience had ended. Two of those participants had mentioned that the thoughts hooks expressed in the text were ones to which they connected and recognized as realizations to which they had also come on their own at different points in their careers. While this experience could have offered an opportunity to understand more about how people who identify as heterosexual, in this case men who are White, relate or connect to this part of their identity (Worthington \& Mohr, 2002), it seems as though the majority of them did not find parts of the book that brought the experience to the surface to be further explored and understood (Ji, 2007; Simoni \& Walters, 2001). This continued situate heterosexuality as invisible to many of those who hold it as an identity (Evans \& Broido, 2005; Worthington et al., 2002) and perpetuated the hegemony both of heterosexuality within the field of student affairs and the experiences of White men if it is not examined more closely and with deeper intention. Based on the findings of this study, it is important for graduate programs in student affairs and professional development opportunities to create explicit and intentional experiences to examine this dimension of identity more closely, as well as future studies to direct more attention to heterosexuality and its connection to other identities studied within the experiences of the participants.

\section{Allyship Informed by Intersectionality}

All of the participants of this study saw themselves as allies at the time of their participation. Many of the participants spoke to an awareness at some point in the 
experience of reading Teaching to Transgress that they had opportunities to use the privileges that they received to be an agent of change and to benefit others who did not receive those privileges (Broido, 2000; Washington \& Evans, 1991). The participants who spoke to these realizations mostly spoke to it as it related to their White and male identities (Bourassa, 1991; Katz, 1996), and none spoke to the way that could also be used within the context of their heterosexual identity (Herek, 1988).

Additionally, while many of the participants spoke about the internal aspects of allyship being apparent to them before and throughout the process, many asked themselves throughout the experience of reading Teaching to Transgress how they demonstrated that commitment to those with whom they sought to work as allies. We can see this experience as playing some part in working to incorporate the external aspects of allyship rather than only focusing on the internal dimensions of it (Davis \& Wagner, 2005; Reason et al., 2005) and also as a way to harness the social power their voices are given because of their positional experiences (Washington \& Evans, 1991).

Participants also spoke to ways in which they understood their own interconnected experiences of identity as a part of their allyship. While many said they could connect to an identity of their own in which they have experienced oppression, they also spoke to how these experiences are also informed by their identities as White, heterosexual, and male as well as other identities that were salient to the participants (Collins, 2002; Crenshaw, 1991; McCall, 2005). They often offered that this was an opportunity to inform and make more complex the understanding between themselves and those with whom they were working to practice allyship (Berry, 2010; Bullen, 2012; hooks, 1994) rather than expecting those students or colleagues to share their own 
experiences without joining and building bridges (Bullen, 2012; Edwards, 2008; Stewart, 2008).

\section{Identity as a Teacher}

From the findings of this study, it would appear that while the experience of reading Teaching to Transgress can give student affairs professionals an opportunity to connect teaching practices to their work, it appears the process did more to strengthen an already held identity as an educator or a teacher than it did to create new reflections on its possibility. Because a number of the participants had experience with teaching, either through training and previous experience working in a primary or secondary classroom setting or current have opportunities to teach as a part of or adjacent to their current roles as student affairs professionals, they seemed to already hold that as part of their identity. The participants who already held this identity seemed to have it strengthened by hooks' (1994) approach to education.

This assertion is also informed by the findings from participants who in no way indicated have any training as a teacher or experience teaching at the university level but still already understood themselves to be teachers and their work to be oriented around teaching. Given these findings, it is likely that in addressing the second research question of this study - What, if any, impact does learning about transgressive teaching have on White, heterosexual, male student affairs professionals connecting their roles as student affairs professionals to an identity as an educator? - the experience gave participants an opportunity to connect to the identity of educator; it likely would only do so if it were an identity already held to some degree by that person. Again, hooks' (1994) approach to engaging students in educational spaces did not instill or generate this as a new 
connection for the participants, but for those who already held this sense of their work they found it as a point of connection.

\section{Student Affairs Graduate Programs}

In many of the same ways in which the experience of reading Teaching to Transgress could offer benefit to student affairs graduate programs through the connection, suggested by this study's findings, to the work of student affairs professionals, it can also offer opportunities for those in these programs to understand aspects of their own identity and how it shows up in their work with students and colleagues. The experience can offer opportunities to support theories of identity development, as they are being learned (Bullen, 2012; Danowitz \& Tuitt, 2011) by connecting to the examples of how these identities also are at play in larger systems and how they interact in individual experiences.

Additionally and in parallel to the ways in which transgressive teaching can support those learning about how to do the work of student affairs professionals, taking up learning about transgressive teaching in connection to learning about identities can help to create a network of support. This is particularly true when learning about identities which may often have been unexamined or seem invisible to those holding them (Connell et al., 2005; Evans \& Broido, 2005; Evans \& Reason, 2007; Harris, 2010; Keisling, 2007; Reason, 2007; Worthington et al., 2002) because that invisibility contributes to the perpetuation of the harm these normalized expectations can create for those who do not hold privileged identities within these spectra, and student affairs graduate programs can offer an opportunity for those holding these identities to engage through the difficulty of that experience (Davis, 2002; Davis \& Wagner, 2005). These 
opportunities are afforded to the faculty teaching these courses (Danowitz \& Tuitt, 2011) and to the peers in the course (Aguila et al., 2016; Ashlee et al., 2017) to be a part of guiding one another (Stewart, 2008).

\section{Professional Development}

Additionally, student affairs professionals, and particularly those who are White, heterosexual, and male, would benefit from an ongoing experience, or an opportunity to return to their earlier reflections on these identities and how they show up in their work with students (Davis, 2002; Davis \& Wagner, 2005). The experience of reading Teaching to Transgress offered the participants opportunities to reflect on what their White and male identities mean to them, and to a lesser extent their heterosexual identities. This means that this experience can be a way of naming and illuminating identities that are often invisible to those who hold them (Connell et al., 2005; Harris, 2010, Evans \& Broido, 2005; Evans \& Reason, 2007; Keisling, 2007; Reason, 2007; Worthington et al., 2002). It also means that there needs to be intention placed on the illumination of these identities so as not to perpetuate the normalization of them as experiences against which all other experiences are judged (Lipsitz, 1998) but rather to bring this normalization to a place where it can be examined, understood, and engaged actively as a way of addressing its impact both individually and systemically.

The experience would, again, offer an opportunity for support within a group, either from within or across identity groups. Participants offered that a structured, supportive environment would be helpful to support the reflection and development they felt the experience offered them, which is also key to sustaining this work in an ongoing way for student affairs professionals (Chavez et al., 2003; Levtov, 2015; Nicolazzo \& 
Harris, 2014). Again, this also offers the opportunity for communities of support through the process (Aguilar et al., 2016; Ashlee et al., 2017) and also an opportunity to learn both within and among group membership (Connell et al., 2005).

\section{Implications for Leadership and Student Affairs}

Leadership means a variety of things, and those meanings can change a great deal dependent on a number of factors. While the social change model of leadership was specifically designed to address practices of leadership on college campuses (Komives \& Wagner, 2016; Pope et al., 2014), it has been mostly written about in ways related the model's application to students, but not staff. This can have an impact on the ways in which all who are learning about leadership manage these differences and the possible cognitive dissonance that can emerge. The findings of this study, in many ways, point to the possibilities available for leadership practices by student affairs professionals working with students in employing the social change model of leadership.

\section{Participating in Change}

Creating change was a foundational part of how the majority of the participants in this study spoke about defining leadership and practicing it within the field of student affairs. More specifically, the participants of this study often spoke of leadership as creating change by encouraging and making possible a more communal participation in that process of change. Change is also at the core of the social change model of leadership as is the notion that leadership is a process rather than an outcome or a result, and so necessitates participation (Komives \& Wagner, 2016). hooks (1994) described a similar idea when saying that transgressive teaching is, in part, through sharing in both spiritual and intellectual growth along with students rather than simply observing their 
growth (Bullen, 2012; Edwards, 2008; Labbe, 2010). Student affairs professionals, in practicing leadership, can be active in lifting up the voices of their students and their colleagues, and also can engage their own growth as a part of that process by challenging and being challenged to move outside of the current structures. These can all be a way of enacting the social change model, and transgressive teaching, in the practices of student affairs professionals.

This aspect of practicing leadership is also important as it relates to the nature of systems of power and identity. Having a greater awareness of identities and their impact which often are invisible to those who live within them (Connell et al., 2005; Harris, 2010; Evans \& Broido, 2005; Evans \& Reason, 2007; Keisling, 2007; Reason, 2007; Worthington et al., 2002) can mean that student affairs professionals will also be able to be more ready to be challenged and to challenge others assumptions about how leadership can be practiced and how change can be effected (Dugan et al., 2015; Priest \& Clegorne, 2015), or as Bullen (2012) described it, being "conditioned and aware of the conditioning" (pp. 2-3) and which the social change model described as a consciousness of one's self (Komives \& Wagner, 2016). Based on the findings of this study, it appears that transgressive teaching can help to address the realities of authority and power dynamics at individual and systemic levels as part of the process of creating change in ways the social change model by itself does not (Dugan et al., 2015). Transgressive teaching, it would seem, also can help make student affairs professionals more effective in bringing into the processes students who have historically been pushed away from accessing those spaces (Dugan et al., 2012). 


\section{Relationships}

The participants in this study often framed leadership as building relationships in addition to being a participatory and communal change process. Within the social change model, relationships are a key component working toward the change that is in the center of the model, and in fact all practices of leadership (Komives \& Wagner, 2016), and specific kinds of relationships can be particularly helpful in managing the tension that can arise from the more difficulty aspects of the model (Campbell et al., 2012; Dugan, 2006; Priest \& Clegorne 2015). This can be equally important for student affairs professionals in their efforts to practice leadership, as evident by this study's findings, because the relationships they work to develop with students and with colleagues often are an aspect of what helps them to address the more difficult aspects of engaging across differences (Dugan et al., 2012; Dugan et al., 2015). This is made further clear when examined through the lens of privileged identities, again as the findings of this study articulate, that transgressive teaching offers student affairs professionals opportunities to engage themselves, not just the students with whom they work, "to engage individuals and collectives in the process of self-exploration associated with raising power consciousness" (Dugan et al., 2015, p. 11).

\section{Setting an Example}

The participants of this study additionally described leadership as a practice of both role modeling and acting with integrity, which can be seem as two distinct and connected ways of setting an example. This is analogous to what the social change model calls "congruence" (Dugan \& Komives, 2011, p. 526), or a way of acting and thinking in ways that are authentic, genuine, and aligned with expressed and held beliefs (Komives 
\& Wagner, 2016). This can be expressed through the mentoring process, which again is a critical factor in sustaining student participation in the change toward which the social change model is oriented (Campbell et al., 2012; Priest \& Clegorne, 2015). The findings of this study also assert that this can be important in practicing leadership as a student affairs professional, because this creates a more consistent example across the ways in which students are being encouraged to take up leadership and the ways in which leadership practice is being role modeled by mentors and supervisors.

These findings are relevant to the ways in which student affairs professionals practice leadership beyond their interactions with student, and for those holding one or more dominant group identities. Because most of the historical context for practicing leadership as a student affairs professional focuses on the ways in which people with positional authority enact that authority (Bryman, 2007; Dalton, 2002; Dalton \& Gardner, 2002; Sandeen, 1991; Thomas, 2002), and positional authority could be another way of understanding privileged identities and the social power afforded those who hold them (Connell et al., 2005; Harris, 2010; Evans \& Broido, 2005; Evans \& Reason, 2007; Keisling, 2007; Reason, 2007; Worthington et al., 2002), the findings of this study suggest transgressive teaching offered the participants a new way in which to view how they enacted the power they were given. This, in turn, means that they were able to potentially take up new approaches to engaging with their peers and colleagues and in doing so set examples for ways other professionals (and students) to approach these interactions. 


\section{Student Affairs Graduate Programs}

As with the other findings of this study, those on leadership in student affairs also has implications for the potential of transgressive teacher to be incorporated into student affairs graduate programs. Rather than continuing to focus on presenting leadership in student affairs as a hierarchical structure and a function of positional authority (Bryman, 2007; Dalton, 2002; Dalton \& Gardner, 2002; Sandeen, 1991; Thomas, 2002) while teaching theories that articulate students can approach leadership in ways that are transformative and that focus on both challenging and changing systems that diminish participation to become more inclusive (Komives \& Wagner, 2016), the findings of this study encourage a congruence (Dugan \& Komives, 2011; Komives \& Wagner, 2016) as being the example that can be set. This means, in programs that train student affairs professionals, an effort to incorporate an understanding of how to practice transgressive teaching could bolster the potential to work with students in ways that set examples congruent with the models students are encouraged the use (Danowitz \& Tuitt, 2011; Hubain et al., 2016; Jones \& Stewart, 2016).

\section{Professional Development}

While these findings hold substantive implications for the ways in which new student affairs professionals could be trained as they prepare to enter the field, they also offer meaningful opportunities for the professional development of student affairs professionals already practicing in the field. The incorporation of transgressive teaching can be a catalyst for aligning practices of leadership with the work of student affairs professionals individually and also to the sustainability of the field (Chavez et al., 2003; Levtov, 2015; Nicolazzo \& Harris, 2014). This is especially important for the many ways 
in which people from a variety of places within the organizational hierarchy of a college or university take up practicing leadership or is encouraged to practice leadership. Rather than continuing to only frame leadership within the field of student affairs as being connected to positional authority (Bryman, 2007; Dalton, 2002; Dalton \& Gardner, 2002; Sandeen, 1991; Thomas, 2002), transgressive teaching offers an opportunity for student affairs professionals to practice leadership in ways that align with the ways in which they encourage and empower students to practice leadership and professional values (Levtov, 2015; Nicolazzo \& Harris, 2015). Because this process of rethinking can be challenging (Dugan, 2006), it would be helpful to have a supportive group of colleagues with which to process the experience (Aguilar et al., 2016; Ashlee et al., 2017), which the experiences of the participants of this study affirmed.

\section{Implications for Future Research}

There are a number of ways in which the research of this study could be expanded to deepen the understanding that the current findings offer. These would provide opportunities to compare the findings of this study to other identity interactions, to understand the ways that other institutional contexts interact with the experience of participants, the ways in which different positions and types of student interaction also impact the experience and the ways in which different methodological approaches may offer other insights into the impact of reading Teaching to Transgress on the practices of student affairs professionals. The first way is by gathering a greater number of participants and from functional areas of student affairs that are not already represented. 


\section{Further Exploring Heterosexuality}

The majority of the participants in this study spoke to an awareness of the privilege that comes with their heterosexual identity, but the identity remained relatively invisible throughout this study in comparison to the prominence of the examination of White and male identities by all participants. A future study will need to more clearly explore heterosexuality and its role in the experiences of interaction between students and student affairs professionals on college campuses. Making this dimension of identity more explicit would address the ongoing invisibility created by the normalization of heterosexuality that has been addressed in the literature (Evans \& Broido, 2005; Worthington et al., 2002), would address the ways in which, throughout this study, it remained invisible and unaddressed in large part. Left continually unaddressed, heterosexuality's influence on the dynamics of interactions will continue to persist and will likely disrupt efforts to address the many intersecting dynamics of identity that play out on college campuses and which the practices of transgressive teaching seek to address.

\section{Incorporating Other Salient Identities}

While all of the participants in this study acknowledged they had some awareness of their identities as White, heterosexual, and male, there were other identities that were salient for them as well. Two specifically were important for the majority of the participants, before the study and throughout and after the study. It would be important for future research to consider the ways in which these identities could be incorporated and studied in addition to Whiteness, heterosexuality, and maleness. 
Class. While not an explicit part of the study at the beginning, class was a theme that many of the participants discussed throughout the experience of reading Teaching to Transgress. hooks (1994) spoke directly about the way in which class is another system of identity that shapes the experiences, and her speaking directly to this dimension of identity meant that for many participants it was more salient for them throughout their experience reading Teaching to Transgress. For many of the participants, they were aware of the ways in which their position in student affairs, and having an advanced or terminal degree, might afford them access to different resources and capital than those available to them when growing up (Bourdeiu, 1986/2011).

Religion/meaning making. Many of the participants spoke to the ways in which religion (and an absence of religion) was an important part of their experience in the world. To that point, of the nine participants, four described themselves as atheists. While there was not a dimension of the study designed to understand the ways in which that identity was connected to their experience reading Teaching to Transgress, a future study could target participation for atheists or might design research questions that ask participants to reflect more directly on their faith throughout the experience. Unlike class, however, this is not an aspect of identity to which hooks (1994) spoke directly in Teaching to Transgress. So while it may still be salient for participants, a future study would need to be designed to more directly address what ways in which the participants were connecting that salience to their experience reading the text.

\section{Beyond White, Heterosexual, Male Identities}

Another dimension of exploration that would expand and add nuance to the findings of this study would be to examine the experiences of student affairs 
professionals who hold at least one, if not more than one, identity that differs from that of a White, heterosexual, male. This would offer an opportunity to examine the ways in which these experiences diverge in the understanding of transgressive teaching and the impact it may have on practices. The opportunity for comparison also presents the possibility of alignment across different identities. In either instance, these opportunities would help to gain a broader and also a more in-depth understanding of the ways in which transgressive teaching may expand the practices of student affairs professionals.

\section{Unstudied Functional Areas}

In the same way that certain dimensions of identity were not the focus of this study, and in the same way that the data collected would continue to be made more robust and nuanced by an examination of those identities and their interaction with the experience of reading Teaching to Transgress, much of the same could be said about the variety of functional areas there were not represented in the experiences of participants in this study. Each of the functional areas described below have their own unique interactions with students, and the uniqueness of those interactions in combination with the interconnectedness of these experiences to the ones in which the participants of this study engage with students means that it could better understand what, if anything, transgressive teaching offers for student affairs practices.

Greek life. This study offered perspectives from two people who work in student conduct, two in residence life, one in student unions, one in student leadership, one working in a dean of students office, and one in university relations, so there were many areas unrepresented. One such area is Greek life, which, for campuses that have Greek 
life programs, is a major focus of student involvement and where a great deal of student leadership education takes place.

There is no statistic that can indicate just how many college students are involved in Greek life across the United States. However, if I were to have had participation from the student affairs professionals working with Greek organizations at the institutions at which the current participants work, where involvement in Greek life ranges from $7 \%$ to $29 \%$, this would still represent a sizable portion of the student population at these institutions. Expanding that outward, with some schools across the United States reporting as high as $79 \%$ student involvement in Greek life in the academic year beginning 2015 (U.S. News \& World Report, n.d.), which means this an experience that provides a variety of substantive learning opportunities for students at colleges and universities that have Greek Life. The student affairs professionals involved in facilitating these opportunities, in turn, have an important insight into the experiences of students. For these reasons, their perspectives would be valuable in continuing to deepen the understanding of how transgressive teaching can be a part of the work of student affairs professionals.

Academic advising. Another functional area that was not explored was academic advising. This is an area where there is a high degree of student contact and a very specific kind of contact, sometimes overlapping with the kinds of contact experienced by some of the participants of this study. More specifically, academic advisors often interact with students across a host of issues, both academic and social. Another aspect of interest in the ways the experience of this study would impact with the work of academic advisors is the wide variations between individual institutions on the scope and nature of 
the work of academic advisors. All of these differences in the types of student interaction could offer a great deal of further insight into the ways in which transgressive teaching may impact the ways that student affairs professionals take up their work. It also could mean a variety of interesting things depending on the identities of the students at a particular university and how a White, heterosexual, male academic advisor may engage with those students and the impact a transgressive teaching approach might have on rethinking those interactions.

Student health and wellness. Yet another area of student affairs that was not represented in the participants of this study is student health and wellness. Again, these are professionals who have a high degree of interaction with students, and again those interactions take a variety of forms that can sometimes straddle the academic and social arenas of students' college experiences. Often, these staff members engage with students in moments of great vulnerability, either through a health center or in engaging students in proactive wellness programing around a variety of sensitive issues. These interactions also can involve a great deal of learning and development about a variety of actions that directly impact the physical and mental health of students. For these reasons, it would add an additional layer of data and a greater understanding of the ways in which functional context can play a role in ways that transgressive teaching could align with concepts of transgressive teaching. It also offers a different set of opportunities for professionals in this functional area who are White, heterosexual, and male to examine the ways in which those identities, and a call to reflect actively upon them through transgressive teaching, can impact their work. 
Orientation. The staff of orientation, like the other student affairs functional areas described above, have a unique interaction with students in that they are often some of the first people students encounter when beginning their college experience. For staff members who are given such a task, to create the first impression for a student entering college (or at least a particular campus environment, since transfer students attend orientation as well), means that there are opportunities to have transgressive teaching be the first experience students have interacting with the campus community and staff. An active recruitment of professionals who identify as White, heterosexual, and male within this functional area would, as with the other areas mentioned above, offer a greater depth and breadth to the findings of this study.

Outdoor education and recreation. As with the other functional areas mentioned in this section, outdoor education and recreation (which at many schools is often named some combination of those words) holds an experience for student engagement that is unique in that it provides opportunities to engage in the same kinds of learning in contexts such as overnight camping trips, rock climbing, and hiking. This functional area takes these experiences up within the larger system of student affairs. This represents an opportunity to understand how systems of oppression also play out in these environments, as well as representing an opportunity to learn how to address them. While, depending on the college in question, this functional area may have a smaller scope of interaction with students than, for example, orientation, Greek life or student health and wellness, these interactions can still be substantive and fertile groups for learning. For these reasons an active recruitment of White, heterosexual, male 
professionals from this functional area would add a great deal to future studies on the impact of transgressive teaching on the work of student affairs professionals.

\section{Unstudied Institutional Types}

In addition to a variety of functional areas not being represented by the participants, there are also institutional types that were not represented. While all of these schools function generally in the same way that other colleges and universities do, the ones which were not a part of the experiences of the participants also have specific importance to the history and landscape of higher education. These institution types also can have very different cultural aspects to them, given that two of the types of institutions that were not represented are institution types that, predominantly, serve populations that hold identities that are targeted by systems of oppression. For these reasons, it would be important to understand the experiences of White, heterosexual men who work with students at these institutions.

Gender-specific colleges. Before describing this implication, some explanation of the section title is necessary. Most of the colleges to which I am referring would be thought of as women's colleges. I chose the phrase "gender-specific colleges" rather than the phrase "single-gender college," "historically gendered colleges," or "women's colleges" for three reasons. First, most colleges in the United States were at one point only intended to serve a single-gendered environment with many of the most prominent colleges not admitting non-male people until the later half of the $20^{\text {th }}$ century, which means that historically gendered colleges would not accurately refer to those to which I hope to make reference. Second, women's colleges are not the only colleges that continue to serve a community smaller than the full range of gender identities (although they are 
the vast majority of this type in the United States). Finally, many colleges which have historically been thought of as women's college have begun to expand their admissions to include trans* people, based on the orienting mission of these schools being to create spaces in which education can be a tool to push against systems of gender- and sex-based oppression. Therefore they would not be single-gender colleges. So, I will refer to them as gender-specific colleges, since they serve specific gender categories rather than the entirety of gender identities as their constituents.

With that in mind, none of the participants of this study currently work at an institution that is of the type described above. One participant did speak to having, in the past, worked at one such college, and he spoke to the ways in which that experience had an impact in shaping the dimensions of his own salient identities and approach to his work as a student affairs professional. However, he had left that position years before beginning the project, and so was not able to speak to the ways in which the experience of reading Teaching to Transgress had an impact on this approach to his work in that type of environment.

An acknowledgement of this institutional type is important, especially in the context of understanding the practices of White, heterosexual, male student affairs professionals. This is because many of these institutions are designed to challenge the ways in which at least one of those identities has been reified in higher education. Additionally, men's colleges would provide an equally interesting and potentially starkly different opportunity to examine the ways in which White, heterosexual, and male identities inform the practices of student affairs professionals at those institutions and how the experience of reading Teaching to Transgress could impact those practices. This 
also, as mentioned before, could be an opportunity to study the experiences of student affairs professionals who are outside of the White, heterosexual, male experience and examine the ways in which those experiences diverge or align.

Historically Black colleges and universities. In the same way that genderspecific colleges were not an institutional type represented by the participants in this study, historically Black college and universities (HBCUs) were also not represented. While having very different histories, there are similarities in the broader purposes that HBCUs and gender-specific colleges serve the communities they represent because those communities were not being served well by higher education institutions. Particularly for the implications they hold for this study, in that it is likely that a White, heterosexual, male student affairs professional could be employed at one of these schools. Additionally, because White, heterosexual, male student affairs professionals do work at HCBUs, the opportunity to examine the experience they would have in reading Teaching to Transgress and how that experience impacts their work within a very specific institutional context would offer a great deal to the ways in which these practices could be more deeply understood in their application to the work of student affairs professionals.

\section{Additional Methodologies}

In addition to expanding the scope of the research through recruiting a variety of participant experiences that were not a part of this participant group, another way in which the findings of this study could be expanded would be through using additional methodologies to analyze the data. One of the approaches that, given the findings and implications from this study, stands out is the use of a case study methodology. 
Case study methodology. Given the previously mentioned implications for student affairs graduate preparation programs and for professional development provided by the findings in this study, it would then follow that one potential way to approach a future study would be to apply a case study methodology. This would offer an opportunity to study the phenomenon and the context in connection to one another (Baxter \& Jack, 2008; Bryman, 2012; Creswell, 1998; Stake, 1995; Yin, 2003). A case study approach to a specific environment would also lead to the possibility to offer what Stake (1995) called "petite generalizations" in that the findings at least offer the opportunity to make generalizations about a particular context or smaller subset of contexts based on the data collected (p. 7).

While the use of a case study methodology would not, necessarily, lead to generalizations about the entire field of student affairs after simply one study, it would provide a deeper insight into the ways in which institutional contexts interact with the experience of reading Teaching to Transgress, which over time could lead to a more general understanding of the ways in which this could be incorporated into student affairs practice. The location for this case, or a potential multitude of cases, for this future study could also include a comparison between a student affairs graduate preparation program and a professional development opportunity for current professionals, as a way of understanding the differences between these contexts impact on the experience.

\section{Significance}

Ultimately the major significance of this study is that it is the first to examine the experiences of any student affairs professionals as they directly engage with the concepts of transgressive teaching and work to understand how these concepts can be incorporated 
into their work. While other scholars have suggested these practices would be beneficial to the practices of student affairs professionals, those recommendations have been based either solely on reviews of the literature (Chavez et al., 2003; Levtov, 2015; Nicolazzo \& Harris, 2014; Stewart, 2008; Watt, 2015), studying the stated needs of students (McLaughlin, 2017) or the interaction with practices of transgressive teaching through course design by faculty (Danowitz \& Tuitt, 2011). This study affirms these assertions by supporting them with data that student affairs professionals do make connections between the practices of transgressive teaching and their work.

This study also offers data to address possible ways in which people who hold multiple dominant group identities (in this case White, heterosexual, men) can work to be active participants in creating more socially just campus environments through the ways in which they interact with students of a variety of identities. The previous literature around dominant group identities has mostly focused on only singular identities and the ways in which people holding those identities can be catalyzed as change agents (Davis \& Wagner, 2005; Reason et al., 2005; Washington \& Evans, 1991). This study, however, offers a path through which those who hold multiple dominant group identities can reflect on the way those identities shape their experiences in the world and potentially translate that reflection into action on their campuses.

This study also presents data to support the assertion that Teaching to Transgress is a text that not only should be a part of teacher education programs (Berry, 2010; Cochran-Smith, 2001; Grace \& Benson, 1999; Hackman, 2005; Vavrus, 2002) and undergraduate and graduate level faculty development (Barnett, 2012; Bradley, 2009; Danowitz \& Tuitt, 2011; Edwards, 2008; Labbe, 2010; LaMantia, Wagner, \& Bohecker, 
2015; Quaye \& Harper, 2007) but also a part of student affairs graduate preparation programs and student affairs professional development that could offer a path to similarly transformative results. This study offers the first collection of data to support this claim and also offers a great deal of potential for further research and application within the field. More specifically, this study highlights the ways in which Teaching to Transgress provides a framework for White, heterosexual, male student affairs professionals, either in their graduate programs or at a later point in their own professional development, to reflect upon how those identities and develop a different level of awareness of how those identities and their social power can be harnessed to positively impact the experiences of students on their campuses.

Finally, this study addresses a gap in the literature previously identified within the social change model of leadership and also illuminates and addresses a previously unidentified gap. The social change model of leadership often does not acknowledge or challenge the ways in which power and authority are systemically embedded within group functions, even those working toward social change (Dugan et al., 2015), and reading Teaching to Transgress can offer those learning about and working to incorporate The social change model into their work with students and the work toward which they orient their students a way to address these dynamics. Additionally, the social change model of leadership assumes that the student affairs professionals who engage students in this model have reached a level of actualization around the concepts within the model. This assumption is both challenged by Teaching to Transgress, and according to this study, can be addressed by developing capacities for transgressive teaching into the practices of White, heterosexual, male student affairs professionals. 


\section{Summary}

This chapter has offered a discussion of the findings of this study within the context of the previous literature on the areas of research that have informed the generation of this study. Specifically, this chapter focused on situating the findings of this study, examining the experiences of White, heterosexual, male student affairs professionals reading Teaching to Transgress, within literature on transgressive teaching (both in classrooms and in the field of student affairs) and the benefits of its use.

Additionally, the findings were situated within the historical context of dominant group identities (specifically Whiteness, heterosexuality, and maleness) and the social change model of leadership. Through this discussion, a variety of implications for both ongoing development of student affairs graduate preparation programs and ongoing professional development of student affairs professionals have also been offered. These included refining the design of the study to include identities such as class and religion, expanding the participant pool to include White, heterosexual, male student affairs professionals who work in functional areas such as Greek life, student wellness, and outdoor education, as well as professionals who work at gender specific colleges and HBCUs. Finally, the findings of this study offer implications for using a different research methodology, a case study, to follow the experiences of a group rather than a collection of individuals, through the process of examining how, if at all, transgressive teaching can connect to their work as student affairs professionals and how it may be impactful for those who are White, heterosexual, and male. 


\section{REFERENCES}

American College Personnel Association (n.d.). Values. Retrieved from www.acpa.nche.edu/values

American College Personnel Association \& National Association of Student Personnel Administrators (2010). Envisioning the future of student affairs. Retrieved from www.naspa.org/images/uploads/main/Task_Force_Student_Affairs_2010_Re port.pdf

Aguilar, K., Brito, F. N., Salazar, C., \& Alavarez, N. (2016). Access and equity in graduate writing support. Praxis: A Writing Center Journal, 14(1), 9-14

American Council on Education. (1937). The student personnel point of view. Washington, DC.

Anderson, E. (2007). Inclusive masculinity in a fraternal setting. Men and Masculinities, $10,605-620$.

Ashlee, A. A., Zamora, B., \& Karikari, S. N. (2017). We are woke: A collaborative critical autoethnography of three "womxn" of color graduate students in higher education. International Journal of Multicultural Education, 19, 89-104.

Barnett, R. (2012). Learning for an unknown future. Higher Education Research \& Development, 31, 65-77.

Baxter, P., \& Jack, S. (2008). Qualitative case study methodology: Study design and implementation for novice researchers. Qualitative Report, 13, 544-559.

Bensimon, E. M. (2007). The underestimated significance of practitioner knowledge in the scholarship on student success. Review of Higher Education, 30, 441-469.

Berry, T. R. (2010). Engaged pedagogy and critical race feminism. Educational Foundations 24 19-26.

Bonilla-Silva, E. (2010). Racism without racists: Color-blind racism and racial inequality in contemporary America ( ${ }^{\text {rd }}$ ed.). Lanham, MD: Rowman \& Littlefield.

Bourassa, D. M. (1991). How white students and students of color organize and interact on campus. New Directions for Student Services, 1991(56), 13-23.

Bradley, A. J. (2009). Listen to our reality: Experiences of racism, prejudice, and bias in the classroom. The Vermont Connection, 30(1) 12-31. 
Broido, E. M. (2000). The development of social justice allies during college: A phenomenological investigation. Journal of College Student Development, 41, 318.

Bryman, A. (2007). Effective leadership in higher education: A literature review. Studies in Higher Education, 32, 693-710.

Bryman, A. (2012). Social research methods (4 ${ }^{\text {th }}$ ed.). Oxford, England: Oxford University Press.

Bullen, P. E. (2012). The continued relevance of Teaching to Transgress: Education as the Practice of Freedom. Journal of College Teaching and Learning, 9(1), 21-25.

Cabrera, N. L. (2012). Working through whiteness: White, male college students challenging racism. Review of Higher Education, 35, 375-401.

Campbell, C. M., Smith, M., Dugan, J. P., \& Komives, S. R. (2012). Mentors and college student leadership outcomes: The importance of position and process. Review of Higher Education, 35, 595-625.

Chávez, A. F., Guido-DiBrito, F., \& Mallory, S. L. (2003). Learning to value the "other": A framework of individual diversity development. Journal of College Student Development, 44, 453-469.

Charmaz, K. (2014). Constructing grounded theory. Thousand Oaks, CA: Sage.

Cobham, B. A. M. (2011). White college students. In M. J. Cuyjet \& M. F. HowardHamilton (Eds.), Multiculturalism on campus (pp. 213-236). Sterling, VA: Stylus.

Cochran-Smith, M. (2001). Learning to teach against the (new) grain. Journal of Teacher Education, 52(1), 3-4.

Collins, P. H. (2002). Black feminist thought: Knowledge, consciousness, and the politics of empowerment. New York, NY: Routledge.

Connell, R. W., Hearn, J., \& Kimmel, M. S. (2005). Introduction. In M. S. Kimmel, J. Hearn, \& R. W. Connell (Eds.), Handbook of studies on men and masculinities (pp. 1-12). Thousand Oaks, CA: Sage.

Corbin, J., \& Strauss, A. (2008). Basics of qualitative research ( $3^{\text {rd }}$ ed.). Thousand Oaks, CA: Sage.

Crenshaw, K. (1991). Mapping the margins: Intersectionality, identity politics, and violence against women of color. Stanford Law Review, 43(6), 1,241-1,299. 
Creswell, J. W. (1998). Qualitative inquiry and research design: Choosing among five traditions. Thousand Oaks, CA: Sage.

Croteau, J. M., Talbot, D. M., Lance, T. S., \& Evans, N. J. (2002). A qualitative study of the interplay between privilege and oppression. Journal of Multicultural Counseling and Development, 30, 239-258.

Crowfoot, J. E., \& Chesler, M. A. (1996). White men's roles in multicultural coalitions. In B. Bowser \& R. G. Hunt (Eds.), Impacts of racism on White Americans (pp. 202-229). Thousand Oaks, CA: Sage.

D'Augelli, A. R. (1991). Gay men in college: Identity processes and adaptations. Journal of College Student Development, 32, 140-156.

Dalton, J. C. (2002). The art and practical wisdom of student affairs leadership. New Directions for Student Services, 2002(98), 3-10.

Dalton, J. C., \& Imanuel Gardner, D. (2002). Managing change in student affairs leadership roles. New Directions for Student Services, 2002(98), 37-48.

Danowitz, M. A. \& Tuitt, F. (2011). Enacting inclusivity through engaged pedagogy: A higher education perspective. Equity \& Excellence in Education, 44(1), 40-56.

Davis, T. L. (2002). Voices of gender role conflict: The social construction of college men's identity. Journal of College Student Development, 43, 508-521.

Davis, T. L., \& Wagner, R. (2005). Increasing men's development of social justice attitudes and actions. New Directions for Student Services, 2005(110), 29-41.

Dugan, J. P. (2006). Explorations using the social change model: Leadership development among college men and women. Journal of College Student Development, 47, 217-225.

Dugan, J. P. (2011). Students' involvement in group experiences and connections to leadership development. New Directions for Institutional Research, 2011, 17-32.

Dugan, J. P., Kodama, C. M., \& Gebhardt, M. C. (2012). Race and leadership development among college students: The additive value of collective racial esteem. Journal of Diversity in Higher Education, 5(3), 174-189.

Dugan, J. P., \& Komives, S. R. (2011). Influences on college students' capacities for socially responsible leadership. Journal of College Student Development, 52, 525549. 
Dugan, J. P., Komives, S. R., \& Segar, T. C. (2008). College student capacity for socially responsible leadership: Understanding norms and influences of race, gender, and sexual orientation. NASPA Journal, 45, 475-500.

Dugan, J. P., Kusel, M. L., \& Simounet, D. M. (2012). Transgender college students: An exploratory study of perceptions, engagement, and educational outcomes. Journal of College Student Development, 53, 719-736.

Dugan, J. P., Turman, N. T., \& Torrez, M. A. (2015). Beyond individual leader development: Cultivating collective capacities. New Directions for Student Leadership, 2015(148), 5-15.

Edwards, W. (2008). Teaching women with a Y-chromosome: Do men make better feminists?. Feminist Teacher, 18(2), 145-159.

Eliason, M. J. (1995). Accounts of sexual identity formation in heterosexual students. Sex Roles, 32(11-12), 821-834.

Evans, N. J., \& Broido, E. M. (2005). Encouraging the development of social justice attitudes and actions in heterosexual student. New Directions for Student Services, 2005(110), 43-54.

Evans, N. J., \& Reason, R. D. (2007). The complicated realities of Whiteness: From color blind to racially cognizant. New Directions for Student Services, 2007(120), 6776.

Galloway, F. (1994). The importance of high school related skills in the primary and secondary labor market (Doctoral dissertation). Retrieved from ProQuest Dissertations and Theses Global database. (UMI No. 9432397)

Gardiner, J. K. (2005). Men, masculinities, and feminist theory. In M. S. Kimmel, J. Hearn, \& R. W. Connell (Eds.), Handbook of studies on men and masculinities (pp. 35-50). Thousand Oaks, CA: Sage.

Glaser, B. (1978). Theoretical sensitivity: Advances in the methodology of grounded theory. Mill Valley, CA: The Sociology Press.

Glaser, B., \& Strauss, A. (1999). The discovery of grounded theory: Strategies for qualitative research. Hawthorne, NY: Aldine de Gruyter.

Golafshani, N. (2003). Understanding reliability and validity in qualitative research. The qualitative report, 8(4), 597-606.

Grace, A. P., \& Benson, F. J. (1999). Using autobiographical queer life narratives of teachers to connect personal, political and pedagogical spaces. International Journal of Inclusive Education, 4(2), 80-109. 
Guba, E. G., \& Lincoln, Y. S. (1994). Competing paradigms in qualitative research. In Denzin, N. K., \& Lincoln, Y. S. (Eds) Handbook of qualitative research. (pp. 163-194). Thousand Oaks, CA: Sage..

Guiffrida, D. A. (2006). Toward a cultural advancement of Tinto's theory. Review of Higher Education, 29, 451-472.

Gunaratnam, Y. (2003). Researching race and ethnicity: Methods, knowledge and power. Thousand Oaks, CA: Sage.

Guo, S., \& Fraser, M. W. (2014). Propensity score analysis ( $2^{\text {nd }}$ ed.). Thousand Oaks, CA: Sage.

Hackman, H. W. (2005). Five essential components for social justice education. Equity \& Excellence in Education, 38(2), 103-109.

Harper, S. R. (2004). The measure of a man: Conceptualizations of masculinity among high achieving African American male college students. Berkeley Journal of Sociology, 48, 89-107.

Harper, S. R. (2007). Peer support for African American male college achievement: Beyond internalized racism and the burden of "acting White." Journal of Men's Studies, 14, 337-358.

Harper, S. R. (2013). Am I my brother's teacher? Black undergraduates, racial socialization, and peer pedagogies in predominantly White postsecondary contexts. Review of Research in Education, 37, 183-211.

Harper, S. R., \& Quaye, S. J. (2007). Student organizations as venues for Black identity expression and development among African American male student leaders. Journal of College Student Development, 48, 127-144.

Harris, F., III. (2010). College men's conceptualizations of masculinities and contextual influences: Toward a conceptual model. Journal of College Student Development, 51, 297-318.

Harris, F., III, \& Edwards, K. E. (2010). College men's experiences as men: Findings and implications from two grounded theory studies. Journal of Student Affairs Research and Practice, 47, 43-62.

Harris, F., III, Palmer, R. T., \& Struve, L. E. (2011). "Cool posing" on campus: A qualitative study of masculinities and gender expression among Black men at a private research institution. Journal of Negro Education, 80(1), 47-62. 
Harro, B. (2013). The cycle of liberation. In M. Adams, W. J. Blumenfeld, C. Castañeda, H. W. Hackman, M. L. Peters, \& X. Zúñiga (Eds.), Readings for diversity and social justice ( $3^{\text {rd }}$ ed., pp. 463-470). New York, NY: Routledge.

Herek, G. M. (1988). Heterosexuals' attitudes toward lesbians and gay men: Correlates and gender differences. Journal of Sex Research, 25, 451-477.

Heule, C., Knutagård, M., \& Kristiansen, A. (2017). Mending the gaps in social work education and research: Two examples from a Swedish context. European Journal of Social Work, 1-13. doi:10.1080/13691457.2017.1283589

hooks, b. (1994) Teaching to transgress: Education as the practice of freedom. New York, NY: Routlege.

Hubain, B. S., Allen, E. L., Harris, J. C., \& Linder, C. (2016). Counter-stories as representations of the racialized experiences of students of color in higher education and student affairs graduate preparation programs. International Journal of Qualitative Studies in Education, 29, 946-963.

Ji, P. (2007). Being a heterosexual ally to the lesbian, gay, bisexual, and transgendered community: Reflections and development. Journal of Gay \& Lesbian Psychotherapy, 11(3-4), 173-185.

Jones, S. R. and Stewart, D.-L. (2016). Evolution of student development theory. New Directions for Student Services, 2016(154), 17-28.

Jones, S. R., Torres, V., \& Arminio, J. (2013). Negotiating the complexities of qualitative research in higher education: Fundamental elements and issues. New York, NY: Routledge.

Jourian, T. J. (2014). Trans* forming authentic leadership: A conceptual framework. Journal of Critical Thought and Praxis, 2(2), Art. 8.

Katz, J. N. (1996). The invention of heterosexuality. New York, NY: Plume.

Kiesling, S. (2007). Men, masculinities, and language. Language and Linguistics Compass, 1(6), 653-673.

Kim, J. S. (2005). The effects of a constructivist teaching approach on student academic achievement, self-concept, and learning strategies. Asia Pacific Education Review, 6(1), 7-19.

Komives, S. R., \& Wagner, W. (2016). Leadership for a better world: Understanding the social change model of leadership development: Hoboken, NJ: John Wiley \& Sons. 
Labbe, J. (2010). Death by misadventure: Teaching transgression in/through Larsen's Passing. College Literature, 37(4), 120-144.

LaMantia, K., Wagner, H., \& Bohecker, L. (2015). Ally development through feminist pedagogy: A systemic focus on intersectionality. Journal of LGBT Issues in Counseling, 9, 136-153.

Lane, F. C., \& Chapman, N. H. (2011). The relationship of hope and strength's selfefficacy to the social change model of leadership. Journal of Leadership Education, 10, 116-137.

Langan, T. (1959). The meaning of Heidegger: A critical study of existentialist phenomenology. New York, NY: Columbia University Press.

Lawlor, L. (2002). Derrida and Husserl: The basic problem of phenomenology. Bloomington: Indiana University Press.

Levtov, A. H. (2015). Family-friendly? Challenging choices for women in the student affairs field. The Vermont Connection, 22(1), 3.

Lipsitz, G. (1998) The possessive investment in Whiteness. Philadelphia, PA: Temple University Press.

Macintosh, P. (1986). White privilege and male privilege: A personal account of coming to see correspondences through working women's studies. Paper presented at the Virginia Women's Studies Association Conference, Richmond, VA.

Mahoney, A. D. (2016). Culturally responsive integrative learning environments: A critical displacement approach. New Directions for Student Leadership, 2016(152), 47-59.

McCall, L. (2005). The complexity of intersectionality. Signs: Journal of Women in Culture and Society, 30, 1,771-1,800.

McLaughlin, C. P. (2017). Listening for what is being asked: LGBT students of color needs in interacting with student affairs professionals. InterActions: UCLA Journal of Education and Information Sciences, 13(1), 1-17.

Mills, C. W. (1997). The racial contract. Ithaca, NY: Cornell University Press.

Moustakas, C. (1994). Phenomenological research methods. Thousand Oaks, CA: Sage.

Museus, S. D. (2011). Generating ethnic minority student success (GEMS): A qualitative analysis of high-performing institutions. Journal of Diversity in Higher Education, 4(3), 1-16. 
Museus, S. D., \& Quaye, S. J. (2009). Toward an intercultural perspective of racial and ethnic minority college student persistence. Review of Higher Education, 33, 6794.

National Association of Student Personnel Administrators. (n.d.). About NASPA. Retrieved from www.naspa.org/about

Nicolazzo, Z., \& Harris, C. (2014, January-February). This is what a feminist (space) looks like: (Re)conceptualizing women's centers as feminist spaces in higher education. About Campus, 18(6), 2-9.

Priest, K. L., \& Clegorne, N. A. (2015). Connecting to experience: High-impact practices for leadership development. New Directions for Student Leadership, 2015(145), 71-83.

Pope, R. L., Reynolds, A. L., \& Mueller, J. A. (2014). Creating multicultural change on campus. Hoboken, NJ: John Wiley \& Sons.

Quaye, S. J., \& Harper, S. R. (2007). Shifting the onus from racial/ethnic minority students to faculty: Accountability for culturally inclusive pedagogy and curricula. Liberal Education, 92(3), 19-24.

Ramos, M., Snow, J., Giovenale, S., Labadorf, K., \& Cadogan, D. (2016). Leave your "expert" hat at the door: Embracing critical pedagogy to create a community of librarian learners. Retrieved from http://digitalcommons.uconn.edu/libr_pubs/59/

Reason, R. D. (2007). Rearticulating whiteness: A precursor to difficult dialogues on race. College Student Affairs Journal, 26, 127-135.

Reason, R. D., Roosa Millar, E. A., \& Scales, T. C. (2005). Toward a model of racial justice ally development. Journal of College Student Development, 46, 530-546.

Reason, R. D., Scales, T. C., \& Roosa Millar, E. A. (2005). Encouraging the development of racial justice allies. New Directions for Student Services, 2005(110), 55-66.

Rhoads, R. A. (1994). Coming out in college: The struggle for a queer identity. Westport, CT: Greenwood Publishing Group.

Richardson, L. (1990). Narrative and sociology. Journal of Contemporary Ethnography, 19, 116-135.

Richardson, V. (1997). Constructivist teaching and teacher education: Theory and practice. In Richardson, V. Constructivist teacher education: Building a world of new understandings, pp. 3-14. London, England: Falmer Press.

Saldaña, J. (2013). The coding manual for qualitative researchers $\left(2^{\text {nd }}\right.$ ed.). Thousand Oaks: Sage. 
Sandeen, A. (1991). The chief student affairs officer: Leader, manager, mediator, educator. San Francisco, CA: Jossey Bass.

Simoni, J. M., \& Walters, K. L. (2001). Heterosexual identity and heterosexism: Recognizing privilege to reduce prejudice. Journal of Homosexuality, 41, 157172.

Smith, W. A., Allen, W. R., \& Danley, L. L. (2007). "Assume the position... you fit the description": Psychosocial experiences and racial battle fatigue among African American male college students. American Behavioral Scientist, 51, 551-578.

Solorzano, D., Ceja, M., \& Yosso, T. (2000). Critical race theory, racial microagressions, and campus racial climate: The experiences of African American college students. Journal of Negro Education, $V$, 60-73.

Stake, R. E. (1995). The art of case study research. Thousand Oaks, CA: Sage.

Steinhoff, U. (2009). The philosophy of Jurgen Habermas: A critical introduction (K. Schollner, Trans.). Oxford, England: Oxford University Press.

Stewart, D. L. (2008). Confronting politics of multicultural competence. About Campus, 13(1), 10-17.

Swain, J. (2005). Masculinities in education. In M. S. Kimmel, J. Hearn, \& R. W. Connell (Eds.), Handbook of studies on men and masculinities (pp. 213-229). Thousand Oaks, CA: Sage.

Taub, D. E., Blinde, E. M., \& Greer, K. R. (1999). Stigma management through participation in sport and physical activity: Experiences of male college students with physical disabilities. Human Relations, 52, 1,469-1,484.

Thomas, W. (2002). The moral domain of student affairs leadership. New Directions for Student Services, 2002(98), 61-70.

Tillapaugh, D. (2013). Breaking down the "walls of a façade:" The influence of compartmentalization on gay college males' meaning-making. Culture, Society, \& Masculinities, 5, 127-146.

Tillapaugh, D. (2015). Critical influences on sexual minority college males' meaningmaking of their multiple identities. Journal of Student Affairs Research and Practice, 52, 64-75.

U.S. News \& World Report. (n.d.) Most students in fraternities. Retrieved from https://www.usnews.com/best-colleges/rankings/most-frats 
Van Manen, M. (1990). Researching lived experience: Human science for an action sensitive pedagogy. Albany, NY: SUNY Press.

Vavrus, M. (2002). Connecting teacher identity formation to culturally responsive teaching. Paper presented at the National Association of Multicultural Education, Washington, D.C.

Vera, E. M., \& Speight, S. L. (2003). Multicultural competence, social justice, and counseling psychology: Expanding our roles. Counseling Psychologist, 31, 253272.

Washington, J., \& Evans, N. J. (1991). Becoming an ally. In N. J. Evans \& V. Wall (Eds.), Beyond tolerance: Gays, lesbians, and bisexuals on campus (pp. 195-204). Alexandria, VA: American College Personnel Association.

Watt, S. K., \& Gasman, M. (2015). Designing transformative multicultural initiatives: Theoretical foundations, practical applications, and facilitator considerations. Sterling, VA: Stylus.

Wood, J. L., \& Newman, C. B. (2015). Predictors of faculty-student engagement for Black men in urban community colleges: An investigation of the community college survey of men. Urban Education, 1-23. doi:10.1177/0042085915623343

Worthington, R. L., \& Mohr, J. J. (2002). Theorizing heterosexual identity development. Counseling Psychologist, 30, 491-495.

Worthington, R. L., Savoy, H. B., Dillon, F. R., \& Vernaglia, E. R. (2002). Heterosexual identity development: A multidimensional model of individual and social identity. Counseling Psychologist, 30, 496-531.

Yin, R. K. (2013). Case study research: Design and methods. Thousand Oaks, CA: Sage. 
APPENDIX A

Recruitment Email 


\section{Dear Colleagues,}

My name is Conor P. McLaughlin, and I am currently a Doctoral Candidate in the Department of Leadership Studies at The University of San Diego's School of Leadership and Education Sciences. I am seeking participants for my dissertation study who identify as White, heterosexual, and male, and who are currently working full time as a student affairs professional. For the purposes of my study, I am defining a student affairs professional as any full-time employee who works in their college's Division of Student Affairs.

My study seeks to examine what, if any, impact an exposure to concepts of transgressive teaching has on the ways White, heterosexual, male identified student affairs professionals think about their work with students, and also what, if any, ways these concepts can be understood as approaches to leadership development. The study will consist of 3 interviews, as well as participants being asked to read the book Teaching to Transgress: Education as the Practice of Freedom by bell hooks and to do some prompted journaling while reading the book. The total time of the interviews will be roughly 5 hours, and the book is roughly 216 pages. Participants in this study will be given a copy of Teaching to Transgress.

This research will be most valuable if the participant sample is large and diverse. I would greatly appreciate you passing this message on to any of your colleagues across the field of Student Affairs who fit the above listed criteria.

If you have any questions or concerns, please contact the researcher, Conor McLaughlin, at cmclaughlin@sandiego.edu or the Dissertation Chair for this project, Dr. Christopher Newman at cnewman@sandiego.edu or (619) 260-8896.

Thank you for your support.

Conor P. McLaughlin

Doctoral Candidate, Department of Leadership Studies

School of Leadership and Education Sciences

University of San Diego

cmclaughlin@sandiego.edu

Dr. Christopher B. Newman

Assistant Professor, Department of Leadership Studies

School of Leadership and Education Sciences

University of San Diego

cnewman@sandiego.edu

(619) 260-8896 
APPENDIX B

Informed Consent Form 
Thank you for agreeing to participate in this study, which will take place from June 1, 2016 through January 30, 2017. This form details the purpose of the study, a description of the involvement of a participant, and your rights as a voluntary participant.

The purpose of this study is to:

- To understand what, if any, impact the introduction of concepts of transgressive teaching can have on the practices of White, heterosexual, male student affairs professionals.

- To understand what, if any, impact the introduction of concepts of transgressive teaching can have on the self-perception of White, heterosexual, male student affairs professionals as educators.

- To understand if transgressive teaching can also be understood as a way of teaching leadership.

The benefits of this study are

- A potential for increased effectiveness in working with college students.

- A free copy of Teaching to Transgress: Education as the Practice of Freedom.

The methods that will be used in this study are:

- Three (3) one-to-one interviews each lasting between 45 and 120 minutes.

- Prompted journaling while reading Teaching to Transgress: Education as the Practice of Freedom.

You are encouraged to ask questions and raise concerns that you have about this process now, as well as during the interviews if you choose to participate.

Some of the questions in this interview may ask you to recall instances or situations in which you felt uncomfortable or generally experienced a negative reaction to the situation. This is the greatest amount of risk to you foreseen by the researcher (Conor McLaughlin). If at any point during the interviews, or after any of the interviews, you feel any lingering discomfort, please let the researcher know, at which time they will work with you to find the appropriate assistance in your area.

These interviews will be recorded digitally. The recordings will be password protected, and will only be heard by me for the purpose of transcribing the interviews. These files will be kept for a minimum period of 5 years, and then deleted. They will not be stored on a cloud or other third party server. Your name will not be connected to any information you provide, and you will be assigned a pseudonym in any instances where information needs to be reported out. If you feel uncomfortable with the recording at any time, please let me know and I will stop the recording.

You also have the right to withdraw from the study at any time. In the event that you withdrawal, all recording files will be deleted and your participation will not be included in the final report. 
This study is being conducted to fulfill the requirements for the degree of Doctor of Philosophy in the Department of Leadership Studies, in the School of Leadership and Education Sciences, at the University of San Diego. All written versions of the findings of this study will not include your full name, only a pseudonym.

If you have any questions about the process, your participation, or any other aspect of this study, please feel free to contact the researcher (Conor McLaughlin) by email at cmclaughlin@sandiego.edu, or the person chairing the dissertation committee (Christopher B. Newman) at cnewman@sandiego.edu.

By signing my name below I, certify that I have read and agree to the conditions outlined above.

SIGATURE DATE 
APPENDIX C

Interview Protocols 


\section{Pre-Intervention Interview}

\section{Overview Questions}

1. Could you tell me a bit about yourself?

2. Could you tell me about your work in the field of student affairs?

a. What is your position?

b. What type of university do you work at?

c. What functional area do you work in?

d. How long have you been working as a student affairs professional?

\section{Identity Questions}

3. How do you describe your race? Your gender? Your sexual orientation?

4. Are there other social identities that are salient for you in your work?

5. What aspects of your identity do you believe are most salient in your work as a student affairs professional?

6. What aspects of your identity do you believe are least salient in your work as a student affairs professional?

\section{Transgressive Teaching Questions}

7. Have you ever heard the phrases "transgressive teaching" or "engaged pedagogy"?

8. What might those phrases mean to you?

9. Do you think those ideas have any connection to your work as a student affairs professional?

\section{Leadership Questions}

10. What does leadership mean to you?

11. What does practicing leadership mean in student affairs?

12. What ways do you think you practice leadership as a student affairs professional?

13. Do you see any connections between your ideas of leadership and how you think about TT and EP? 


\section{Post-Intervention Interview}

\section{Experience Questions}

1. How would you describe your experience of reading Teaching to Transgress?

2. Are their ideas or concepts that you read that have stayed with you? What/why?

\section{Identity Questions}

3. Has reading Teaching to Transgress offered you any opportunities to reflect on your own identities? Could you tell me about that?

4. While reading did you think about how you were interpreting this experience through the lenses of Whiteness, maleness, and straightness? Tell me about that.

5. What dimensions of your identity are salient to you when you think about your experience reading the book?

6. What came up for you around that/those part(s) of your identity?

7. Where there dimensions of your identity that were not salient for you during your reading of the book?

a. Why do you think that is?

\section{Transgressive Teaching and Student Affairs Questions}

8. Do you see a connection between the ideas of Transgressive Teaching and your work with students? What/why?

9. Do you think these ideas could be incorporated into your work with students?

10. Do you think incorporating these ideas into your work with students would have an impact on your students? If so, what impact might it have?

11. What actions might you take to incorporate these ideas into your work?

12. What do you think these practices will mean for your position and identity as a White, straight, man?

13. Has this experience impacted the way you think about teaching? How/why?

14. Has this experience impacted what you think it means to be a student affairs professional? How/why?

\section{Leadership Questions}

15. Do you think this experience has had an impact on how you might practice leadership? How/why?

16. Has this experience impacted the way you think about practicing leadership? How/why?

17. What might that mean in relationship to your identities as a White, straight, male?

18. What do you think it means to practice leadership as a student affairs professional? 


\section{Post-Post-Intervention Interview}

\section{Experience Questions}

1. Are there aspects of Teaching to Transgress that have stayed with you since you finished reading it? What/why?

2. Have you had any new thoughts or insights into your experience since the time you completed reading Teaching to Transgress? What/why?

\section{Action Questions}

3. Have you tried to incorporate any of the concepts from Teaching to Transgress into your work with students? What/why?

a. What actions have you taken?

b. What has that experience been like for you?

\section{Identity Questions}

4. What aspects of your identity are the most salient for you when interacting with your students and in your role?

a. Why do you think that is?

5. What aspects of your identity are least salient to you when interacting with your students and in your role?

a. Why do you think that is?

\section{Leadership Questions}

6. What does leadership mean to you?

7. What does it mean to you to practice leadership in student affairs?

\section{Professional Development Questions}

8. Do you think reading Teaching to Transgress would be helpful for other student affairs professionals in their own professional development? Why? 


\section{APPENDIX D}

Journal Prompts 


\section{Reading Reflection \#1 Questions}

Please spend some time journaling after reading the Introduction and Chapters 1 and 2 (pages 1-34).

Name:

Date:

\section{Journaling Questions}

1. What are some initial thoughts and feelings you have after reading these chapters?

2. What, if any, connections did you make between the ideas you were reading and your work as a student affairs professional?

\section{Free Journaling}

3. This is a space for you write more about your experience in this reading session. Include other thoughts, feelings, ideas, or perspectives beyond what the above questions bring out. 


\section{Reading Reflection \#2 Questions}

Please spend some time journaling after reading Chapters 3-6 (pages 35-92).

Name:

Date:

\section{Journaling Questions}

1. What are some initial thoughts and feelings you have after reading these chapters?

2. What, if any, connections did you make between the ideas you were reading and your work as a student affairs professional? What about your experiences as a White, heterosexual, male identified person?

\section{Free Journaling}

3. This is a space for you write more about your experience in this reading session. Include other thoughts, feelings, ideas, or perspectives beyond what the above questions bring out. 


\section{Reading Reflection \#3 Questions}

Please spend some time journaling after reading Chapters 7-10 (pages 93-166).

Name:

Date:

\section{Content Questions}

1. What are some initial thoughts and feelings you have after reading these chapters?

2. What, if any, connections did you make between the ideas you were reading and your work as a student affairs professional?

3. What about your experiences as a White, heterosexual, male identified person?

4. What, if any, relevance do you believe this has to how you do your work as a student affairs professional who holds White, heterosexual, and male identities?

\section{Free Journaling}

5. This is a space for you write more about your experience in this reading session. Include other thoughts, feelings, ideas, or perspectives beyond what the above questions bring out. 


\section{Reading Reflection \#4 Questions}

Please spend some time journaling after reading Chapters 11-14 (pages 167-209).

Name:

\section{Date:}

\section{Content Questions}

1. What are some initial thoughts and feelings you have after reading these chapters?

2. What, if any, connections did you make between the ideas you were reading and your work as a student affairs professional?

3. What about your experiences as a White, heterosexual, male identified person?

4. What, if anything, has reading this book offered you about your work as a student affairs professional who identifies as a White, heterosexual, male?

\section{Free Journaling}

5. This is a space for you write more about your experience in this reading session. Include other thoughts, feelings, ideas, or perspectives beyond what the above questions bring out. 


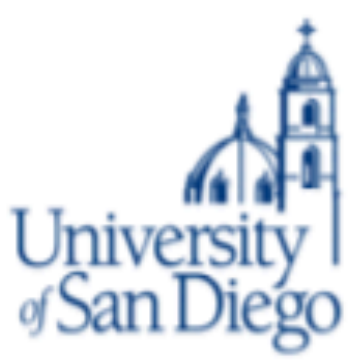

\section{Institutional Review Board Project Action Summary}

Action Date: Apnl 26, $2016 \quad$ Note: Approval expires one year after this date.

Type: __ New Ful Review _X_New Expedited Review ___Continuation Review Exempt Review Modification

Action:

X_Approved

Approved Pending Modification

Not Approved

Project Number. 2016-04-218

Researcher(s): Conor P. Mclaughlin Doc SOLES

Christopher B. Newman, Fac SOLES

Project Title: Exploring the Impact of Transgressive Teaching on Student Affairs Practices of White, Heterosexual Men

Note: We send IRB correspondence regarding student research to the faculty adviscr, who bears the utimate responsibility for the conduct of the research. We request that the faculty advisor share this comespondence with the student researcher.

Modifications Required or Reasons for Non-Approval

None

The next deadline for submitting project proposals to the Provost's Office for full review is N/A. You may submit a project proposal for expedited review at any time.

Dr. Thomas R. Heminton

Administrator, Institutional Review Board

University of San Diego

herrinton @sandiego.edu

5998 Alcalá Park

San Diego, Califomia 92110-2492

Office of the Executive Vice President and Provost

Hughes Administration Center, Room 214

5998 Alcalá Park, San Diego, CA $92110-2492$

Phone (619) 260-4553 * Fax (619) 260-2210 * www.sandiego.edu 